\title{
Spatial demography of Calanus finmarchicus in the Irminger Sea
}

\author{
M.R. Heath ${ }^{\mathrm{a}, *}$, J. Rasmussen ${ }^{\mathrm{a}}$, Y. Ahmed ${ }^{\mathrm{b}}$, J. Allen ${ }^{\mathrm{c}}$, C.I.H. Anderson ${ }^{\mathrm{d}}$,
} A.S. Brierley ${ }^{\text {d }}$, L. Brown ${ }^{\text {c }}$, A. Bunker ${ }^{\text {e }, ~ K . ~ C o o k ~}{ }^{\text {a }}$, R. Davidson ${ }^{\text {c }}$, S. Fielding ${ }^{\text {c }}$, W.S.C. Gurney ${ }^{\text {f }}$, R. Harris ${ }^{\text {g }}$, S. Hay ${ }^{\mathrm{a}}$, S. Henson ${ }^{\mathrm{c}}$, A.G. Hirst ${ }^{\text {h }}$, N.P. Holliday ${ }^{\mathrm{c}}$, A. Ingvarsdottir ${ }^{i}, X$. Irigoien ${ }^{c}$, P. Lindeque ${ }^{\text {g }}$, D.J. Mayor ${ }^{c}$, D. Montagnes ${ }^{j}$, C. Moffat ${ }^{\text {a }}$, R. Pollard ${ }^{\text {c }}$, S. Richards ${ }^{\text {a }}$, R.A. Saunders ${ }^{\text {d }}$, J. Sidey ${ }^{\text {k }}$, G. Smerdon ${ }^{\mathrm{g}}$, D. Speirs ${ }^{\text {f }}$, P. Walsham ${ }^{\text {a }}$, J. Waniek ${ }^{\text {c }}$, L. Webster ${ }^{\text {a }}$, D. Wilson ${ }^{j}$

${ }^{a}$ Fisheries Research Services, Marine Laboratory, 375 Victoria Road, Aberdeen AB11 9DB, UK

b The Robert Gordon University, Schoolhill, Aberdeen AB10 IFR, UK

${ }^{\mathrm{c}}$ National Oceanography Centre, Southampton, University of Southampton, Waterfront Campus, European Way, Southampton SO14 3ZH, UK

${ }^{\mathrm{d}}$ Gatty Marine Laboratory, School of Biology, University of St. Andrews, St. Andrews, Fife KY16 8LB, UK

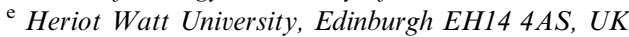

${ }^{\mathrm{f}}$ Department of Statistics and Modelling Science, University of Strathclyde, Livingstone Tower, 26 Richmond Street, Glasgow G1 1 XH, UK g Plymouth Marine Laboratory, Prospect Place, The Hoe, Plymouth PL1 3DH, UK

${ }^{\mathrm{h}}$ British Antarctic Survey, High Cross, Madingley Road, Cambridge CB3 OET, UK

${ }^{\mathrm{i}}$ School of Biological Sciences, Zoology Building, Tillydrone Avenue, University of Aberdeen, Aberdeen AB24 $2 T Z, U K$

${ }^{j}$ School of Biological Sciences, University of Liverpool, P.O. Box 147, Liverpool L69 3BX, UK

${ }^{\mathrm{k}}$ Sir Alister Hardy Foundation for Ocean Science, The Laboratory, Citadel Hill, Plymouth PL1 2PB, UK

\begin{abstract}
Continuous Plankton Recorder data suggest that the Irminger Sea supports a major proportion of the surface living population of the copepod Calanus finmarchicus in the northern North Atlantic, but there have been few studies of its pop ulation dynamics in the region. In this paper, we document the seasonal changes in the demographic structure of $C$. finm archicus in the Irminger Sea from a field programme during 2001/2002, and the associations between its developmental stages and various apparent bio physical zones. Overwintering stages were found widely at depth $(>500 \mathrm{~m})$ across the Irm inger Sea, and surviving females were widely distributed in the surface waters the following spring. However, recruitment of the subsequent generation was concentrated around the fringes of the Irminger Sea basin, along the edges of the Irm inger and East Greenland Currents, and not in the central basin. In late summer animals were found descending back to overwintering depths in the Central Irminger Sea. The key factors dictating this pattern of recruitment appear to be (a) the general circulation regime, (b) predation on eggs in the spring, possibly by the surviving G0 stock, and (c) mortality of first feeding naupliar stages in the central basin where food concentrations appear to be low throughout the year.

We compared the demographic patterns in 2001/2002 with observations from the only previous major survey in 1963 and with data from the Continuous Plankton Recorder (CPR) surveys. In both previous data sets, the basic structure of
\end{abstract}

* Corresponding author. Tel.: +44 1224 876544; fax: +44 1224295511.

E mail address: heathmr@marlab.ac.uk (M.R. Heath). 
G0 ascent from the central basin and G1 recruitment around the fringes was a robust feature, suggesting that it is a recur rent phenomenon. The Irminger Sea is a complex mixing zone between polar and Atlantic water masses, and it has also been identified as a site of sporadic deep convection. The physical oceanographic characteristics of the region are therefore potentially sensitive to climate fluctuations. Despite this, the abundance of $C$. finmarchicus in the region, as measured by the CPR surveys, appears not to have responded to climate factors linked to the North Atlantic Oscillation Index, in con trast with the stocks in eastern Atlantic areas. We speculate that this may because biological factors (production and mor tality), rather than transport processes are the key factors affecting the population dynamics in the Irminger Sea.

Keywords: Plankton; Oceanography; Atlantic Ocean; Greenland; Copepods; Mortality; Feeding

\section{Introduction}

Most of our understanding of the ocean basin-scale spatial and temporal dynamics of Calanus finmarchcicus and other mesozooplankton taxa in the North Atlantic derives from the Continuous Plankton Recorder (CPR) surveys (Planque and Batten, 2000). These have revealed two primary population centres of $C$. finmarchicus that coincide with the major gyres of the surface ocean circulation in the North Atlantic the Norwegian Sea gyre, and the Labrador/Irminger Sea (Fig. 1; Greene and Pershing, 2000; Head et al., 2001; Heath et al., 2001). However, for all their value, the CPR data provide poor stage resolution, are semi-quantitative, and are restricted to the upper $10 \mathrm{~m}$ of the water column. For example, the CPR cannot provide any information on $C$. finmarchcus during the 6 months or so of the year when the majority of the population is overwintering and absent from the surface waters. To better understand how the coupling between life-cycle process and physical oceanography gives rise to the basin scale surface distribution detected by the CPR, it is necessary to assemble at least a seasonal sequence of vertically and horizontally resolved, demographic and physiological state data, with concurrent physical measurements.

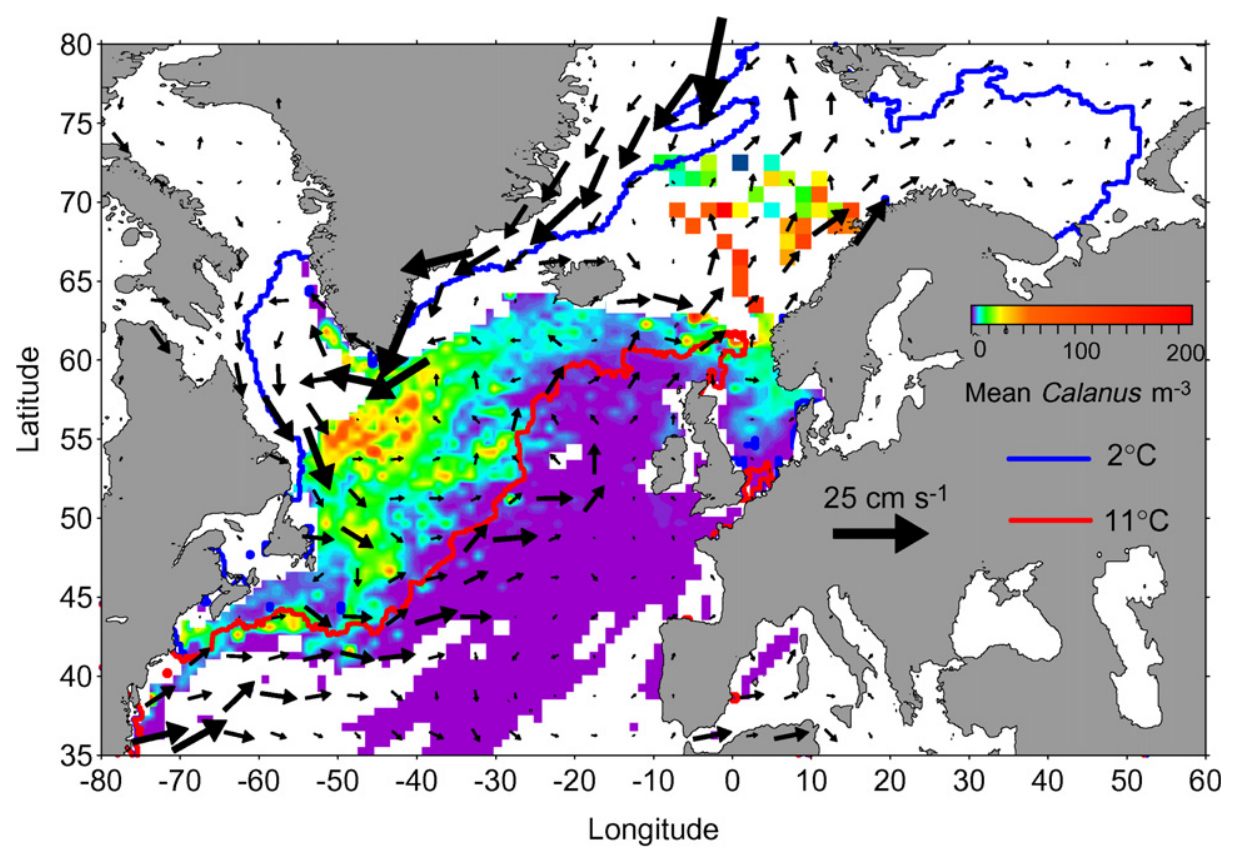

Fig. 1. Time averaged C. finmarchicus $\mathrm{C} 5 \mathrm{C} 6$ abundance $\left(\mathrm{m}^{3}\right)$ at $710 \mathrm{~m}$ depth from a combination of CPR samples collected between 1958 and 2000, and plankton sampling in the Norwegian Sea during the EU TASC project (adapted from Heath et al., 2001), overlaid with annual average velocity at $10 \mathrm{~m}$ depth (arrows) and the $2{ }^{\circ} \mathrm{C}$ and $11^{\circ} \mathrm{C}$ annual average isotherms from the OCCAM Global circulation Model (de Cuevas et al., 1999; Webb et al., 1998). OCCAM data were simulated with meteorological conditions for 1997. 
Detailed demographic studies of $C$. finmarchicus have so far only been practically possible on a sub-regional scale. Gyre-scale population dynamics have been studied in the Norwegian Sea and northeastern Atlantic during the EU-TASC and EU-ICOS projects (Heath and Coombs, 1999; Tande and Miller, 2000). The data and knowledge collected during those programmes have subsequently supported a numerical simulation effort, in which lifecycle hypotheses have been tested by comparing model results with observations (e.g. Speirs et al., 2006). Studies of population dynamics in the Labrador/Irminger gyre have been less advanced. Tittensor et al. (2003) developed a model for $C$. finmarchicus in the Labrador Sea, but they were hampered by a lack of high quality supporting demographic observations. Apart from CPR samples, the available data were fragmentary and comprised: (1) observations from the NORWESTLANT programme in 1963 (ICNAF, 1968), but only of copepodite stages in the upper $100 \mathrm{~m}$ during spring and summer; (2) a time series of plankton abundance in the surface waters at Ocean Weather station B $\left(56^{\circ} 30^{\prime} \mathrm{N}, 51^{\circ} 00^{\prime} \mathrm{W}\right)$ during 19501951 (Kielhorn, 1952); (3) a series of spring/summer surface water observations around the Flemish Cap during 197981 (Anderson, 1990); (4) spring and early summer surveys in the Davis Strait in the late 1970s (Huntley et al., 1983), and (5) an annual series of copeopodite abundance and egg production observations along transects across the Labrador Sea in May/June from 1995 onwards (Head et al., 2000). None of those sources provided any data on the depth distribution and abundance of overwintering stages of $C$. finmarchicus. Interactions between seasonal/stage-dependent vertical migrations and the three-dimensional circulation regime had been strongly implicated as factors in the space time dynamics of demography in the northeast Atlantic (e.g. Backhaus et al., 1994). Other detailed demographic studies in the northwestern Atlantic during the 1990s had been largely confined to the continental shelf and slope regions along the Scotian Shelf and Gulf of Maine (Durbin et al., 2000; Head et al., 1999). Only subsequent to the modelling study of Tittensor et al. (2003), were the first depth resolved winter observations of stage abundance in the Labrador Sea collected by Erica Head in December 2002 (pers. comm.).

Demographic data from the Irminger Sea, other than the CPR, were also scarce prior to the 2001/2002 studies which we report in this paper. The NORWESTLANT surveys in 1963 sampled the upper waters of the Labrador Sea and also extended to the Irminger Sea between Greenland and Iceland. Apart from that, there was no detailed demographic sampling until the studies of Gislason and co-workers in 1997 and thereafter (Gislason and Assthorsson, 2000; Jónasdóttir et al., 2002; Gislason, 2003, 2005; Gislason et al., 2007). Those authors reported on the seasonal changes in C. finmarchicus demography, depth distribution and egg production in the shelf and slope waters south and southwest of Iceland, and at two stations in the northern Irminger Basin (>2000 $\mathrm{m}$ water depth). Their data showed that stage C5 copepodites were abundant in the northern Irminger Sea at depths of $2001800 \mathrm{~m}$ in Atlantic-origin water of temperature $36{ }^{\circ} \mathrm{C}$ during November and December. Ascent to the surface commenced in March and continued through to early May. The studies provided detailed information on connections between the offshore stock of $C$. finmarchicus in the northern Irminger and Iceland Basins, and production on the Iceland shelf (Gislason et al., 2000) but, due to the restricted spatial coverage, relatively little regarding the controls on population dynamics at the scale of the Irminger Sea basin.

Understanding population dynamics in the Labrador/Irminger gyre was clearly the next major step towards developing a model of the ocean basin-scale population of $C$. finmarchicus, the connections between sub-populations and the responses, if any, to climate fluctuations. Considering the summary of published data and knowledge of zooplankton given above, it appeared that the greater part of the Irminger Sea was almost unexplored territory. The north-western half of the region, along the east Greenland shelf, was not covered by the CPR surveys and, as far as we could ascertain, had never been sampled since the NORWESTLANT surveys in 1963 . Hence, we focussed our attention on this region as one of the UK contributions to the International GLOBEC programme.

One of our first activities, which helps to set the analysis presented in this paper into context, was to produce a pan-Atlantic synthesis of the abundance and vertical distribution of overwintering stages of $C$. finmarchicus during November January (Heath et al., 2004). Experience from the north-eastern Atlantic suggested that these stages would be found at depths of $4002000 \mathrm{~m}$ in the open ocean, well out of the sampling range of the CPR and hence largely unknown at the basin scale. Initial results from winter (November and December 2001 and 2002) surveys in the Irminger Sea, which we further analyse in more detail in this paper, were combined with the database of winter sampling from the northeast Atlantic and Icelandic waters (Heath et al., 
2000b), and with sampling in December 2002 in the Labrador Sea (E. Head, pers. comm.). That exercise identified a number of epicentres of the pan-Atlantic population: in the Labrador Sea, northern Irminger Sea, Iceland Basin, and eastern Norwegian Sea. It was argued that these epicentres defined the structure of the oceanbasin scale population, out of which must emerge the more diffuse, reproductive population in the surface waters which is sampled by the CPR surveys, and into which sufficient individuals must descend again in the autumn in order to repeat the process in the following year. The Irminger Sea basin was clearly identified as an important epicentre, and the depth distribution of copepodites and associated temperature and salinity conditions were more consistent with those in the Labrador Sea than those in the Iceland Basin to the east.

Oceanographic conditions in the Irminger Sea at the end of the 1990s were substantially different from those in 1963. In the earlier study, sea ice extended south along the east coast of Greenland as far as Cape Farewell throughout the NORWESTLANT survey period (ICNAF, 1968). High phytoplankton biomass

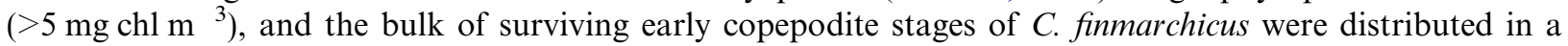
narrow band along the ice edge (ICNAF, 1968; Bainbridge and Corlett, 1969). In contrast, during the late 1990s the extent of sea-ice cover was reduced to the minimum observed values since at least the mid-20th century (Walsh and Chapman, 2001; Serreze et al., 2003). Deep-water overflow across the Greenland Scotland Ridge has also significantly reduced in the intervening years (Hansen et al., 2001; Osterhus et al., 2001), affecting the potential overwintering habitat for C. finmarchicus. During the 1990s alone there has been a pronounced warming of the upper $200 \mathrm{~m}$ of the water column (Hughes and Holliday, 2006), with marked consequences for the distribution of the main commercially exploited species in the region (Atlantic redfish, Sebastes mentella), which occupy a temperature range of $3.45 .7^{\circ} \mathrm{C}$ (Sigurdsson et al., 1999). We therefore hypothesised that the patterns of $C$. finmarchicus ascent from overwintering, and the spatial patterns of C. finmarchicus recruitment in the Irminger Sea in 2001 2002, might differ from those in 1963, in a manner that could be explained in terms of changes in the circulation and water mass distributions, and possibly predation.

\subsection{Oceanography of the Irminger sea}

The Irminger Sea basin lies in the Atlantic Arctic Province (Longhurst, 1998) bounded by the east Greenland shelf to the west, the Reykjanes Ridge to the east, the Denmark Strait to the north and the Polar Front to the south. The circulation in the Irminger Sea is dominated by a cyclonic gyre (Jakobsen et al., 2003) (Fig. 1), with weakly cyclonic mean flow in the central basin with a core near $61^{\circ} \mathrm{N}, 36^{\circ} \mathrm{W}$ (Reverdin et al., 2003). The cyclonic circulation leads to up-doming of the isopycnal surfaces, creating an area with potential for water mass transformation (Centurioni and Gould, 2004). Detailed descriptions of the water masses and hydrography of the region are presented by Holliday et al. (2006), Waniek and Holliday (2006), and Waniek et al. (2005). A summary is given below.

The surface waters of the interior of the basin are dominated by cool fresh Sub-Arctic surface Water (SAW) with its origin in the surface waters of the Labrador Sea (Read, 2001; Holliday et al., 2006). This SAW becomes Subarctic Intermediate Water (SAIW) when subducted beneath the North Atlantic Current (NAC). The eastern Irminger Sea is occupied by the strong, northward flowing Irminger Current (IC), a branch of the NAC which remains west of Reykjanes Ridge and the Mid-Atlantic Ridge (Fig. 2). Variable temperature and salinity are typically found in this region as a result of the strong horizontal mixing with the adjacent water types. The Irminger Current is subjected to winter vertical mixing induced by seasonal wind stirring and buoyancy (heat) loss, which leads to changing characteristics along its pathway. One part of the salty and warm Modified North Atlantic Water (MNAW) transported by the Irminger Current exits the Irminger Sea towards the north through the Denmark Strait and another part flows southwestward along the Greenland coast where it joins the East Greenland Current (Orvik and Niiler, 2002). The southwest branch of the Irminger Current forms a sharp thermal front with the stratified much cooler and fresher waters of the southward flowing East Greenland Current (EGC). The shallow ( $<700 \mathrm{~m})$ East Greenland Current flows above the continental slope and shelf, and carries water and ice from the Arctic and Nordic Seas into the subpolar gyre. The EGC itself consists of a mixture of water masses: cold, fresh Arctic Polar Water (temperature $<0{ }^{\circ} \mathrm{C}$, salinity $<34.5$ ), Arctic Intermediate Water (temperature $03{ }^{\circ} \mathrm{C}$ ), and an additional inshore component (temperature $0.4{ }^{\circ} \mathrm{C}$, salinity 30.2) that flows as a jet current within $5 \mathrm{~km}$ of the coast of Greenland (East Greenland Coastal Current; Bacon et al., 2002; Bruce, 1995). 


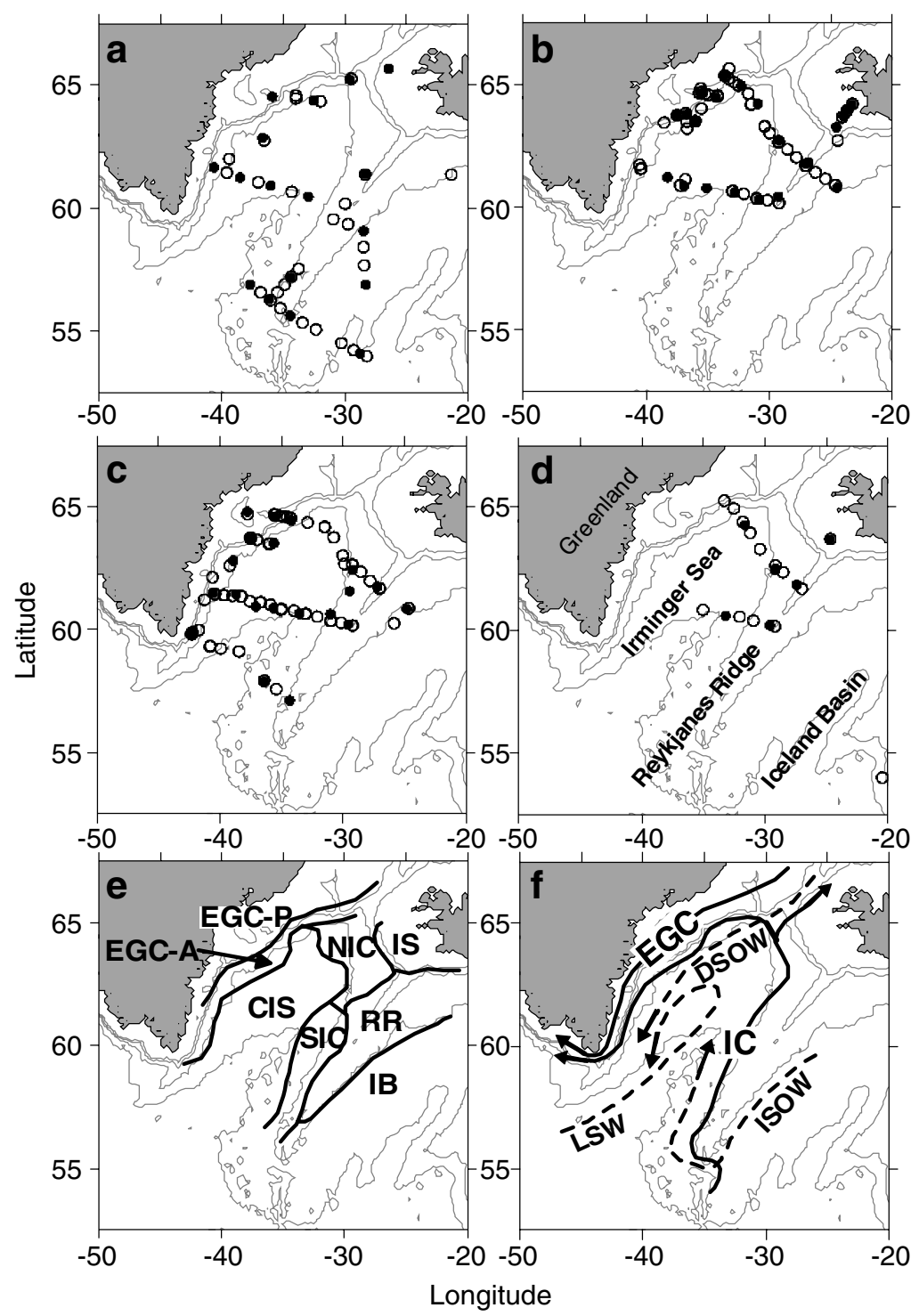

Fig. 2. Sampling locations in the Irminger Sea during Discovery surveys (a) D258 (8 November 12 December 2001), (b) D262 (21 April 24 May 2002), (c) D264 (28 July 23 August 2002), and (d) D267 (15 November 14 December 2002). Solid symbols indicate plankton and hydrographic sampling locations. Open symbols indicate sampling locations where only hydrographic measurements were carried out. (e) Average boundaries of biophysical zones (according to Holliday et al., 2006) to which the sampling stations in the four cruises were assigned (East Greenland Current Polar (EGC P), East Greenland Current Atlantic (EGC A), Central Irminger Sea (CIS), North Irminger Current (NIC), South Irminger Current (SIC) and Reykjanes Ridge (RR)), plus the two additional zones Iceland Shelf (IS) and Iceland Basin (IB) which were only sparsely sampled. (f) Schematic of the major currents and water masses in the region. Solid arrows indicate surface flows, dashed arrows indicate deep flows: (East Greenland Current (EGC), Irminger Current (IC), Denmark Strait Overflow Water (DSOW), Iceland Scotland Overflow Water (ISOW), and Labrador Sea Water (LSW)). Isobaths in each panel are shown at $500 \mathrm{~m}, 1000 \mathrm{~m}, 2000 \mathrm{~m}$ and $3000 \mathrm{~m}$.

The intermediate $(>700 \mathrm{~m})$ and deep waters $(>1800 \mathrm{~m})$ of the Irminger Sea also flow cyclonically around the basin (Lavender et al., 2005; Dickson and Brown, 1994). The interior of the basin contains Labrador Sea Water (LSW), characteristically a thick layer ( $\sim 5002000 \mathrm{~m})$ of homogeneous low salinity water. The reduced stratification is often expressed as low potential vorticity which reflects its origins as a mode water formed by deep convective mixing. The core of the LSW is usually characterised by temperature and salinity conditions of $3.5^{\circ} \mathrm{C}$ and 34.90 , respectively at depths of $1700 \mathrm{~m}$, and the mean flow occurs in a closed cyclonic 
gyre (Lavendar, 2001) present all year round even though the wind forcing occurs only in the winter (Spall and Pickart, 2003). The LSW in the Iceland Basin, the Irminger Sea and the rest of the subpolar gyre is generally assumed to have spread from the Labrador Sea (Talley and McCartney, 1982). However, recent studies have shown that gale-force winds in the region are enhanced by orographic processes at the southern tip of Greenland, resulting in a 'tip jet' that can cause large heat fluxes out of the western part of the Irminger Sea surface waters and cause overturning events to $15002000 \mathrm{~m}$ depth similar to those observed in the Labrador Sea (Pickart et al., 2002, 2003; Bacon et al., 2003). Such conditions appear to be linked to high values of the North Atlantic Oscillation (NAO) index. Thus a form of deep water similar to LSW can be generated in the Irminger Sea, though Pickart et al. (2003) concluded that LSW probably does also spread from Labrador Sea into the Irminger Sea whether or not there is convection locally. Historically the LSW in the Irminger Sea has been observed as a single layer with one low salinity core. However since 1999 the LSW in the Irminger Sea has been observed to have two low salinity cores; one at $\sim 680 \mathrm{dbar}$ and another at $\sim 1750 \mathrm{~m}$. According to S.A. Malmberg (quoted in van Aken, 2003) such a feature was common in the 1950s and early 1960s.

A minor water mass sometimes found over the Reykjanes Ridge at intermediate depths is called Icelandic Slope Water (ISW, after van Aken and de Boer, 1995) or, less precisely North Atlantic Water (NAW, eg. Read, 2001). This water mass has come from the Iceland Basin and has high temperature, high salinity and low oxygen compared to LSW of the same density. This water mass can be seen in some, but not all historical data (for example, it was observed in July 1990 and April-May 1991 (van Aken, pers. comm.) and in August 1981 (illustrated in Dickson and Brown, 1994)). The implication of those observations is that the Irminger Sea does, at least occasionally, receive water at $10001500 \mathrm{~m}$ directly from the Iceland Basin. Evidence for this circulation around the Reykjanes Ridge at $1500 \mathrm{~m}$ can be seen on the margins of the float displacement data set shown in Fig. 15 of Lavender et al. (2005).

Around the margins of the Irminger Sea below $800 \mathrm{~m}$ are found the dense northern overflow waters. The deep waters on the west side of the basin contain modified Iceland Scotland Overflow Water (ISOW). At the Iceland Scotland sill, the overflow is cold and dense $\left(-0.7\right.$ to $3.0^{\circ} \mathrm{C}$, salinity 34.9 to 35.1 at the sill), but along its path it descends from $500 \mathrm{~m}$ and mixes with the ambient water masses (Subpolar Mode Water in its early stages and Labrador Sea Water below approximately $1000 \mathrm{~m}$ ). Nevertheless it retains its cool, saline, stratified and dense signal compared to LSW. The pathway of the ISOW is effectively restrained by topography, and it can only flow westwards into the Irminger Sea through the Charlie Gibbs Fracture Zone on the Reykjanes Ridge at around $55^{\circ} \mathrm{N}$. There the ISOW properties have been modified considerably by mixing, and have been observed to be $2.403 .35^{\circ} \mathrm{C}$, salinity 34.9434 .975 at depths $16003500 \mathrm{~m}$ (Saunders, 2001). Having left the Fracture Zone at $2500 \mathrm{~m}$, the highly modified ISOW is believed to turn northwards and cross the basin to eventually join the deep western boundary current and the Denmark Strait Overflow Water (DSOW). Around $3 \mathrm{~Sv}$ of DSOW crosses the sill in the Denmark Strait and heads southward and down-topography forming the core of the deep western boundary current below the East Greenland Current. At the sill the water has temperature -1.0 to $2.0^{\circ} \mathrm{C}$ and salinity 34.735 .0 at $250900 \mathrm{~m}$, but by the time it reaches Cape Farewell it is 2000 to $3400 \mathrm{~m}$ deep and its temperature rises to 1.4 to $3.0^{\circ} \mathrm{C}$, with salinity between 34.90 and 34.93 (Saunders, 2001).

The deep western boundary current containing DSOW and modified ISOW enters the Labrador Basin and eventually the Newfoundland Basin where Antarctic Bottom Water is added to the mixture. The continual mixing with adjacent water masses modifies the properties to such an extent that by the time it is exported from the Newfoundland Basin it has formed a different water mass, the North-east Atlantic Deep Water (NADW). Part of the boundary current re-circulates and enters the deepest regions of the Irminger Sea and Iceland Basin, where the NADW is identifiable by a deep salinity maximum.

\section{Methods}

Sampling was carried out on four surveys by the RRS 'Discovery' ( 8 November 12 December 2001, 25 April 24 May 2002, 28 July 23 August 2002 and 15 November 13 December 2002). These surveys are referred to as D258, D262, D264 and D267, respectively, the numbers of the Discovery cruises. The spatial extent of each survey (Fig. 2) varied principally due to constraints of weather conditions. In the main they were centered on the Irminger Sea basin, and the fringing east-Greenland shelf, southwest Iceland shelf, 
and the northern end of the mid-Atlantic Ridge, referred to as the Reykjanes Ridge. A few samples were collected farther east in the Iceland Basin during each survey, but especially during D267 where a number of locations in the eastern Atlantic were sampled. No attempt was made in any of the surveys to structure the sampling according to time of day.

\subsection{Hydrographic and water sampling}

At each sampling location, vertical profiles of temperature, conductivity and chlorophyll- $a$ fluorescence, and a set of water samples, were collected with a Seabird 9-11 CTD system and a rosette of Niskin bottles. The water collected by the Niskin bottles was sub-sampled for salinity and chlorophyll- $a$ analysis. Salinity was measured to WOCE standards (accuracy \pm 0.002 ), and the data were used to calibrate the conductivity measurements from the CTD. Water samples for chlorophyll- $a$ analysis (usually 7 depths per cast) were filtered through $25 \mathrm{~mm}$ Whatman $\mathrm{GF} / \mathrm{F}$ filters which were then placed in glass vials containing $10 \mathrm{ml}$ of $90 \%$ acetone and stored in the dark at $5{ }^{\circ} \mathrm{C}$ for $24 \mathrm{~h}$ to extract the pigments. Extracts were warmed to room temperature before the fluorescence was measured using a Turner Designs fluorometer (TD700). Chlorophyll- $a$ standard solutions (from Sigma-Aldrich) covering the expected chlorophyll- $a$ range were used to calibrate the fluorometer before each set of samples was analysed. The data were used to derive cruiseby-cruise calibrations for converting the fluorescence data from the CTD to chlorophyll- $a$ concentration $\left(\mathrm{mg} \mathrm{m}^{3}\right)$.

\subsection{Microplankton sampling and analysis}

Samples for taxonomic identification of phytoplankton and microzooplankton were typically taken from Niskin bottles closed at the surface, at the chlorophyll- $a$ fluorescence maximum and at $100 \mathrm{~m}$ depth. Duplicate $100 \mathrm{ml}$ samples at each depth were preserved with 1\% Lugol's solution and 2\% buffered formalin. Identification and enumeration of microplankton were performed by inverted microscopy. Heterotrophic dinoflagellates were separated from autotrophic forms according to Lessard and Swift (1986) and Burkill et al. (1993). Biovolume was calculated for each species (Kovala and Larrance, 1966) and then converted to carbon biomass following carbon to biovolume relationships described for diatoms (Menden-Deuer and Lessard, 2000) and non-diatom protist plankton (Strathmann, 1967).

\subsection{Zooplankton sample collection and storage}

Zooplankton was sampled with the ARIES system (Dunn et al., 1993), and the OCEAN Sampler (adapted from Dunn et al., 1985; Sameoto et al., 2000). Both of these samplers were designed to collect a sequential set of discrete plankton net samples and corresponding water samples delineated by sub-sea pressure intervals during the descent and ascent legs of an oblique tow. The ARIES used a $200 \mu \mathrm{m}$ aperture mesh filtering net with a nose-cone diameter of $37 \mathrm{~cm}$, and stored a sequence of samples at intervals corresponding to 50 or $75 \mathrm{~m}$ depth between the sea surface, a maximum of $3000 \mathrm{~m}$ depth and back to the surface. The maximum number of samples collected in a single haul was 100. The OCEAN Sampler carried an integrating net which was open throughout the descent and ascent-legs of each tow (referred to as the pup-net), plus seven nets which were opened and closed in sequence on the ascent-leg of each tow from $400 \mathrm{~m}$ to the surface, according to a pressure schedule corresponding to $100 \mathrm{~m}$ depth intervals between 400 and $100 \mathrm{~m}$ and $25 \mathrm{~m}$ intervals between $100 \mathrm{~m}$ and the surface. All of the nets on the OCEAN sampler were of $95 \mu \mathrm{m}$ aperture mesh with a nose-cone diameter of $10 \mathrm{~cm}$.

Both samplers were fitted with Valeport impeller flowmeters mounted centrally in the mouth of the nets and electronically integrated with the control and data logging systems. Flow data were logged at $1 \mathrm{~s}$ intervals throughout each tow and subsequently integrated over the duration of each sampling net exposure interval. Calibrations (revolutions $\mathrm{m}^{1}$ ) for each flowmeter were provided by the manufacturers, and checked in situ by reciprocal tows of the samplers at a fixed depth over a measured distance in a weakly tidal area with the collecting nets removed. In this way the meters were in free-flow and subject to interference only by the rigid structures of the sampler during the calibration. 
The $200 \mu \mathrm{m}$ coarse mesh in the ARIES system retained Calanus spp. copepodite stages $\mathrm{C} 1$ and later, but not eggs or nauplii. The $95 \mu \mathrm{m}$ fine mesh of the OCEAN sampler retained all development stages, but undersampled the late copepodites due to the smaller volume filtered per sample (typically $12 \mathrm{~m}^{3}$ compared to 10 $15 \mathrm{~m}^{3}$ per ARIES sample).

The catches in the descent-leg nets from ARIES were preserved in 4\% formalin and returned to the laboratory for microscopic analysis. The ascent-leg ARIES nets were examined by eye to determine which ones contained high numbers of Calanus (nets with many Calanus appeared reddish and oily). A few nets showing peak plankton concentrations were put on ice and sub-samples of Calanus spp. individuals were sorted by moult stage (C4 C6 male and female) under a dissecting microscope with cold light source. Sets of 10 carefully selected, visually pristine same-stage specimens were preserved for lipid analysis in dry cryovials (10 per vial) which were flushed with nitrogen gas and submerged in liquid nitrogen. Further sets of 10 same-stage animals (where numbers allowed) were preserved for molecular analysis in cryovials containing 95\% ethanol, with a maximum of 10 per ml. The remainder of bulk material from each ascent-leg sample was preserved in $4 \%$ formalin.

The depth-resolved fine mesh nets from OCEAN Sampler were preserved in 4\% formalin for microscopic analysis on return to the laboratory. The integrated $95 \mu \mathrm{m}$ pup-net samples were stored in either $30 \mathrm{ml}$ or $100 \mathrm{ml}$ of $95 \%$ ethanol depending on the amount of material. These samples were also returned to the laboratory to be further sorted microscopically prior to molecular analysis.

The ARIES system also carried a CTD system (Seabird 9 11) and in situ chlorophyll- $a$ fluorometer (SeaPoint). Data from these sensors were logged at a frequency of $1 \mathrm{~Hz}$ throughout each tow. The calibration of the conductivity sensor was checked by reference to salinometer analyses of selected water samples collected from the bottles on the ARIES system. Analytical fluorescence of acetone extracted pigments from these samples was used to calibrate the in situ chlorophyll- $a$ sensor.

\subsection{Egg production rate measurements}

During the D262 and D264 surveys, on-board measurements were made of the rate of egg production by female $C$. finmarchicus. Live specimens were collected by vertical hauls of a $200 \mu \mathrm{m}$ mesh conical net fitted with a non-filtering cod-end, from a depth of $100 \mathrm{~m}$ to the surface. The freshly collected plankton was then sorted in a constant-temperature room set at in situ sea temperature, and female C6 C. finmarchicus copepodites were individually sorted into 11 incubation chambers (one animal per chamber) of $95 \mu \mathrm{m}$ filtered seawater from the same site. No attempt was made to discriminate between immature and mature females, so the eventual results in terms of per-capita egg production effectively included a component due to the maturity state of the population, as well as the physiological state of the mature individuals.

The incubation chambers were divided into two parts separated by a $350 \mu \mathrm{m}$ mesh screen. The females were placed in the larger part, and the eggs which were produced fell through the screen into the other part and were therefore protected from cannibalism by the parental female. The chambers were incubated in a batch in a dark tank irrigated with temperature-controlled water, the whole arrangement being contained in a constant-temperature room.

After $24 \mathrm{~h}$ of incubation, the eggs produced by each female were drained from the incubation chamber through a sampling port and counted, and then observed periodically until all had either hatched or were visibly dead. The proportion of eggs which successfully hatched was recorded for each set of eggs.

\subsection{Naupliar feeding rate measurements}

Measurements of naupliar feeding rates on microplankton groups have been described by Irigoien et al. (2003). In summary, live stage N4 N6 (mainly stage N5) C. finmarchicus nauplii were sorted from catches taken with a vertical haul net at each study site, and 1525 specimens incubated in $200 \mathrm{ml}$ bottles filled with un-screened water from the depth of the chlorophyll- $a$ maximum. In each experiment, three replicate experimental and three replicate control bottles were incubated on a plankton wheel $(0.1 \mathrm{rpm})$ for $\sim 24 \mathrm{~h}$ at sea surface temperature. A further bottle was filled and immediately fixed with acidic Lugol to estimate the initial 
food concentration. Experiments were terminated by adding acidic Lugol to the bottles. Initial and terminal microplankton concentrations were estimated microscopically as described earlier for microplankton samples. Filtration and ingestion rates were calculated from the microplankton carbon concentrations following Frost (1972) for the taxa where there was a significant difference in concentration between controls and incubation bottles.

\subsection{Enumeration of plankton taxa in zooplankton samples}

\subsubsection{Microscopic analysis of specimens from $200 \mu \mathrm{m}$ mesh nets (ARIES)}

The formalin preserved descent-leg ARIES nets were analysed at the University of Aberdeen through a series of multi-analyst workshops to enumerate key taxonomic groups including Calanus spp. The numbers of individuals of each Calanus developmental stage C1 C6 were determined. Copepods were initially divided by size and then examined at a higher magnification to identify, where possible, the correct species and stage. Calanus spp. stages were identified by the number of urosome segments and the number of pairs of swimming legs. In addition an elongated second urosome segment and a broadened base of the antennae were used to discriminate adult males, and a swollen first urosome segment to identify adult females. The larger Calanus hyperboreus were distinguished from other Calanus species by size. Calanus finmarchicus and Calanus helgolandicus stages C5 and C6 males and females were distinguished by the curvature of the inside of the 5th pair of swimming legs; earlier stages were undistinguishable as they do not show this difference in curvature. Calanus glacialis was not distinguishable by routine microscopy from $C$. finmarchicus and $C$. helgolandicus at any stage (Lindeque et al., 1999).

The same diagnostic morphological criteria were used in the microscopic analysis onboard ship to distinguish sub-samples of Calanus species for molecular analysis from the ascent-leg of the ARIES tows. However, removal of the 5th pair of swimming legs to distinguish between $C$. finmarchicus and $C$. helgolandicus was not possible at sea, and $C$. hyperboreus were deliberately not sorted as these were identifiable by their size.

\subsubsection{Microscopic analysis of specimens from $95 \mu \mathrm{m}$ mesh nets (OCEAN Sampler)}

Calanus early moult stages N1 N3, N4 N6, C1, C2 and C3 were identified from the fine mesh samples from OCEAN Sampler by microscopic analysis. The developmental stages of nauplii for all Calanus congeners were discriminated by the number and arrangement of the spines at the posterior end of the body and the number and arrangement of the setae on the distal segment of the first antenna. Copepodite stages were identified by the number of urosome segments and the number of pairs of swimming legs. These samples were used to enumerate the key taxonomic group of Calanus at each developmental stage N1 C3. There are no morphological features distinguishable by light microscopy suitable to discriminate between $C$. finmarchicus, C. helgolandicus, and $C$. glacialis at any of these early developmental stages or between these congers and $C$. hyperboreus at the naupliar stages.

Calanus early moult stages as described above were sorted from the ethanol-preserved integrated pup-net samples for molecular analysis. Groups of 10 individuals at each moult stage were preserved in $1.5 \mathrm{ml}$ vials containing 95\% ethanol. Individual Calanus were identified to species level using the molecular technique described in the next section.

Calanoid copepod eggs were enumerated in the OCEAN Sampler collections. However, we did not attempt to sort them into ethanol from the pup-net samples, and hence we do not have molecular data on which to base any positive species identification of eggs. We have therefore excluded egg abundance data from the analysis reported here.

\subsubsection{Molecular analysis}

Individual Calanus from either ARIES or OCEAN Sampler were identified to species level according to the RFLP signature of its mitochondrial 16S rDNA, following PCR amplification, restriction digestion and agarose gel electrophoresis, using the molecular identification technique described by Lindeque et al. (2006). The technique was modified and partially automated to increase the processing rate. The final technique is described by Lindeque et al. (2006). The majority of the manipulations were performed using a robotic molecular biology platform (RoboSeq 4204S, MWG Biotech). 


\subsubsection{Blending of microscopic and molecular analysis data}

It was only possible to perform molecular analyses on specimens from a small subset of the samples collected during the surveys, too few in fact to permit sample or haul-specific estimates of the Calanus speciation. Hence, it was necessary to aggregate the molecular data over several stations and depth intervals to provide statistically robust estimates of species composition for each developmental stage.

The principal requirement for any aggregation across stations was that the samples concerned must be drawn from a common population hypothesised to be homogeneous with respect to Calanus speciation. As the basis for aggregation of the stations, we used the zonal definitions for the Irminger Sea developed by Holliday et al. (2006). Within each survey and zone, the data were also grouped according to depth as being either shallower or deeper than $400 \mathrm{~m}$. This depth horizon was chosen as separating the $\mathrm{C} 4 \mathrm{C} 5$ winter resting phase of $C$. finmarchicus from the spring and summer growth and reproductive phases (Heath et al., 2004), and being the maximum deployment depth of the OCEAN sampler. The proportional species composition of each stage as estimated from the aggregated stage-specific molecular data was then applied to all samples collected within the corresponding survey, zone and depth interval. Full details of the blending method are given in Lindeque et al. (1999).

\subsection{Lipid analysis of C. finmarchicus}

From each set of 10 same-stage specimens stored in liquid nitrogen, 5 were removed and measured (prosome length and body length) and weighed after drying for $24 \mathrm{~h}$ at $60^{\circ} \mathrm{C}$. From the other five specimens, lipids were extracted by a variation of the Folch method (Folch et al., 1956). The method was scaled down to enable the extraction of lipids from small quantities of sample material. The major lipid classes were identified using thinlayer chromatography (TLC) and quantified using high performance liquid chromatography coupled with evaporative light scattering detection (HPLC-ELSD). Analysis of reference materials indicated that this method underestimated the minor triglyceride component, but gave a good estimate of the major wax ester component. The fatty acid and fatty alcohol compositions of the material were determined following transesterification of the lipid extract in methanol. Fatty acids and fatty alcohols were initially identified by comparison with authentic standards and by mass spectroscopy. Using gas chromatography with flame ionisation detection (GC-FID), the normalised area-percentage of the fatty alcohols and fatty acid methyl esters (FAMEs) were determined simultaneously in one run. These methods are described in full by Webster et al. (2006).

Lipid content was categorised as wax ester (WE) and triglyceride (TG) (mean $\mu \mathrm{g}$ individual ${ }^{1}$ ) for each group of specimens and, by reference to the group mean dry weight per individual, as the weight-specific content $\left(\mathrm{g} \mathrm{g}^{1}\right)$.

The data on fatty acid and alcohol compositions were analysed to derive markers of the dietary composition of $C$. finmarchicus stages. No single fatty acid can act as a marker for a specific dietary species, but there are well established correspondences between certain fatty acids and broad functional groups of microplankton (Dalsgaard et al., 2003; Graeve et al., 1994). We analysed data on 4 fatty acids (C16:0, C16:1(n-7), C18:2(n-6) and C18:4(n-3)) to examine variations in the relative contributions of microzooplankton, flagellates and diatoms to the diet.

Following Falk-Petersen et al. (2000) and Virtue et al. (2000), we took the normalised area-percentages of the $\mathrm{C} 16: 1(n-7)$ and $\mathrm{C} 18: 4(n-3)$ fatty acids as representing the dietary contributions of diatoms and flagellates (dinoflagellates and microflagellates), respectively. The selection of a marker for feeding on other prey classes presented more difficulty. Most of the commonly used markers for carnivorous feeding by zooplankton have been established to identify the diet composition of euphausiids, which prey mainly on copepods. However, whilst $C$. finmarchicus is known to feed on copeopod nauplii, the main source of heterotrophic prey is probably protozoan. Chu et al. (2003) have shown that some protozoa are capable of synthesising fatty acids, including the unit C18:2(n-6), which Desvilettes et al. (1997) identified as being a marker of copepod grazing on protozoa in freshwater systems. Veefkind (1997) identified C18:2(n-6) as being the principal fatty acid of cultured rotifers, and found a correlation with nanoflagellate abundance in field samples. However, Hamm et al. (2001) identified the same fatty acid as a specific marker for colonial Phaeocystis pouchetii in northern Norway. Hence, the appearance of the C18:2(n-6) unit in copepods has potential as a marker of grazing on Phaeocystis and/or micro-heterotrophs. 
We referenced each of the markers to the normalised area-percentages $\mathrm{C} 16: 0$, which is a widespread constituent of microalgae that is transferred up the food chain. Hence, the ratio C16:1(n-7)/C16:0 was applied as an index of the contribution of diatoms to the diet, C18:4(n-3)/C16:0 as an index of the flagellate contribution, and C18:2(n-6)/C16:0 as an index of the Phaeocystis/micro-heterotroph contribution.

\subsection{Estimation of stage-specific mortality rates}

In the absence of any time series information on stage abundances at any location in the region, we can only make approximate estimates of mortality rates under limiting assumptions. We used a modification of the Vertical Life Table (VLT) method of Aksnes and Ohman (1996). We define 11 stages of Calanus development ( $i$ 1 11), where $i \quad 1$ denotes eggs, $i \quad 2$ denotes stage 1 nauplii, and so on to $i \quad 11$ which denotes stage 4 copepodites. The number of individuals observed in any stage, $N_{i}$, is determined by the balance between the rate of recruitment into the stage, $R_{i}$, the mortality rate, $M_{i}$, and the rate at which individuals mature to the next stage. If the mortality within the stage is constant, and the stage duration is $d_{i}$ then maturation rate at time $t$ is simply the recruitment rate at time $t-d_{i}$ multiplied by the through-stage survival, $\exp \left(-M_{i} d_{i}\right)$. Thus the rate of change in $N_{i}$ is given by

$$
\frac{\mathrm{d} N_{i}}{\mathrm{~d} t}=R_{i}(t)-M_{i} N_{i}(t)-\mathrm{e}^{-M_{i} d_{i}} R_{i}\left(t-d_{i}\right)
$$

If we assume that the recruitment rate is constant for periods longer than $d_{i},\left(R_{i} \quad R_{i}(t) \quad R_{i}\left(t-d_{i}\right)\right)$ the number in the stage will be close to its equilibrium value

$$
N_{i}=\frac{R_{i}}{M_{i}}\left(1-\mathrm{e}^{-M_{i} d_{i}}\right)
$$

If we further assume that the egg production rate, $R_{\mathrm{o}}$, remains approximately constant then we can obtain $R_{i}$ for each $i$ from the recurrence relation

$$
R_{i+1}=R_{i} \mathrm{e}^{-M_{i} d_{i}}
$$

To estimate stage-specific mortality rates of eggs, nauplii and copepodites at a given sampling station we applied Eqs. (2) and (3). Starting with estimates of population egg production rate $\left(\mathrm{m}^{2} \mathrm{~d}^{1}\right.$, given by the product of the measured female per capita daily egg production rate $\left(d^{1}\right)$ and depth integrated female abundance $\left(\mathrm{m}^{2}\right)$ ) and an initial guess of stage specific daily mortality rates, we sequentially estimated the recruitment rates to, and hence numbers in, each of the successive development stages. The development time $\left(\mathrm{d}_{i}\right)$ of each stage was estimated from a depth-weighted mean temperature over the upper $300 \mathrm{~m}$ of the water column at each station, assuming development to be a function only of temperature and using the equation and parameters of Hind et al. (2000). The depth-weighting gave equal weight to the mean temperature above and below the median depth of the population and, thus, reflected the average temperature experienced by individuals. We then iterated the process using the Simplex method (Nelder and Mead, 1965), optimising the stage specific mortality rates to minimise an objective function expressing the difference between the observed population stage abundances and those estimated using Eq. (3). To reduce the number of fitted parameters, we assumed that mortality rates of stages $i \quad 2$ and 3 (naupliar stages 1 and 2) were identical, as were the rates for stages $i \quad 4$ and 5,6 and 7, 8 and 9, 10 and 11. The objective function was defined as:

$$
\sum_{i=2}^{i 11}\left[\left(\log \left(Q_{i}\right)-\log \left(N_{i}\right)\right)^{2}\right]
$$

where $Q_{i}$ was the observed abundance $\left(\mathrm{m}^{2}\right.$ ) of stage $i$. The method was programmed using the R-package (R Development Core Team, 2005).

Egg abundances were not included in the optimization, since we lacked genetic data to discriminate between C. finmarchicus, C. glacialis, C. helgolandicus, C. hyperboreus and other species for egg specimens. Hence, the measured egg production rate was taken as a known input to the model. We attempted to include the egg production rate in the optimization by incorporating the observed egg abundances into the objective function, 
assuming all sampled eggs to be $C$. finmarchicus. However, egg production and mortality rates were then under-constrained and the results were entirely dependent on the arbitrary initial conditions.

\subsection{Satellite data on chlorophyll-a distribution}

For a wider perspective of the distribution of surface chlorophyll- $a$ in the study region we compiled data from the satellite borne 'Sea-viewing Wide Field-of-view Sensor' (SeaWIFS; http://oceancolor.gsfc.nasa.gov/SeaWiFS/) (McClain et al., 2004). $4 \mathrm{~km}$ resolution, level-3 processed, daily data from over-flights of the study region, were retrieved for the period March October 2002. Individual $4 \mathrm{~km}$ pixels were then averaged over each month, and visualised as colour-scaled images.

\subsection{NORWESTLANT data}

In 1963, the International Commission for the Northwest Atlantic Fisheries (ICNAF) co-ordinated a major oceanographic, plankton and fisheries study of the Irminger and Labrador Seas (NORWESTLANT) (ICNAF, 1968; Bainbridge and Corlett, 1969). Three surveys of the region were carried out (NW1: 31 March 9 May, NW2: 30 April 30 June, NW3: 30 June 3 August) by an international team of ships and scientists, and the sampling covered detailed physical oceanographic measurements, phyto/microplankton, zooplankton (focussing specifically on the demography of $C$. finmarchcicus copepodites, Thysanoessa longicaudata and Meganyctiphanes norvegica), fish larvae and cetaceans. Several different samplers were used to collect zooplankton (Hensen net, Stramin net and Icelandic high speed sampler), and the sampling was confined to the upper $100 \mathrm{~m}$ of the water column. Filtration volume estimates for these samplers were unfortunately rudimentary or non-existent, so absolute estimates of taxonomic abundance are difficult to derive and may not be reliable. Similarly, the taxonomic and stage resolution employed during the microscopic analysis of the plankton samples varied between analysts so some care is required in the interpretation of the data. We selected the data from analysis of Hensen net samples for comparison with our data from 2001/2002, since these were the most uniform in terms of sample collection, analysis and documentation.

\subsection{Continuous plankton recorder $(C P R)$ data}

Sample-by-sample data on the CPR colour index, and accepted numbers of Calanus spp. copepodites stage C1 C4, and C. finmarchicus copepodites stages C5 and C6 (Beare et al., 2003; Beaugrand et al., 2004), from a transect polygon across the Irminger Sea from the Greenland shelf to the Reykjanes Ridge $\left(45^{\circ} \mathrm{W}, 59^{\circ} \mathrm{N}\right.$ to $\left.25^{\circ} \mathrm{W}, 61^{\circ} \mathrm{N}\right)$ were supplied by the Sir Alister Hardy Foundation for Ocean Science (SAHFOS), Plymouth, UK, who operate the surveys. The transect corresponded to collections along the shipping route between Cape Farewell at the southern tip of Greenland and the north of Scotland, which was monitored between 1962 and 1986. The other main CPR sampling routes through the region are between Reykjavic and North America but these run along the crest of the Reykjanes Ridge and so provided poor coverage of the basin. Since 1991, only the route between Reykjavic and St. Johns, Newfoundland, has been sampled.

The colour index reflected the green-staining produced on the silk collecting mesh of the sampler by algae and was expressed on a 4-point categorical scale loosely related to phytoplankton biomass. The relationship is loose because the intensity of staining is a function of the type of algae as well as their abundance. Small, fragile flagellate algae produce more green-staining per unit biomass than the more robust diatom species (Batten et al., 2003; Hays and Lindley, 1994).

The zooplankton data consisted of records of the catches of plankton at $6.5 \mathrm{~m}$ depth below the sea surface, integrated over alternate (every other) $18.5 \mathrm{~km}$ sections of the track followed by the ship. In terms of volume, this represents approximately $3 \mathrm{~m}^{3}$ of seawater (Warner and Hays, 1994). The numbers of specimens of each zooplankton taxonomic group present on the sampler collecting mesh exposed during each section of the tow are recorded by the CPR analysts according to ordered categories, not as absolute numbers. The absolute number interval increases approximately exponentially with category and, in addition, the category intervals vary from species to species. These categorical data are referred to as 'recorded numbers' (Beare et al., 2003). 
For each recorded number interval, there is a corresponding 'accepted number', which represents the average absolute number of specimens in the given category.

The CPR data collected within the transect polygon were divided into 3 periods of years corresponding as closely as possible to equal numbers of samples, given the constraint that the periods had to run from January in the start-year to December in the end-year (1960 1968, 1847 samples; 1969 1975, 1728 samples; 1976 1986, 1805 samples). Within each period, the log-transformed accepted numbers +1 of Calanus taxa, and the logtransformed colour index +1 , were averaged by month and $2^{\circ}$ longitude intervals.

Coefficients of correlation and their levels of significance between time series of annually aggregated accepted numbers of CPR taxa within selected $2^{\circ}$ longitude intervals were derived according to the modified Chelton method (Pyper and Peterman, 1998). This method accounts for serial autocorrelation within each series, which affects the critical value of the correlation coefficient for a given level of significance. Long-term autocorrelations due to trends within the time series were removed according to Barton et al. (2003) by conducting linear trend analysis and subtracting the underlying trend from each series.

\subsection{North atlantic oscillation (NAO) index data}

Winter (December March) values of the NAO index for the period 1958 2002, based on the difference in normalized sea level pressure between Lisbon, Portugal, and Stykkisholmur/Reykjavik, Iceland (Hurrell, 2001), were downloaded from the website of J.W. Hurrell (National Centre of Atmospheric Research; http://www.cgd.ucar.edu/cas/jhurrell/nao.stat.winter.html). These data were compared to time series of annually aggregated CPR data by means of the modified Chelton test as described above.

\section{Results}

\subsection{Environmental conditions}

Within the Irminger Sea region, we discriminated six distinct physical zones in the upper $400 \mathrm{~m}$ of the water column (East Greenland Current-Polar (EGC-P), East Greenland Current-Atlantic (EGC-A), Central Irminger Sea (CIS), North Irminger Current (NIC), South Irminger Current (SIC) and Reykjanes Ridge (RR); Fig. 2), which persisted over an annual cycle with unique hydrographic properties (temperature, salinity, stratification and nutrient concentrations). In addition, the surveys sampled a few locations on the Iceland Shelf (IS) and in the Iceland Basin (IB), which we treated as two additional zones. Detailed descriptions of the characteristics of each zone are contained in Holliday et al. (2006). The distribution of sampling locations on each survey relative to these zones is shown in Fig. 2. A total of 72 deployments of ARIES and 61 of the OCEAN sampler were completed during the four surveys, plus an additional 181 hydrographic sampling stations. All descent-leg samples from all of the ARIES deployments were analysed microscopically (2266 samples), and all samples from 24 out of 46 of the spring and summer survey (D262 and D264) OCEAN sampler deployments (143 samples). OCEAN samples were more time consuming to analyse than those from the ARIES, and were prioritised for analysis to ensure coverage of zones during the surveys when Calanus spp. naupliar stages were likely to be present in the water.

The temperature and chlorophyll- $a$ data from each survey were summarised by averaging first over the upper $50 \mathrm{~m}$ of the water column at each sampling location, and then within each zone (Fig. 3). Within each zone, the data collected during the ARIES deployments provided a representation of the seasonal and spatial patterns that was in agreement with that from the CTD stations. Hence, we concluded that the more limited ARIES dataset was not markedly biased in the extent to which it represented the various zones. The eastern zones (North Irminger Current (NIC), South Irminger Current (SIC) and Reykjanes Ridge (RR)) were consistently warmer than the western zones. Chlorophyll- $a$ concentrations were generally low, and mean concentrations $>1 \mathrm{mg} \mathrm{m}^{3}$ were found only at the eastern and western fringes of the region in April/May.

The biomass estimates for microplankton categories in each zone are shown in Fig. 4. The data indicated that the high chlorophyll concentrations in the East Greenland Current-Polar (EGC-P) zone during April/ May were due mainly to Phaeocystis spp. and diatoms, whilst the Central Irminger Sea (CIS) and Irminger Current zones were dominated by ciliates and flagellates. In the late summer, diatoms were still abundant 

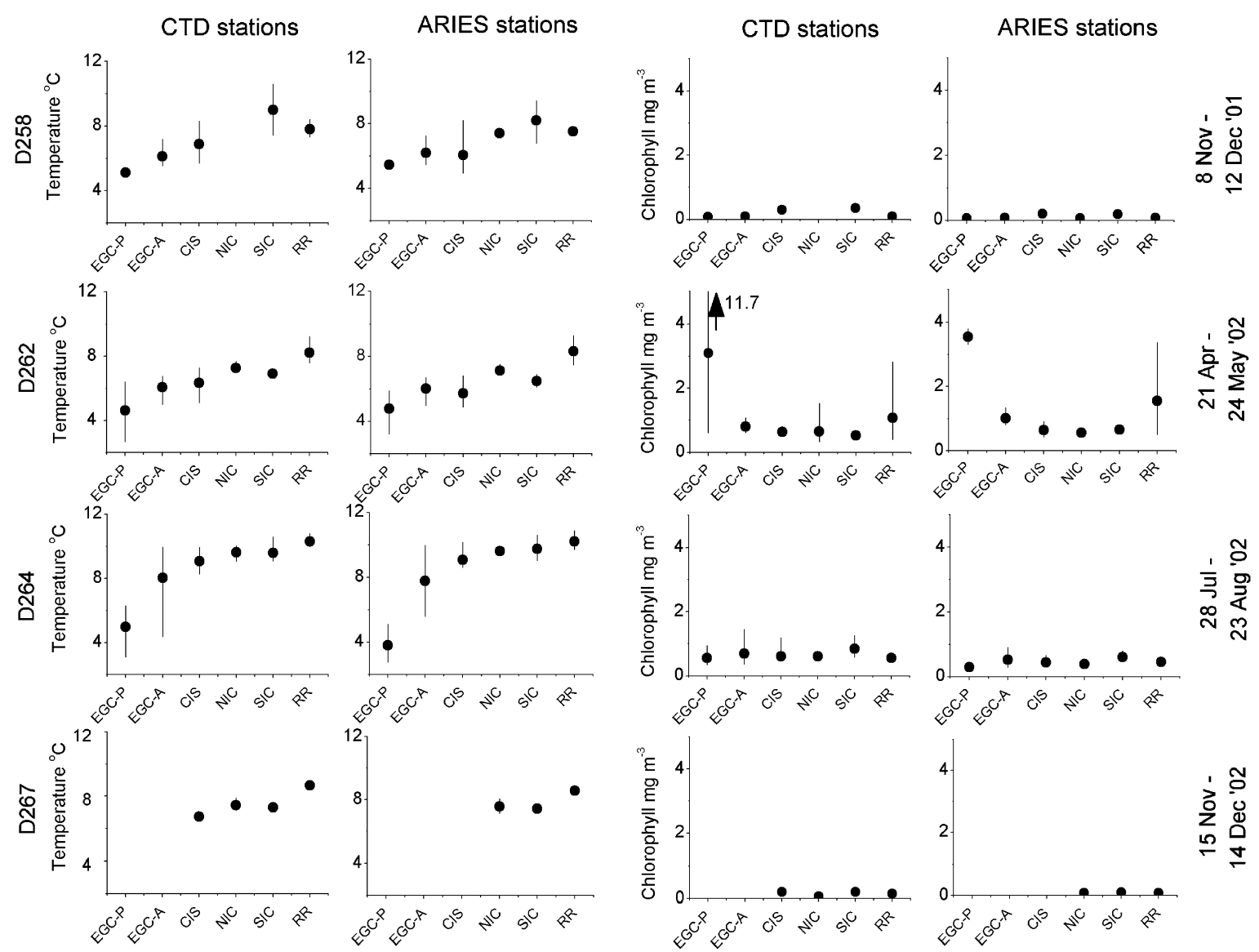

Fig. 3. $050 \mathrm{~m}$ averaged temperature $\left({ }^{\circ} \mathrm{C}\right)$ (left panel) and chlorophyll $a\left(\mathrm{mg} \mathrm{m}^{3}\right)$ (right panel), averaged over stations assigned to each of the biozones on each survey, Left column of each panel: data from hydrographic stations. Right column of each panel: data from plankton sampling stations. Symbols indicate the mean value, and range bars indicate the maximum and minimum in each case.

in the EGC-P zone, whilst flagellates and ciliates were dominant elsewhere. Diatoms were not prevalent in the CIS and East Greenland Current-Atlantic (EGC-A) zones during any of the surveys.

\subsection{Demography, distribution and lipid content of Calanus finmarchicus}

The proportion of Calanus spp. specimens identified by the molecular analysis as being C. finmarchicus varied with zone, depth interval and developmental stage within each survey. A total of 458,923 formalin preserved specimens of Calanus stages N1 C6 were identified microscopically from the samples collected during the four surveys to give estimates of abundance (D258: 25734; D262: 159717; D264: 257422; D267: 16050). Molecular analyses for dis-aggregating the microscopic data into constituent species were carried out on 5368 individuals of stage N1 C6 (D258: 468; D262: 1705; D264: 2890; D267: 305). Further details of these raw data are tabulated in Lindeque et al. (1999). In summary, copepodite specimens collected in the CIS and Irminger Current were almost exclusively $C$. finmarchicus. Calanus helgolandicus was almost completely absent from the region, but contributed significantly to samples collected farther east in the Iceland Basin. Calanus glacialis made a significant contribution to the naupliar and copepodite stages samples in the EGC zones. Calanus hyperboreus was easily discriminated by microscopy from the other Calanus species as copepodites, but not as nauplii, and a proportion of the Calanus spp. nauplii collected were identified as C. hyperboreus by the molecular analysis, mainly in the EGC zones. Below $400 \mathrm{~m}$ depth in the winter surveys, the Calanus spp. copepodites sampled were exclusively C. finmarchicus, except in the EGC-P zone, where a 


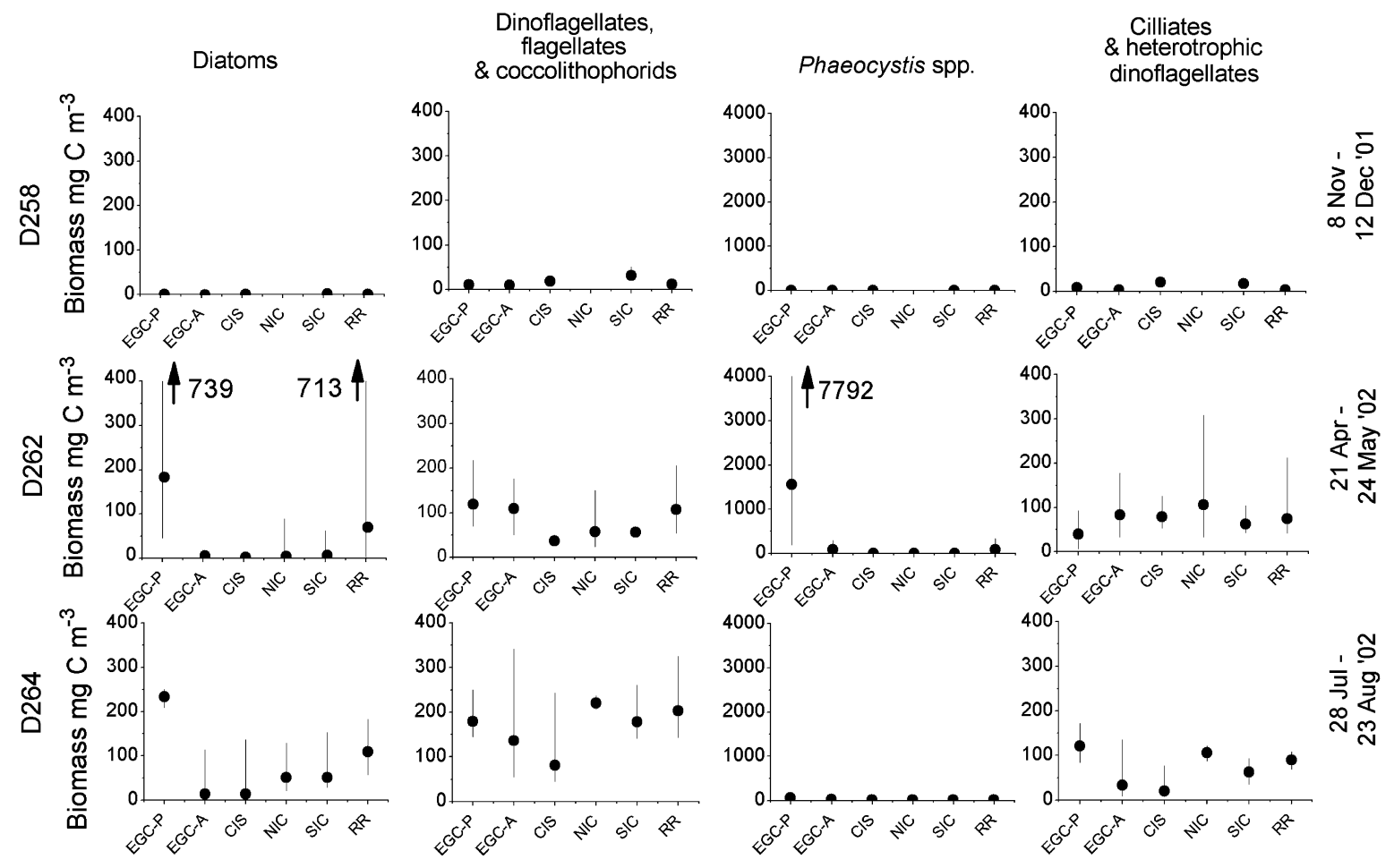

Fig. 4. Carbon biomass $\left(\mathrm{mg} \mathrm{C} \mathrm{m}^{3}\right)$ of microplankton categories averaged over water samples collected at the depth of the maximum chlorophyll $a$ fluorescence at stations in each zone. Symbols indicate the geometric mean and the bars indicate the maximum minimum range.

small proportion of $C$. glacialis was present. However, the seabed depth below the EGC-P was approximately $450 \mathrm{~m}$ compared to $>1000 \mathrm{~m}$ in the other zones, so the contribution of this sub-set of the deeper layer samples is probably slight.

After blending of the molecular data with the microscopic estimates of species numbers in each sample, the concentration $\left(\mathrm{m}^{3}\right)$ of each $C$. finmarchicus developmental stage was integrated vertically at each sampling location to obtain an estimate of the total abundance $\left(\mathrm{m}^{2}\right)$. These data are shown in Figs. 5 , where various stages have been grouped together for brevity.

At the large scale, the depth-integrated abundance data show that during November and December the population of $C$. finmarchicus was almost entirely in stages C4 and C5. By April the population had progressed to stage C6 females and males and had begun to reproduce as evidenced by the presence of naupliar stages. We refer to these C6 individuals as Generation $0(\mathrm{G} 0)$, and their offspring as G1. Under food-replete conditions, the development times from spawning to the end of $\mathrm{C} 5$ at the temperatures measured over the upper $300 \mathrm{~m}$ of the region $\left(59^{\circ} \mathrm{C}\right.$ ) were estimated to be $4565 \mathrm{~d}$ (average $54 \mathrm{~d}$; Hind et al., 2000). Hence, G1 eggs spawned in mid-May, would be ready to either enter the overwintering state or progress to C6 at around mid-July, assuming no food limitation of development.

In late July and early August, all developmental stages from N1 to C6 were present in the population, but particularly $\mathrm{C} 4$ and $\mathrm{C} 5$. Male and female $\mathrm{C} 6$ were present, but at lower abundances than in spring. We assume that the copepodite stages C3 6 were most likely to be G1 individuals, but the presence of early naupliar stages clearly indicates that a proportion of G1 had progressed to spawning and produced a $\mathrm{G} 2$ cohort. The proportion of the G1 cohort which had developed to C6, rather than arrest in C5 in preparation for overwintering, was estimated as the proportional contribution of $\mathrm{C} 6$ to the depth integrated abundance of $\mathrm{C} 5$ and $\mathrm{C} 6 \mathrm{com}-$ bined. Across all stations, 7\% of the cohort were estimated to have developed to C6 (Fig. 9) with no significant differences between regions ( $t$-test, $p>0.05$ ). 


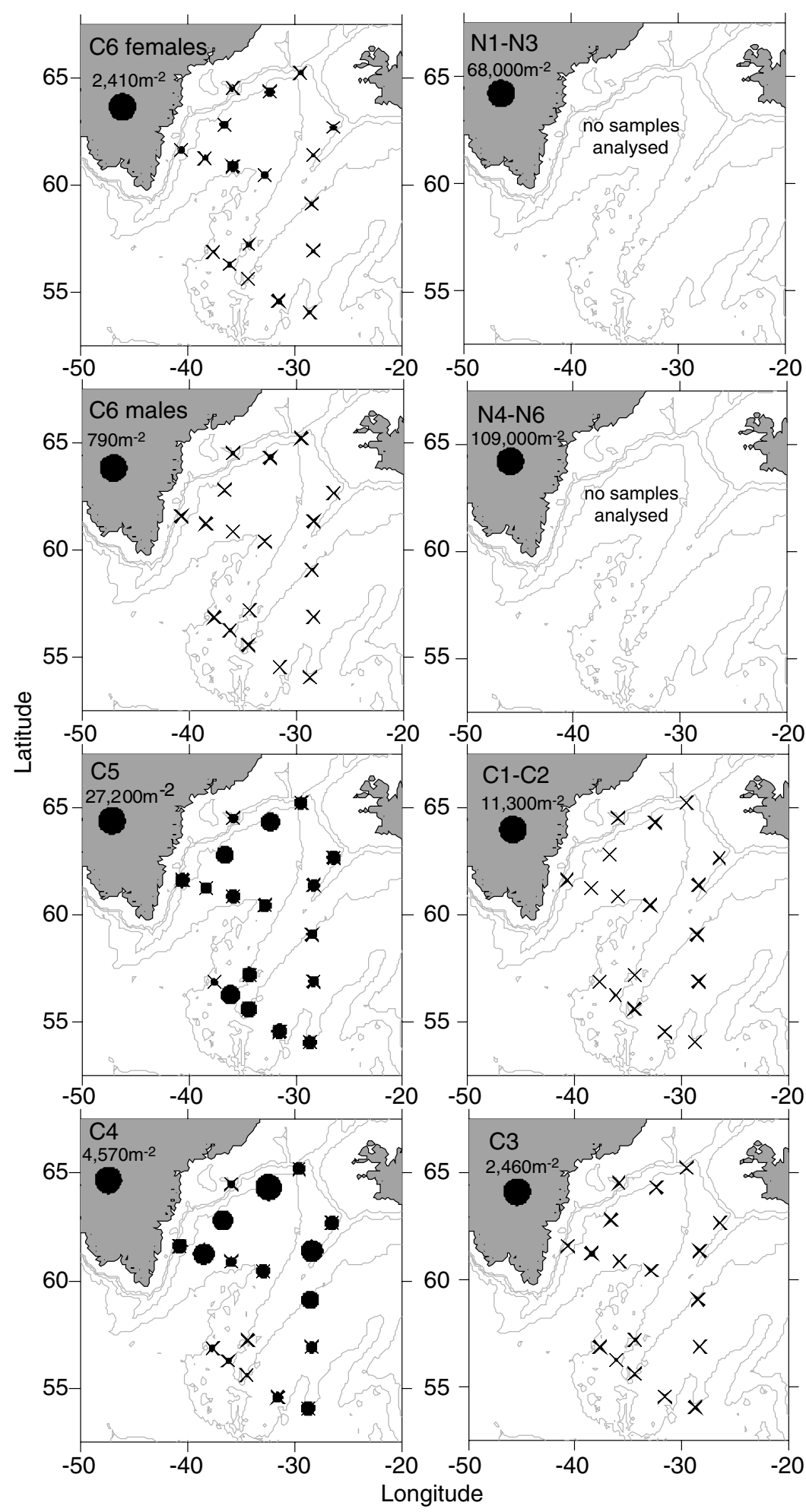

Fig. 5. Abundance of $C$. finmarchicus developmental stages during survey D258 (8 November 12 December 2001), integrated from the surface to the seabed at each sampling location. X symbols indicate the collection position of samples which were analysed for each stage. The areas of filled circular symbols superimposed on the collection positions are scaled to the stage abundance ( $\mathrm{m}^{2}$ ), with the scaling factor indicated by the symbol size and value $\left(\mathrm{m}^{2}\right)$ in the upper left corner of each panel. Note that the symbol for area scaling differs between development stages, but has been chosen to be equal across Figs. 58 for any given stage. 

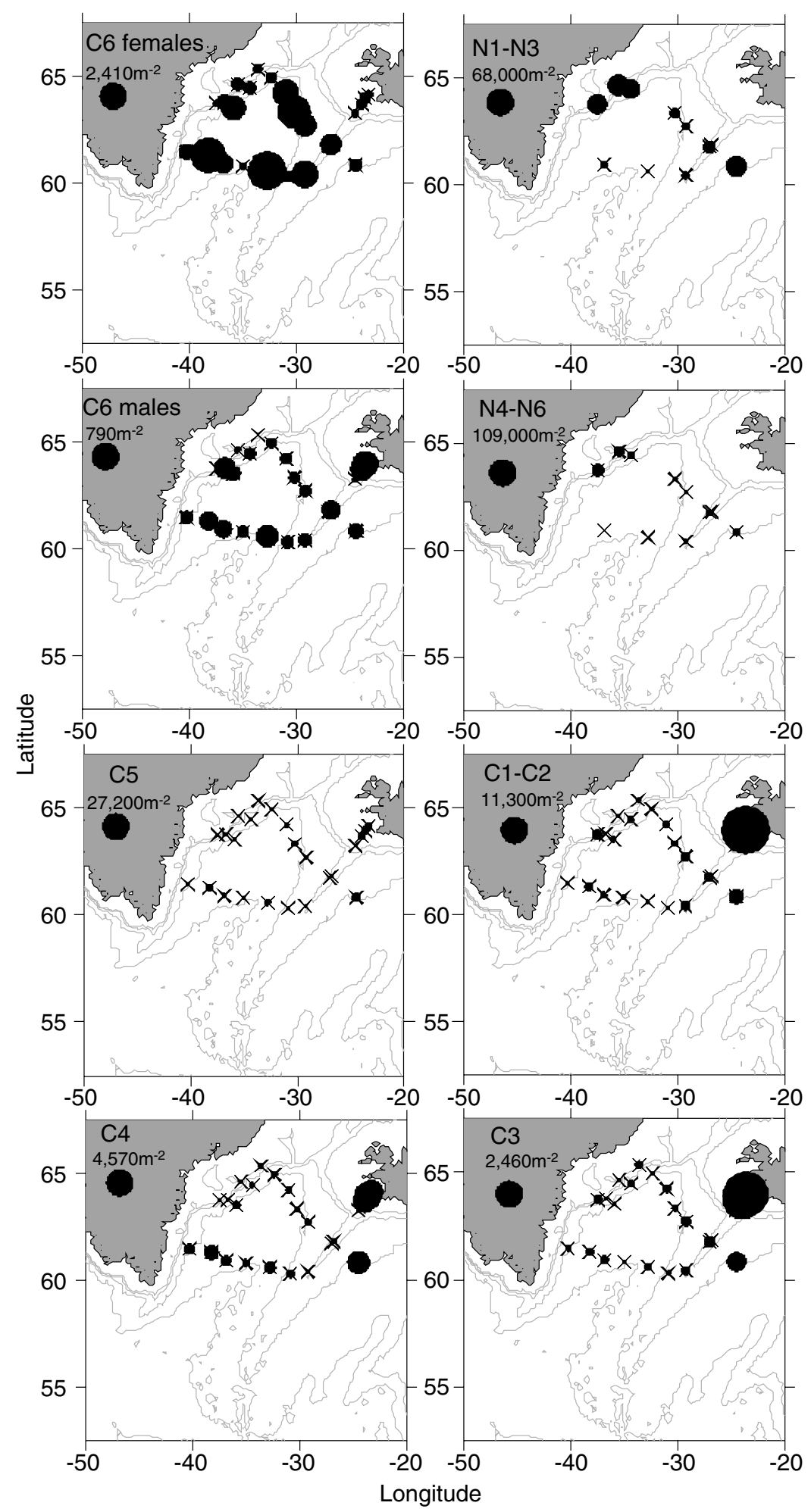

Fig. 6. Abundance of C. finmarchicus developmental stages during survey D262 (21 April 24 May 2002), integrated from the surface to the seabed at each sampling location. Scaling of symbols as for Fig. 5. 


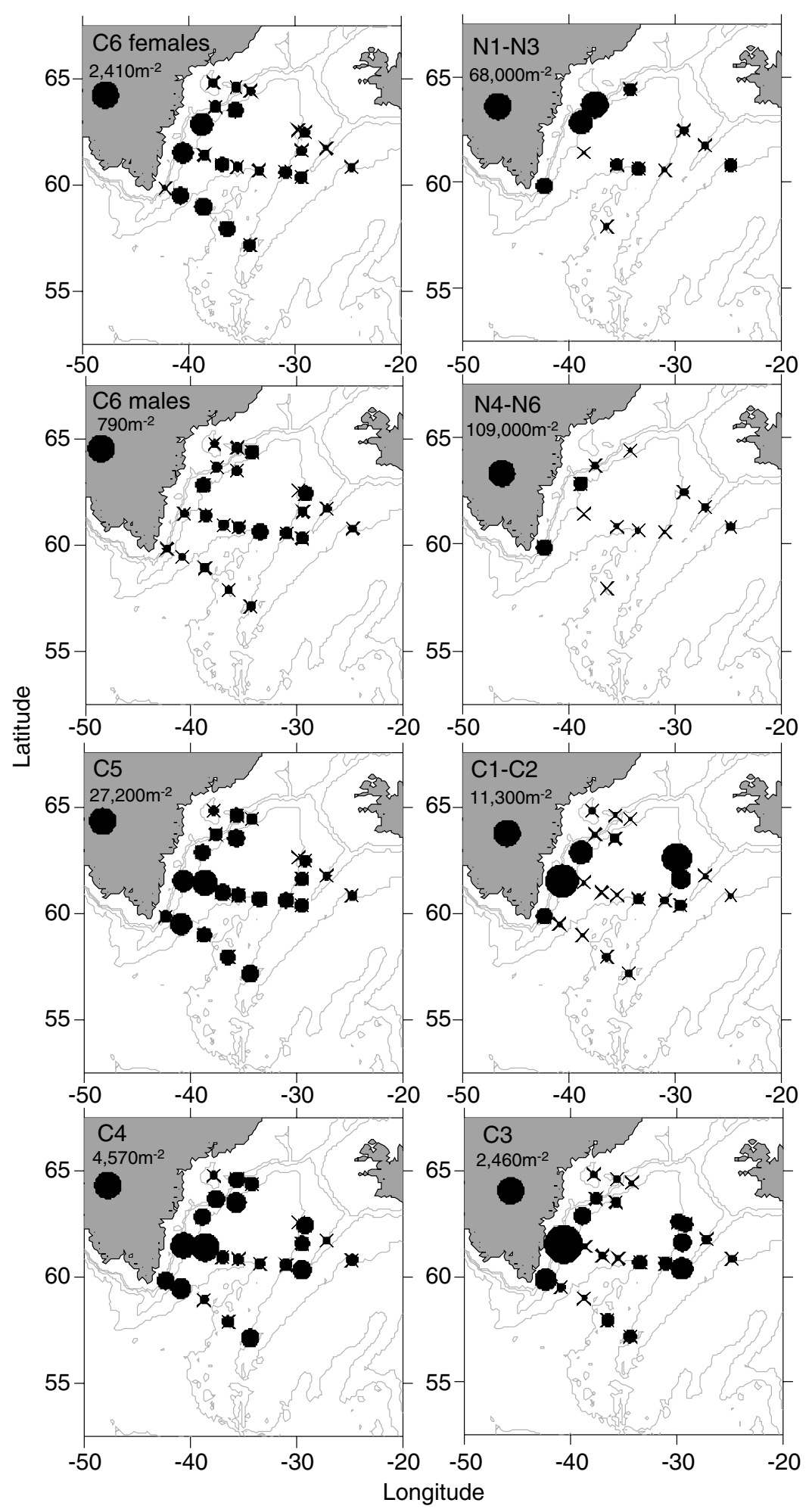

Fig. 7. Abundance of C. finmarchicus developmental stages during survey D264 (28 July 23 August 2002), integrated from the surface to the seabed at each sampling location. Scaling of symbols as for Fig. 5. 


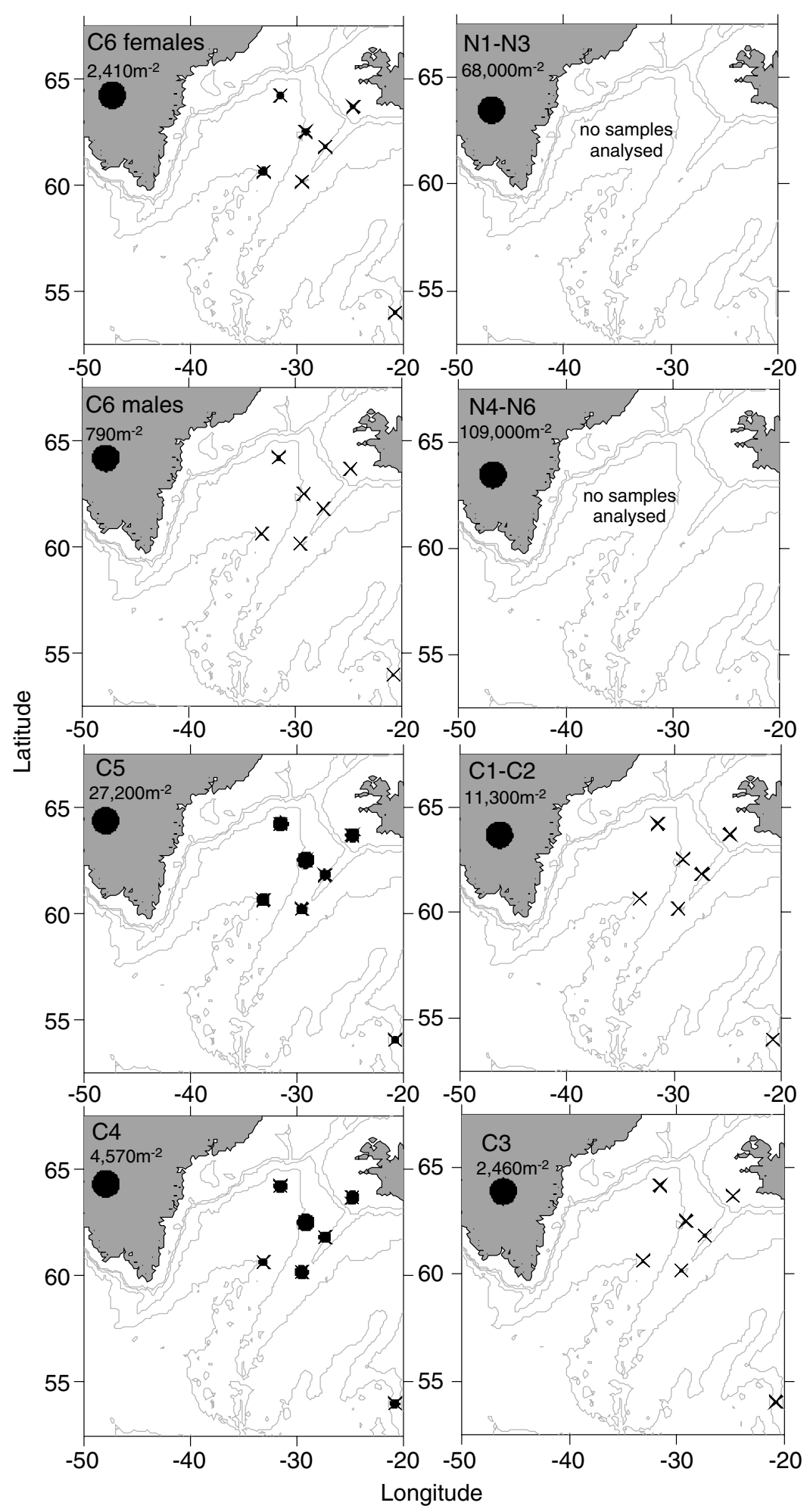

Fig. 8. Abundance of C. finmarchicus developmental stages during survey D267 (15 November 14 December 2002), integrated from the surface to the seabed at each sampling location. Scaling of symbols as for Fig. 5. 


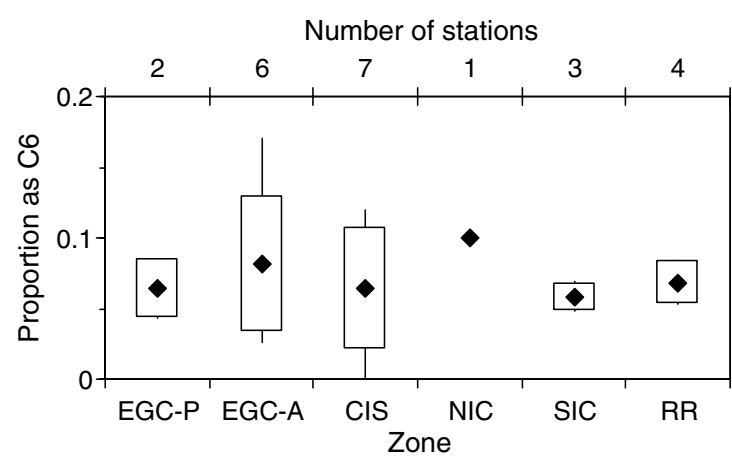

Fig. 9. Proportional contribution of C6 to the combined depth integrated abundances of C5 and C6 during July/August (survey D264). Box and whisker plots the maximum and minimum, and the arithmetic mean \pm 1 s.d. for stations sampled within each zone. Numbers of stations sampled in each zone are shown along the upper $x$ axis.

The spatial distributions of stage-abundance suggested that whilst females were widely distributed across the region during April/May, recruitment of naupliar and early copepodite stages was most active around the fringes of the Basin, ie. in the Irminger Current and EGC-A zones, rather than in the central basin. Similarly, in the late summer, copepodite recruits were most abundant around the fringes. The highest abundances of $\mathrm{C} 3$ and $\mathrm{C} 4$ stages approaching entry to overwintering were along the East Greenland slope, in the boundary between the EGC-A and CIS zones, and in the Irminger Current. However C5 in late summer were more uniformly distributed across the region.

Overwintering C4 and C5 stages in November and December were vertically distributed between 500 and $2000 \mathrm{~m}$ in the boundary area between the EGC-A and CIS (Fig. 10), with C4 being typically distributed deeper than C5. By May, the surviving overwintering population had partially matured to C6 (85\% females averaged over all stations), and was concentrated in the upper $50 \mathrm{~m}$ of the water column, though clearly we could not have sampled the same population of individuals on a given station in both November and May due to horizontal advection. The early stage nauplii surviving from the eggs produced by the females were distributed in the upper $200300 \mathrm{~m}$, but concentrated towards the surface. Averaged over all stations, the relative vertical distributions of nauplii varied little between stages. In spring, approximately $50 \%$ of the population was shallower than $50 \mathrm{~m}$, and $98 \%$ was shallower than $300 \mathrm{~m}$. In late summer, nauplii were slightly more concentrated towards the surface than in spring. Also in the summer, small numbers $\left(<1 \mathrm{~m}^{3}\right)$ of $\mathrm{C} 1$ copepodites were distributed down to $1500 \mathrm{~m}$, whilst the later-stage copepodites (stages C2 C5) had a bimodal depth distribution with a component at depth $(4001600 \mathrm{~m})$ and a shallow component concentrated in the upper $50 \mathrm{~m}$. Farther east, in the eastern CIS and on the Reykjanes Ridge (Fig. 11), the winter distribution of C4 and C5 was shallower, and the proportion of C4 and C5 remaining in the upper $100 \mathrm{~m}$ in late summer was substantially less than in the western areas. We interpret this as indicating that the late copepodite populations at the eastern sites in late summer were in a more advanced stage of entry to the overwintering stock than those to the west, despite being sampled 10 days earlier. However, in contrast to the western sites, there was little evidence at the eastern sites of the vertical distribution of C1-C3 stages extending deeper than $400 \mathrm{~m}$ despite higher concentrations in the upper $100 \mathrm{~m}$.

We employed a Generalised Additive Model (GAM) (Hastie and Tibshirani, 1990) to investigate the space time dynamics of descent to overwintering depth in late summer. Estimates of the proportion of the C5 population deeper than $200 \mathrm{~m}$ at each sampling location were modelled as smooth functions of sampling date, longitude and latitude, using the GAM fitting function in the R-package. The optimum model combined a tensor-product spline smoothing of sampling date and a thin-plate regression spline smoothing of latitude and longitude (Wood, 2004), and explained $77.3 \%$ of the deviance in the observations (Fig. 12). We then predicted the proportion deeper than $200 \mathrm{~m}$ with respect to longitude and latitude on two separate dates (1st and 21st of August) at the beginning and end of the survey period (Fig. 12). The results clearly show that descent occurred later in the south-west of the region than in the north-east. The model predicted that the onset of descent must have been before julian day 209 (28 July) in the north-eastern part of the basin $\left(64^{\circ} \mathrm{N} 30^{\circ} \mathrm{W}\right)$, 


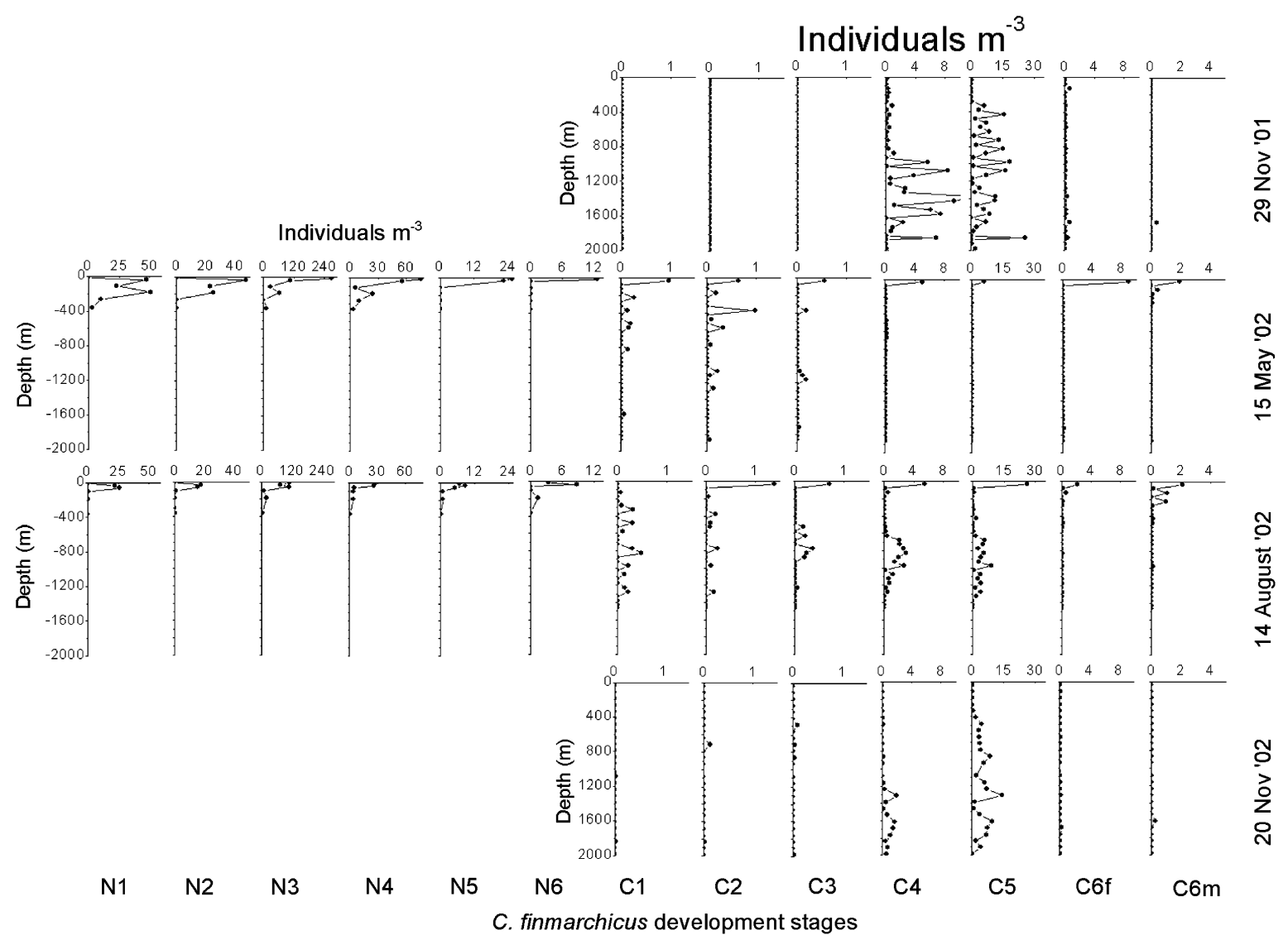

Fig. 10. Vertical distribution of $C$. finmarchicus developmental stages at station $\mathrm{C} 10$ (average position $64^{\circ} 29.6^{\prime} \mathrm{N} 32^{\circ} 36.5^{\prime} \mathrm{W}$, northern $\mathrm{CIS}$ zone close to the boundary with the EGC A and NIC zones) on each of the four surveys. Concentrations ( $\mathrm{m}^{3}$ ) of naupliar stages N1 N6 were estimated from samples collected with the OCEAN sampler, and those of copepodite stages C1 C6 from ARIES samples. Times of day (GMT) during which samples were collected: 29 November 2001, 11:39 14:37; 15 May 2002, 19:48 20:27 (OCEAN) and 21:23 23:45 (ARIES); 14 August 2002, 03:09 05:01 (ARIES) and 08:00 08:32 (OCEAN); 20 November 2002, 04:08 07:10.

and around day $229\left(17\right.$ August) at the south-western part $\left(59^{\circ} \mathrm{N} 40^{\circ} \mathrm{W}\right)$. The difference (at least $\left.20 \mathrm{~d}\right)$ corresponds approximately to the difference in estimated food-replete development time from spawning to the end of $\mathrm{C} 5$ at $5^{\circ} \mathrm{C}$ and $9^{\circ} \mathrm{C}$, which are approximately the mean $0300 \mathrm{~m}$ temperatures in the Irminger Current and EGC-A zones. Hence, given spawning on the same dates in these two areas, the observed difference in descent timing would be consistent with temperature dependent development rates assuming little or no food limitation. Clearly, however, there is no a priori reason to assume that all survivors to the descent phase in different regions originated from the same spawning date.

The weight-specific lipid content (WE $+\mathrm{TG}, \mathrm{g} \mathrm{g}{ }^{1}$ dry weight) data were summarised by aggregation across zones within the region. Lipid contents of C5 above and below $200 \mathrm{~m}$ depth in late summer were similar in the east of the region (SIC and RR zones; geometric mean $0.63 \mathrm{~g} \mathrm{~g}{ }^{1}$ above $200 \mathrm{~m}\left(\begin{array}{ll}n & 6\end{array}\right), 0.67 \mathrm{~g}^{1}$ below $200 \mathrm{~m}$ ( $n$ 12), $t$-test, $p>0.05$, Fig. 13). However, in the EGC-A, EGC-P and CIS zones, the C5 animals below $200 \mathrm{~m}$ contained more lipid per unit dry weight than those above (geometric mean $0.48 \mathrm{~g} \mathrm{~g}{ }^{1}$ above $200 \mathrm{~m}$ $\left(\begin{array}{ll}n & 17\end{array}\right), 0.83 \mathrm{~g} \mathrm{~g}^{1}$ below $200 \mathrm{~m}\left(\begin{array}{ll}n & 26\end{array}\right)$, $t$-test, $p<0.05$,). We take this as further evidence of the less advanced state of lipid loading for entry to the overwintering population in the south-west of the region than of that in the north-east. In November and December, lipid content was relatively uniform across the region, but lower than in late summer at the onset of overwintering (geometric mean across all samples $0.32 \mathrm{~g} \mathrm{~g}{ }^{1}$ ( $n$ 34) during survey D258). Four to five months later in the annual cycle, females emerging from the overwinter stock and sampled near the surface in April/May (survey D262) in the Irminger Current and CIS zones 


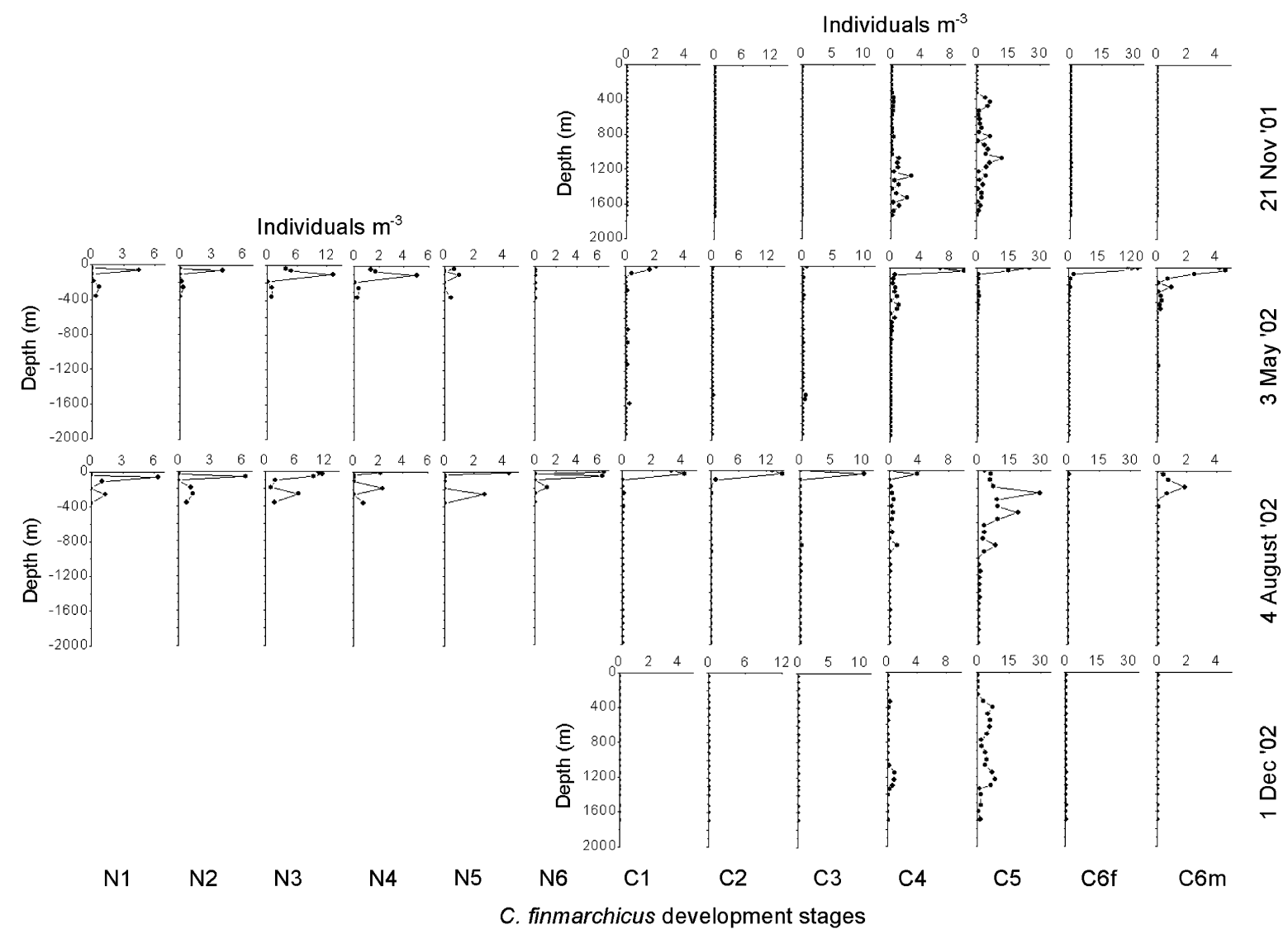

Fig. 11. Vertical distribution of $C$. finmarchicus developmental stages at station D9 (average position $60^{\circ} 34.5^{\prime} \mathrm{N} 33^{\circ} 03.05^{\prime} \mathrm{W}$, SIC zone) on each of the four surveys. Concentrations $\left(\mathrm{m}^{3}\right)$ of naupliar stages N1 N6 were estimated from samples collected with the OCEAN sampler, and those of copepodite stages C1 C6 from ARIES samples. Times of day (GMT) during which samples were collected: 21 November 2001, 09:56 11:59; 3 May 2002, 00:14 02:12 (ARIES) and 11:54 12:35 (OCEAN); 4 August 2002, 17:18 17:53 (OCEAN) and 19:36 21:52 (ARIES); 1 December 2002, 07:33 10:28.

had lipid content of $0.10 .3 \mathrm{~g} \mathrm{~g}^{1}$ (geometric mean $0.16 \mathrm{~g} \mathrm{~g}^{1}, n$ 10) However, those sampled in the EGC zone had very depleted lipid reserves (geometric mean $0.05 \mathrm{~g} \mathrm{~g}^{1}, n^{19}$ ).

The data from the central-line of sampling locations spanning the Greenland shelf to the Reykjanes Ridge $\left(40^{\circ} \mathrm{W}, 61^{\circ} \mathrm{N}\right.$ to $\left.29^{\circ} \mathrm{W}, 60^{\circ} \mathrm{N}\right)$ revealed that the overwintering stages descending out of the surface waters in late summer (D264) entered a different water mass and circulation regime. Shallow Labrador Sea Water (LSW) formed a $1000 \mathrm{~m}$ thick layer beneath the CIS and Irminger Current zones. Overflow water from the Iceland Scotland Ridge and the Denmark Strait, deep LSW, and North East Atlantic Deep Water all lay beneath this layer (Fig. 14). Data from November and December 2001, showed that the overwintering copepodites remained in the shallow LSW, and only a small proportion of C5 descended into the deeper water masses (Fig. 14).

The spatial data on depth integrated stage abundances were summarised by averaging the stations occurring within each zone. The numbers of stations sampled in each zone and cruise were few, so standard estimates of variance were inappropriate. We therefore estimated the geometric mean and maximum-minimum range of values in each zone (Fig. 15). These confirmed that overwintering stages and emerging females in spring were broadly distributed through the region (excepting for the EGC-P zone), whilst recruitment of naupliar and early copepodite stages was mainly confined to the peripheral EGC and RR zones. The implications were therefore that (a) population egg production was lower, and/or (b) that egg and naupliar mortality rates were higher in the CIS zone than around the periphery of the basin due to predation and/or egg condition. 

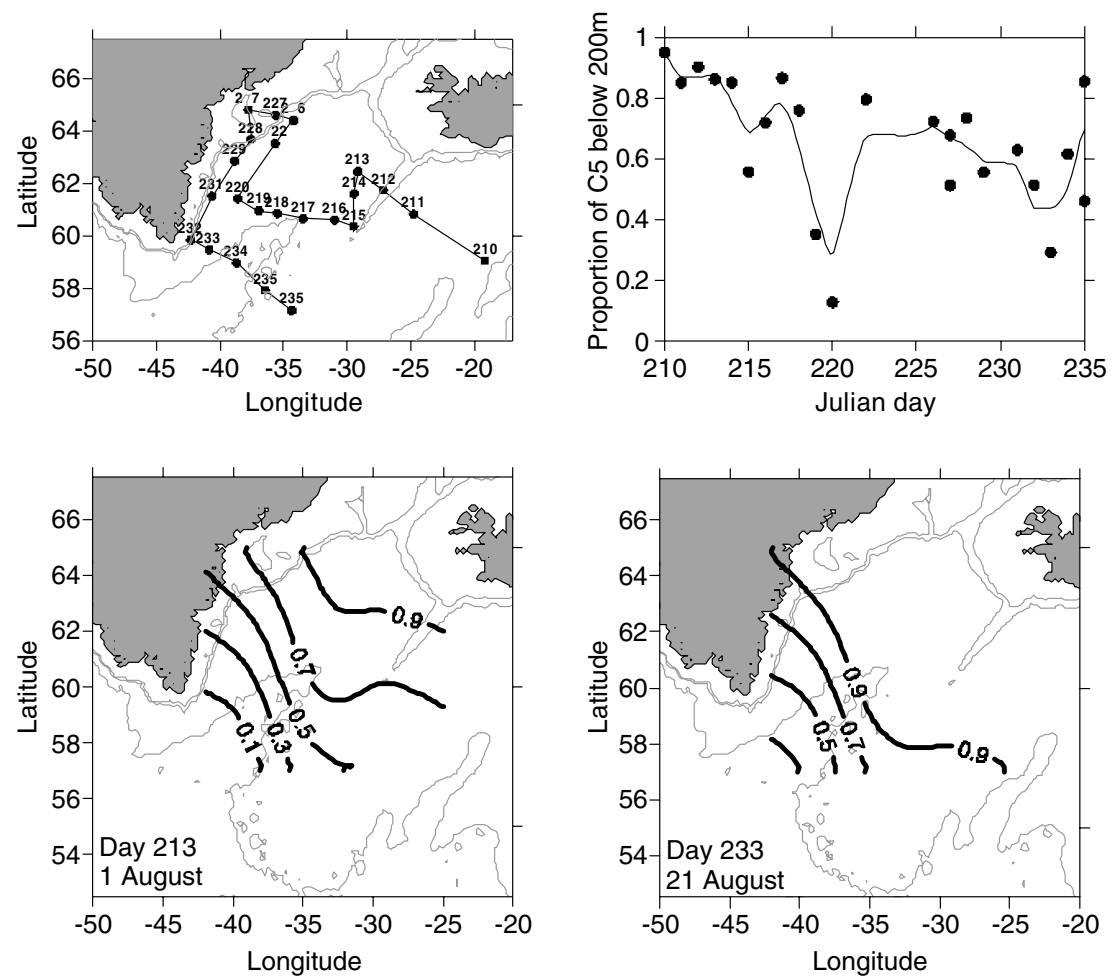

Fig. 12. General additive model (GAM) predictions of the proportion of the depth integrated population of $C$. finmarchicus stage C5 deeper than $200 \mathrm{~m}$, as an index of the state of overwintering entry. The GAM explained 77.3\% of the deviance in the observations (adjusted $r^{2}=0.575$ ). Upper left panel, survey track and sampling locations between julian day 210 (29 July) and day 235 (23 August). Labels above sampling locations indicate julian day number. Upper right panel, observed proportions of the population deeper than $200 \mathrm{~m}$ on each sampling date along the cruise track (symbols), together with the GAM prediction of along track changes in proportion as a function of time (line plot). Lower left panel, spatial prediction for julian day 213 (1 August) of the proportion of C5 deeper than $200 \mathrm{~m}$. Lower right panel, spatial prediction for julian day 233 (21 August) of the proportion of C5 deeper than $200 \mathrm{~m}$.

\subsection{Egg production and mortality rates}

Per capita egg production rates of females estimated from shipboard incubations showed no obvious relationship with in situ chlorophyll concentration (Fig. 16a) or temperature, and were not significantly lower in the CIS than in other regions (Fig. 16b). In fact, mean per capita egg production was slightly lower in the EGC zones than elsewhere, perhaps reflecting the lower lipid content of the females (Fig. 13). Per capita rates were measured on specimens collected from the upper $100 \mathrm{~m}$, but a proportion of the total depth integrated female population was distributed deeper in the water column (average 9\% in April/May and 43\% in July/August; mostly between 100 and $300 \mathrm{~m}$; not significantly different between zones). Assuming that the measured per capita rates were equally applicable to the more deeply distributed fraction of the population, the population egg production rate $\left(\mathrm{m}^{2} \mathrm{~d}^{1}\right)$ in the CIS in April/May was estimated to be 24 times higher than in the peripheral areas (Fig. 15). Hence, assuming that the measured egg production rates were representative for each zone, the spatial pattern of recruitment could not be explained by reproductive rates.

Egg production rates, fine mesh collections of naupliar abundance and coarse mesh collections of copepodite abundance were all available at nine stations in the spring survey and 12 in late summer (Tables 1 and 2). Temperature profiles from these locations were depth-averaged giving equal weight to the mean from the surface to $50 \mathrm{~m}$, and from 50 to $300 \mathrm{~m}$. The resulting estimates of the mean temperature experienced by the population of nauplii and copepodites varied between $5.5^{\circ} \mathrm{C}$ in the EGC-P zone in spring and $9.5^{\circ} \mathrm{C}$ over the Reykjanes Ridge in late summer. The predicted range in age at the end of $\mathrm{C} 4$ resulting from these temperatures was $3150 \mathrm{~d}$, mean $43.5 \mathrm{~d}$ in spring, $39.5 \mathrm{~d}$ in late summer (Hind et al., 2000). 

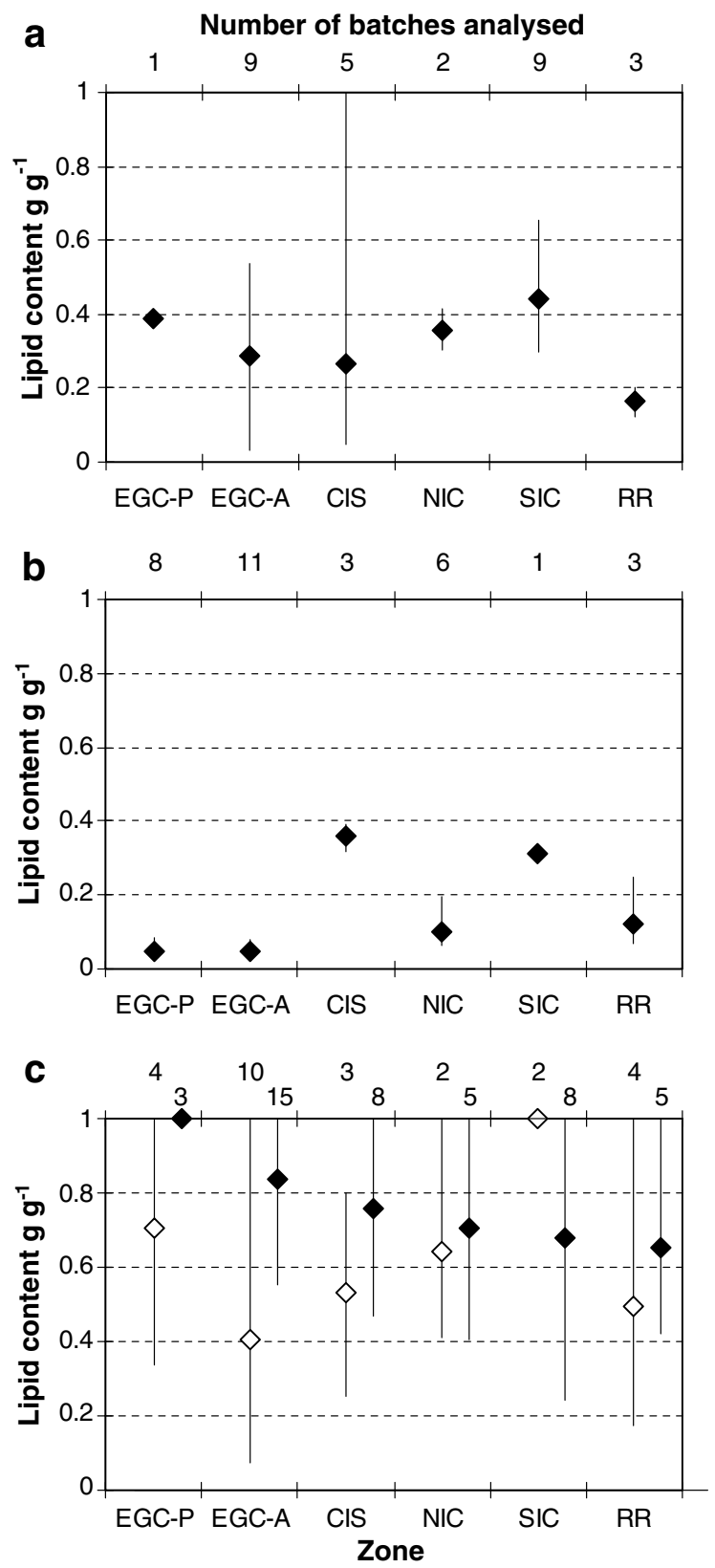

Fig. 13. Mean and range of lipid content (wax ester plus tri acyl glyceride; $\mathrm{g}$ ( $\mathrm{g}$ dry weight) ${ }^{1}$ ) of $C$. finmarchicus, averaged over each zone for each survey. (a) Stage C5 during survey D258, (b) stage C6 females during survey D262, (c) stage c5 during survey D264. Numbers along the upper $x$ axis of each panel indicate the batches of specimens analysed from each zone. For survey D264, animals collected above and below the $200 \mathrm{~m}$ depth horizon are discriminated by the symbols (open symbols shallower than $200 \mathrm{~m}$, filled symbols deeper than $200 \mathrm{~m}$; batches of specimens analysed: upper row shallower than $200 \mathrm{~m}$, lower row deeper than $200 \mathrm{~m}$ ).

Estimates of stage-specific mortality rates showed high variability between stations and stages. Some of this could be attributed to failure of the observations to meet the demands of the underlying assumptions in the modified VLT model. For example, at five stations the numbers of first stage nauplii present in the plankton samples were too numerous to be explained by constant egg production at the rate measured in the incubation experiments. In a few cases, the stage distribution was discontinuous, with one or two stages missing from the 

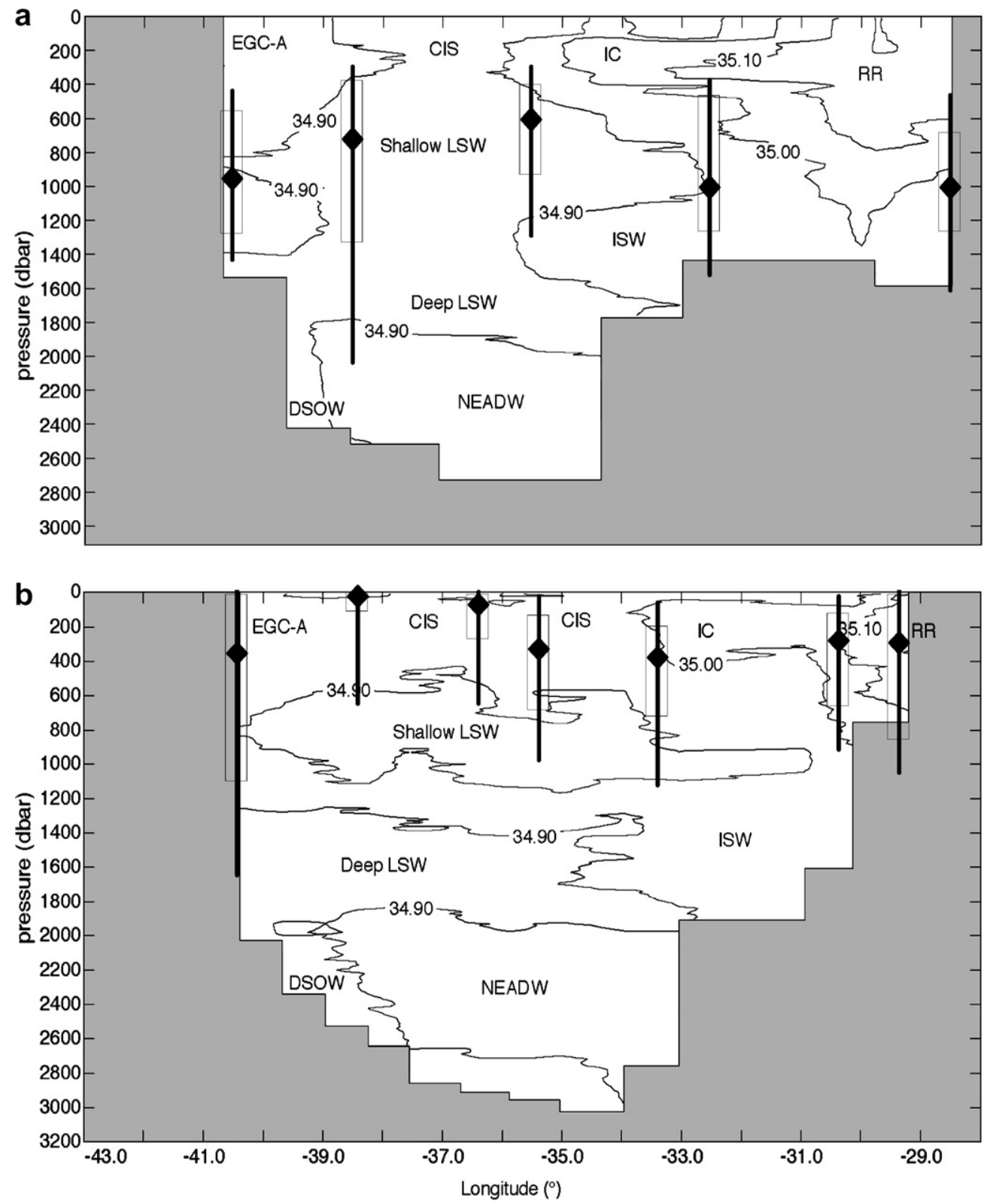

Fig. 14. West east vertical section along the central transect across the Irminger Sea $\left(62^{\circ} \mathrm{N} 41 \mathrm{~W}\right.$ to $60^{\circ} \mathrm{N} 29^{\circ} \mathrm{W}$, see Fig. 2$)$, of salinity and centiles of the vertical distribution of $C$. finmarchicus stage C5 at each sampling location. (a) survey D258 (November December 2001), (b) survey D264 (July August 2002). Box and whisker plots show the median depth (filled symbol), 17th 83rd centiles (box) and 5th 95th centiles (whiskers) of $C$. finmarchicus. Contours show salinity, and water masses are labelled as follows: East Greenland Current Atlantic (EGC A), Central Irminger Sea (CIS), Irminger Current (IC), Reykjanes Ridge (RR), Labrador Sea Water (LSW), Iceland Scotland Overflow Water (ISW), Denmark Strait Overflow Water (DSOW), Northeast Atlantic Deep Water (NEADW).

population. Such inconsistencies resulted in fitted mortality rates $<-1.0$ or $>3.0$ and we discarded all cases outside this range. The discarded data amounted to 39 out of a total of 126 estimates $(31 \%)$.

For the remaining data, the survey mean mortalities showed a similar pattern with stage (Fig. 17). Initially high egg mortality rates $\left(>0.8 \mathrm{~d}^{1}\right)$ declined to approximately $0.15 \mathrm{~d}^{1}$ for early stage nauplii, increased to around $0.5 \mathrm{~d}^{1}$ for late stage nauplii and then declined again to $<0.1 \mathrm{~d}^{1}$ for stage 3 and 4 copepodites. Standard errors on the mortality estimates were such that the mean rates were not statistically different between 


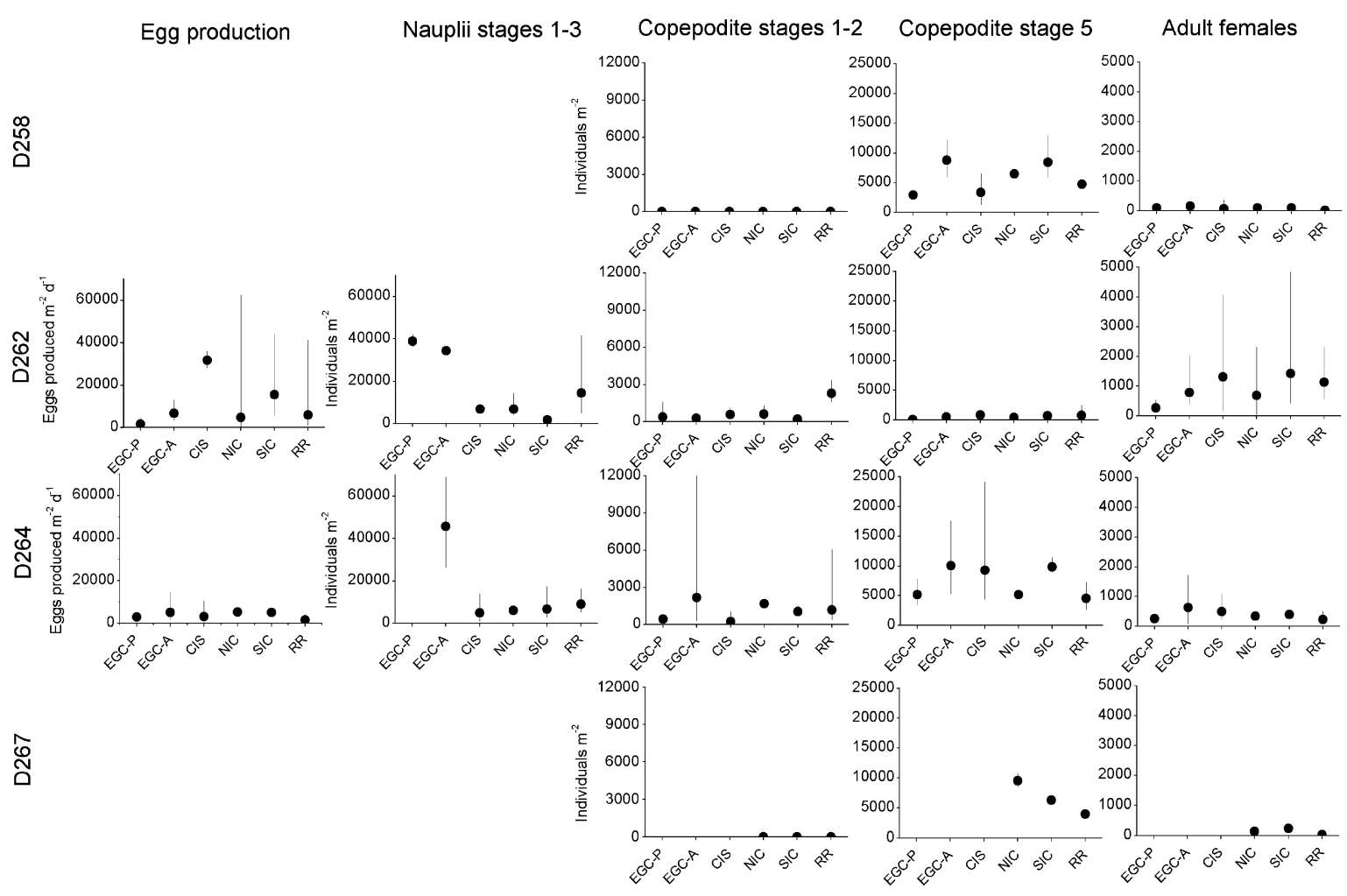

Fig. 15. Population egg production rates (eggs $\mathrm{m}^{2} \mathrm{~d}{ }^{1}$ ) and depth integrated stage abundances of $C$. finmarchicus aggregated by zone for each survey. Symbols represent geometric mean values, bars represent maximum and minimum values.

spring and late summer, though the tendency was for egg mortalities to be higher in spring than late summer, and vice-versa for naupliar and early copepodite mortality rates.

Egg mortalities at individual stations were estimated to range between $0.42 .8 \mathrm{~d}^{1}$ in spring and $02.6 \mathrm{~d}^{1}$ in late summer, with significant differences between stations. In both spring and late summer there was a trend of increasing egg mortality from west to east (Fig. 18). The low egg mortality rates were found consistently in the EGC zone where temperature was lowest, but there was no significant relationship between mortality rate and temperature across the region as a whole during either spring or summer.

First, we examined the possibility that the pattern of egg mortality was due to systematic variation in the viability of eggs due to, for example, infertility, malformations or other internal deficiencies in the embryos resulting from the diet composition of the adult females (Jónasdóttir and Kiørboe, 1996; Jónasdóttir et al., 1998). Since predators (including the parental female) were excluded from the shipboard incubations of eggs, the proportion hatching in these experiments represented an independent estimate of the component of total egg mortality in the sea which was due to hatching failure $\left(\mathrm{M}_{1(\text { hatch })}, \mathrm{d}^{1}\right)$ :

$$
M_{1(\text { hatch })}=-\frac{\log _{e}(\text { proportion hatching })}{d_{1}}
$$

where as in Eqs. (1) (3), the term $d_{1}$ refers to the egg stage duration (d).

The proportion of eggs hatching per station in the incubations varied between 0 and 0.87 , with the survey mean being not significantly different between spring and late summer (spring 0.41 late summer 0.36 ). Within each survey there was no clear systematic pattern of viability (proportion hatching) between zones that could be resolved by the data (Fig. 19), and there was no evident relationship between the proportion hatching in incubations and per capita egg production. Egg hatching success data and modified VLT estimates of total mortality were both available from only a sub-set of the stations sampled. However, these data showed that

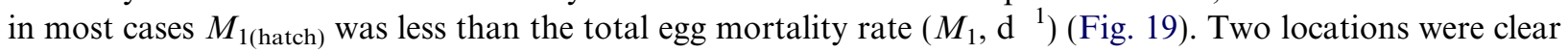



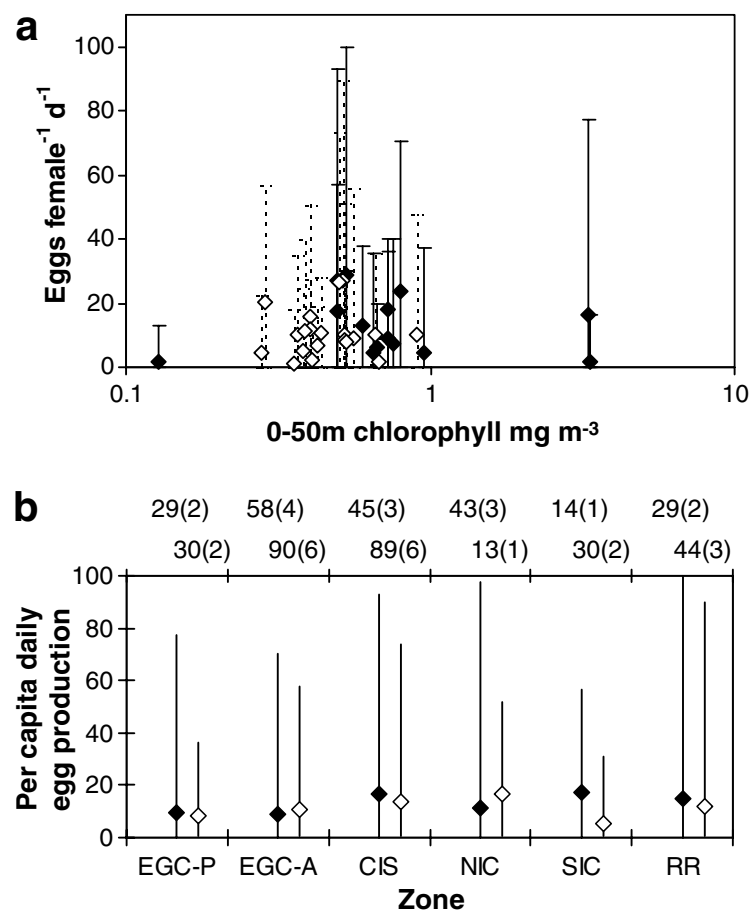

Fig. 16. (a) Individual station estimates of $C$. finmarchicus female per capita egg production rate (eggs female ${ }^{1} \mathrm{~d}^{1}$ ), in relation to in situ depth averaged chlorophyll concentration $\left(\mathrm{mg} \mathrm{m}^{3}\right.$ ) over the upper $50 \mathrm{~m}$. Symbols indicate the geometric mean of replicate incubations at each station, range bars indicate the range of values for individual incubations. Filled symbols and solid bars, D262 (April/May); open symbols and dashed bars, D264 (July/August). (b) Geometric mean per capita egg production rate of C. finmarchicus (eggs female $^{1} \mathrm{~d}^{1}$ ) aggregated by zone for surveys D262 (April/May, filled symbols) and D264 (July/August, open symbols). Bars represent the maximum and minimum values encountered in each zone. Filled symbols, D262 (April/May), open symbols D264 (July/August). Rows of values above the upper $x$ axis indicate the number if individuals indicated from each zone and, in brackets, the number of stations where incubations were performed. Upper row, survey D262; lower row, survey D264.

outliers since, taking account of the standard deviation estimates for the total mortality rate, the ratio $M_{1 \text { (hatch) }} / M_{1}$ was significantly greater than 1.0, implying an inconsistency between the two measurements. Discounting these outliers, the mean ratio over all station in the CIS, NIC, SIC and RR zones was 0.30, with possibly lower values in the warmer RR and SIC zones (0.19), and higher values in the NIC and CIS zones (0.38), implying that hatching success was not the main component of egg mortality. However, there was tentatively a different conclusion for the ECG-A zone where the ratio was not significantly different from 1.0 implying that hatching success fully accounted for the total egg mortality in this zone, though this zone was represented by only a single station.

Predation seems the most likely alternative to hatching failure to account for the estimated egg mortality. Late copepodite stages of $C$. helgolandicus are known to be capable of preying on their own eggs (Bonnet et al., 2004), and there is no reason to suppose that $C$. finmarchicus would be any different. Ohman and Hirche (2001) have suggested that egg cannibalism could be an important regulatory mechanism for population dynamics. We therefore examined the data from this perspective. The numbers of stages $\mathrm{C} 4, \mathrm{C} 5$ and female C6 in the upper $200 \mathrm{~m}$ of the water column were taken as a measure of the copepodite predator abundance. Copepodites distributed deeper in the water column than $200 \mathrm{~m}$ during late summer were assumed to be nonfeeding and/or outside the depth range of the majority of eggs. The predicted abundance of eggs in the water was estimated using Eq. (2), and the number of eggs lost per day through mortality was estimated as the difference between the measured egg production rate $\left(\mathrm{d}^{1}\right)$ and the predicted recruitment rate to the first naupliar stage ( ${ }^{1}$, from Eq. (1)). If cannibalism was the major source of total egg mortality, then the per capita daily consumption of eggs (eggs predator ${ }^{1} \mathrm{~d}^{1}$ ), was given by the loss rate divided by the copepodite numbers. 
Table 1

Population egg production rates $\left(\mathrm{m}^{2} \mathrm{~d}^{1}\right.$ ) and stage abundances of C. finmarchicus ( $\mathrm{m}^{2}$, integrated over the full water column) for the subset of sampling locations during D262 where the combination of egg production incubations, and blended molecular and microscopic analyses of plankton from OCEAN and ARIES sample collections were all present

\begin{tabular}{|c|c|c|c|c|c|c|c|c|c|c|c|c|c|c|c|c|c|c|c|}
\hline Date & Station & Zone & $\begin{array}{l}\text { Longitude } \\
\left({ }^{\circ} \mathrm{W}\right)\end{array}$ & $\begin{array}{l}\text { Latitude } \\
\left({ }^{\circ} \mathrm{N}\right)\end{array}$ & $\begin{array}{l}\text { Temperature } \\
\left({ }^{\circ} \mathrm{C}\right)\end{array}$ & $\begin{array}{l}\text { Eggs } \\
\left(\mathrm{m}^{2} \mathrm{~d}^{1}\right)\end{array}$ & N1 & $\mathrm{N} 2$ & N3 & N4 & N5 & N6 & $\mathrm{C} 1$ & $\mathrm{C} 2$ & $\mathrm{C} 3$ & $\mathrm{C} 4$ & $\mathrm{C} 5$ & $\begin{array}{l}\text { C6 } \\
q\end{array}$ & $\begin{array}{l}\text { C6 } \\
\hat{0}\end{array}$ \\
\hline $15 / 05 / 02$ & C9 & EGC P & 35.54 & 64.63 & 5.57 & 555 & 9923 & 8014 & 24157 & 11738 & 3044 & 1298 & 83 & 66 & 50 & 95 & 110 & 527 & 37 \\
\hline $15 / 05 / 02$ & $\mathrm{C} 10$ & EGC A & 34.39 & 64.45 & 6.30 & 12865 & 9085 & 5999 & 19304 & 7671 & 1631 & 267 & 515 & 192 & 156 & 186 & 369 & 538 & 156 \\
\hline $07 / 05 / 02$ & DD5 & CIS & 36.87 & 60.91 & 5.59 & 35933 & 1299 & 1299 & 2598 & 0 & 0 & 0 & 350 & 271 & 240 & 606 & 623 & 1255 & 337 \\
\hline $19 / 05 / 02$ & B6 & CIS & 30.26 & 63.33 & 6.28 & 27991 & 2633 & 2412 & 3961 & 1493 & 495 & 340 & 606 & 36 & 137 & 142 & 1267 & 3704 & 132 \\
\hline $20 / 05 / 02$ & B4 & NIC & 29.23 & 62.71 & 6.90 & 10301 & 1692 & 1362 & 2505 & 715 & 283 & 63 & 825 & 434 & 333 & 254 & 431 & 1680 & 150 \\
\hline $21 / 05 / 02$ & B1 & NIC & 27.03 & 61.75 & 7.37 & 165 & 4026 & 3082 & 7307 & 3979 & 2094 & 468 & 731 & 577 & 403 & 84 & 103 & 37 & 14 \\
\hline $03 / 05 / 02$ & DD9 & SIC & 32.78 & 60.59 & 5.92 & 43866 & 217 & 136 & 1401 & 506 & 141 & 0 & 162 & 52 & 147 & 829 & 1288 & 4841 & 523 \\
\hline $01 / 05 / 02$ & DD13 & RR & 29.26 & 60.41 & 7.48 & 41147 & 1268 & 1738 & 1987 & 1234 & 398 & 329 & 662 & 903 & 257 & 84 & 252 & 2350 & 191 \\
\hline $22 / 05 / 02$ & $\mathrm{I} 3$ & RR & 24.51 & 60.83 & 8.80 & 861 & 8985 & 6938 & 25619 & 5090 & 3207 & 922 & 2012 & 1355 & 1245 & 3197 & 2500 & 548 & 237 \\
\hline
\end{tabular}

Data sorted by zone and then date. N1 N6 abundances from OCEAN sampler, C1 C6 from ARIES. Temperature $\left({ }^{\circ} \mathrm{C}\right)$ is the depth weighted mean over the upper $300 \mathrm{~m}$, giving equal weight to the averages over $050 \mathrm{~m}$ and $50300 \mathrm{~m}$. 
Table 2

Population egg production rates $\left(\mathrm{m}^{2} \mathrm{~d}^{1}\right.$ ) and stage abundances of $C$. finmarchicus $\left(\mathrm{m}^{2}\right.$, integrated over the full water column) for the subset of sampling locations during D264 where the combination of egg production incubations, and blended molecular and microscopic analyses of plankton from OCEAN and ARIES sample collections were all present

\begin{tabular}{|c|c|c|c|c|c|c|c|c|c|c|c|c|c|c|c|c|c|c|c|}
\hline Date & Station & Zone & $\begin{array}{l}\text { Longitude } \\
\left({ }^{\circ} \mathrm{W}\right)\end{array}$ & $\begin{array}{l}\text { Latitude } \\
\left({ }^{\circ} \mathrm{N}\right)\end{array}$ & $\begin{array}{l}\text { Temperature } \\
\left({ }^{\circ} \mathrm{C}\right)\end{array}$ & $\begin{array}{l}\text { Eggs } \\
\left(\mathrm{m}^{2} \mathrm{~d}^{1}\right)\end{array}$ & N1 & $\mathrm{N} 2$ & N3 & N4 & N5 & N6 & $\mathrm{C} 1$ & $\mathrm{C} 2$ & $\mathrm{C} 3$ & $\mathrm{C} 4$ & $\mathrm{C} 5$ & $\begin{array}{l}\text { C6 } \\
q\end{array}$ & $\begin{array}{l}\text { C6 } \\
\hat{0}\end{array}$ \\
\hline $16 / 08 / 02$ & C6 & EGC A & 37.56 & 63.69 & 5.25 & 4588 & 20068 & 19457 & 29436 & 6000 & 1126 & 266 & 357 & 139 & 449 & 1952 & 5942 & 432 & 105 \\
\hline $18 / 08 / 02$ & $\mathrm{H} 10$ & EGC A & 38.85 & 62.85 & 7.11 & 11480 & 4466 & 3869 & 44415 & 15950 & 7316 & 6044 & 5308 & 3162 & 1076 & 1776 & 9570 & 1712 & 247 \\
\hline $20 / 08 / 02$ & D1 & EGC A & 42.30 & 59.85 & 6.16 & 1612 & 2453 & 5684 & 18069 & 16505 & 10517 & 12389 & 1831 & 2265 & 1626 & 1964 & 5262 & 78 & 59 \\
\hline $06 / 08 / 02$ & DD7 & CIS & 35.48 & 60.85 & 7.31 & 3113 & 3551 & 481 & 9787 & 1423 & 1982 & 0 & 55 & 57 & 96 & 706 & 7886 & 283 & 151 \\
\hline 08/08/02 & DD3 & CIS & 38.60 & 61.42 & 6.74 & 436 & 303 & 119 & 494 & 30 & 0 & 0 & 92 & 146 & 112 & 5123 & 24143 & 359 & 165 \\
\hline $14 / 08 / 02$ & $\mathrm{C} 10$ & CIS & 34.22 & 64.41 & 7.64 & 2058 & 1349 & 909 & 11708 & 2480 & 742 & 512 & 117 & 108 & 91 & 1293 & 4330 & 204 & 222 \\
\hline $23 / 08 / 02$ & D5 & CIS & 36.45 & 57.93 & 7.73 & 10465 & 1371 & 530 & 1196 & 37 & 90 & 0 & 224 & 835 & 592 & 846 & 8756 & 872 & 72 \\
\hline $01 / 08 / 02$ & B4 & NIC & 29.17 & 62.46 & 8.17 & 5278 & 255 & 980 & 4771 & 5406 & 1944 & 1990 & 777 & 909 & 769 & 1849 & 5145 & 334 & 239 \\
\hline $04 / 08 / 02$ & DD11 & SIC & 30.99 & 60.60 & 7.99 & 4289 & 341 & 428 & 1740 & 304 & 303 & 396 & 296 & 602 & 628 & 985 & 8958 & 508 & 157 \\
\hline $05 / 08 / 02$ & DD9 & SIC & 33.46 & 60.66 & 7.82 & 6079 & 7192 & 8664 & 1472 & 1472 & 0 & 2944 & 304 & 1220 & 690 & 670 & 9291 & 227 & 287 \\
\hline $30 / 07 / 02$ & I3 & $\mathrm{RR}$ & 24.76 & 60.82 & 9.51 & 504 & 2727 & 2261 & 11231 & 7690 & 2132 & 1272 & 238 & 182 & 229 & 830 & 3199 & 218 & 58 \\
\hline $31 / 07 / 02$ & B1 & RR & 27.16 & 61.74 & 8.65 & 1911 & 0 & 281 & 4775 & 1124 & 843 & 7930 & 165 & 215 & 272 & 389 & 2588 & 71 & 78 \\
\hline
\end{tabular}

Data sorted by zone and then date. N1 N6 abundances from OCEAN sampler, C1 C6 from ARIES. Temperature $\left({ }^{\circ} \mathrm{C}\right)$ is the depth weighted mean over the upper 300 m, giving equal weight to the averages over $050 \mathrm{~m}$ and $50300 \mathrm{~m}$. 


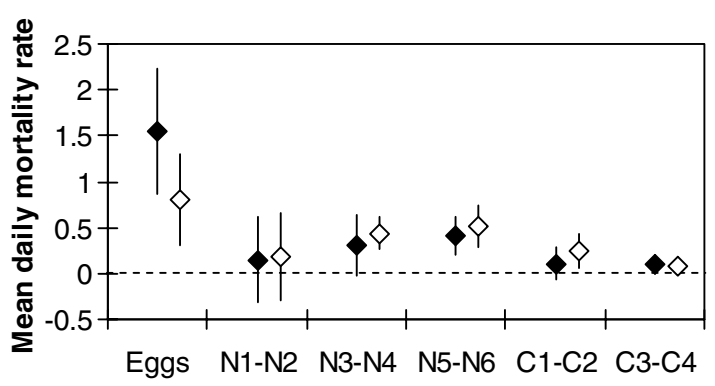

Fig. 17. Stage specific mortality rates $\left(\mathrm{d}^{1}\right.$ ) of $C$. finmarchicus, averaged over all stations in surveys D262 (April/May, filled symbols) and D264 (July/August, open symbols). Bars indicate the mean standard deviation of the estimates at each station. Number of stations in each zone as in Tables 1 and 2 .
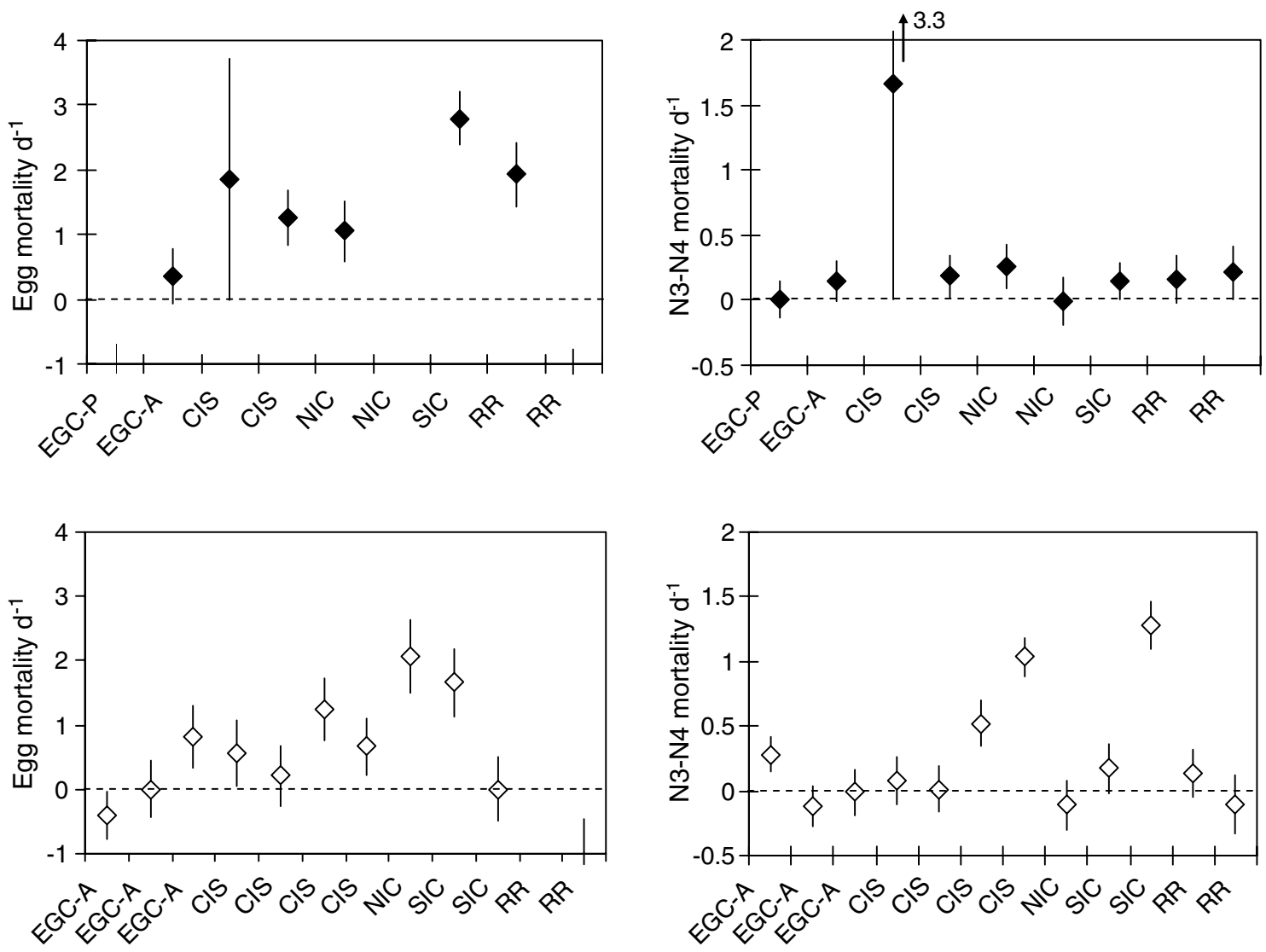

Fig. 18. Egg mortality rates $\mathrm{d}^{1}$ (left column) and N3 N4 mortality rates d ${ }^{1}$ (right column) for survey D262 (April/May, top row, filled symbols) and D264 (July/August bottom row, open symbols). Each symbol and bar represents the mortality rate and standard deviation of the estimate, for a single station. Stations are identified by their zone assignment.

The results (Fig. 20) showed that, taking the spring and summer data together, the supposed per capita consumption rate of eggs increased with egg abundance, consistent with some form of functional response. However, given the ranges of egg abundances encountered in spring and summer, the resolution of the likely shape and consistency of the response was poor. For example, whilst the spring data taken in isolation were consistent with an underlying relationship, the summer data taken in isolation were not. Nevertheless, we cannot 

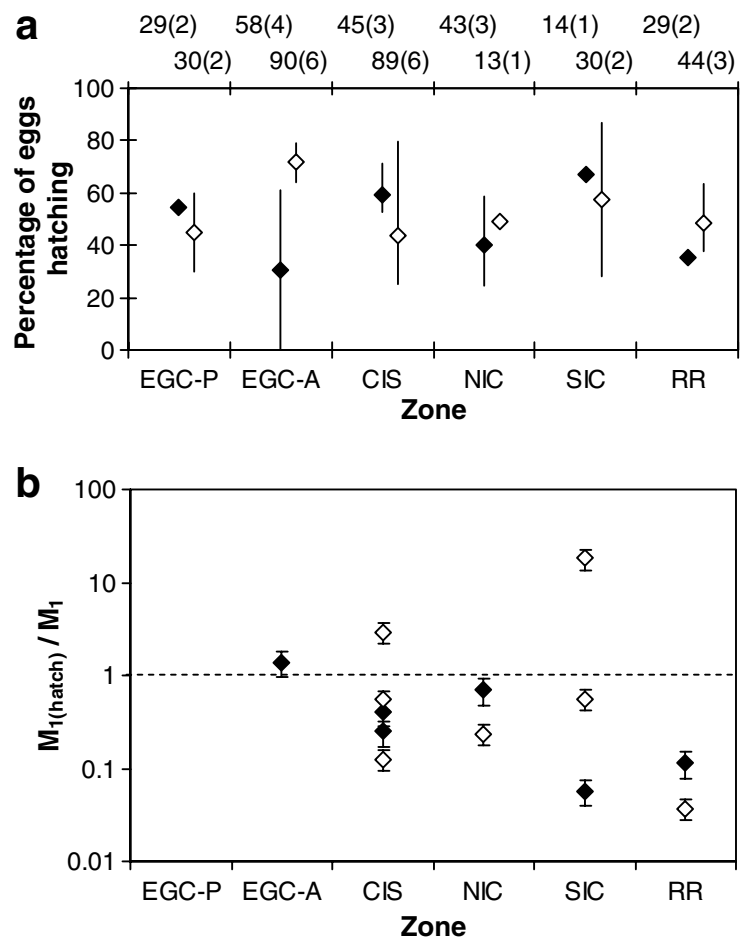

Fig. 19. Upper panel: percentage of eggs hatching successfully in incubation experiments, aggregated across zones for each survey. Symbols represent the mean hatching success within a zone, bars represent the maximum and minimum values encountered in a given zone. Rows of values above the upper $x$ axis indicate the number of individuals incubated from each zone and, in brackets, the number of stations where incubations were performed. Upper row, survey D262; lower row, survey D264. Lower panel: ratio of $M_{1 \text { (hatch) }}$ (mortality due to hatching failure) to $M_{1}$ (total egg mortality from the modified VLT method) for individual stations where both egg incubation and VLT data were available, plotted in relation to zone. Bars represent the range of ratio values implied by the standard deviation estimates for the total mortality rates. Both panels: filled symbols, D262 (April/May), open symbols D264 (July/August).

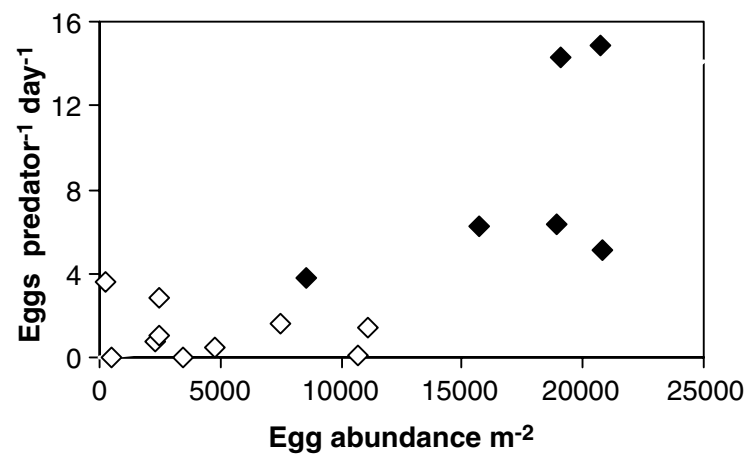

Fig. 20. Functional response of the consumption rate of eggs by $\mathrm{C} 4 \mathrm{C} 6 \mathrm{C}$. finmarchicus in relation to egg abundance, assuming that all predation losses were due to cannibalism.

dismiss the possibility that cannibalistic predation was a significant factor in the observed mortality pattern of the eggs, but the precise form of the predator-prey relationship was not well defined.

Mortality rates of naupliar stages 1 and 2 showed no significant differences between stations during either spring or late summer, and the mean levels were similar in both seasons. Similarly, with the exception of one station where naupliar stages 3, 4 and 5 were absent - implying either mass mortality of stage 3 or contravention of the assumptions of the VLT model mortality rates of stage 34 nauplii were not significantly different 


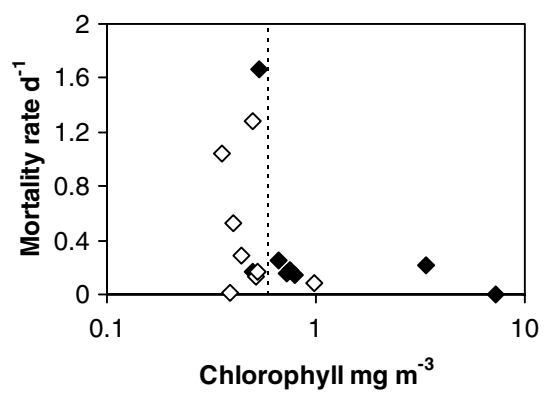

Fig. 21. Mortality rate $\left(\mathrm{d}^{1}\right)$ of $C$. finmarchicus naupliar stages N3 N4 at individual stations in relation to chlorophyll $a$ concentration $\left(\mathrm{mg} \mathrm{m}^{3}\right)$ averaged over the upper $50 \mathrm{~m}$ of the water column. Filled symbols, D262 (April/May), open symbols D264 (July/August). The vertical dashed line represents a chlorophyll $a$ concentration of $0.6 \mathrm{mg} \mathrm{m}^{3}$.

between stations in spring. However, in late summer the overall mortality rate of naupliar stage 3 and 4 was higher than in spring $\left(0.40 \mathrm{~d}^{1}\right.$ in late summer, as opposed to $0.31 \mathrm{~d}^{1}$ in spring), and there was a pattern of low mortality at the fringes of the area (EGC and RR zones) and higher rates in the central areas. (Fig. 18).

Mortality rates of first-feeding copepod nauplii are highly sensitive to food concentration (Lopez, 1996). We therefore examined the N3 N4 mortality rate data for a relationship with chlorophyll- $a$ concentrations at each sampling station. Both $050 \mathrm{~m}$ depth averaged chlorophyll- $a$ concentrations, and peak concentrations, showed a similar relationship to mortality rates (Fig. 21). Mortality rates were less than $0.2 \mathrm{~d}^{1}$ for depth averaged chlorophyll- $a$ concentrations $>0.6 \mathrm{mg} \mathrm{m}^{3}$, and increased sharply below this threshold. Assuming a carbon:chlorophyll- $a$ ratio of approximately 40, this threshold corresponds to a food concentration of $24 \mathrm{mg} \mathrm{C} \mathrm{m}^{3}$. SeaWIFS data received during 2002 and processed to monthly composite images (Fig. 22) showed clearly that chlorophyll- $a$ concentrations in the CIS zone remained below our implied threshold of approximately $0.6 \mathrm{mg} \mathrm{m}^{3}$ throughout the year. However, concentrations in excess of the threshold were persistent around the fringes of the Irminger Basin. Thus, the various strands of evidence support our finding that recruitment of $C$. finmarchicus in the Irminger Sea was concentrated around the fringes of the basin, and not in the central region above the overwintering aggregation.

\subsection{Feeding and diet}

The naupliar feeding experiments indicated a greater proportion of flagellates (including autotrophic dinoflagellates), and a lesser proportion of micro-heterotrophs (ciliates and heterotrophic dinoflagellates) in the diet in July/August compared to April/May, broadly reflecting the differences in composition of the microplankton in the water between the two surveys (Fig. 23). During April/May, nauplii showed a low preference for flagellates and dinoflagellates, and at sites where the biomass proportion of diatoms was low, the diet consisted almost entirely of micro-heterotrophs. There were few sites where both diet composition and valid estimates of naupliar mortality rates were available, but of these, the lowest mortality occurred at the sites with a micro-heterotroph-rich diet. In contrast, during July/August, the highest mortality coincided with the greatest proportion of micro-heterotrophs in the diet. Thus, there was no clear general relationship between naupliar diet composition and mortality rates.

An indication of the dietary composition of later development stages was provided by the normalised area percentages of fatty acid biomarkers. The three dietary indices (diatoms, flagellates and Phaeocystis/microheterotrophs) were calculated for each sample comprising a batch of up to 10 same-stage individuals. For surveys 262 and 264, indices were then averaged over all samples of copepodite stages C5 and female C6 collected in the upper $500 \mathrm{~m}$ within each zone. The results indicated that across all zones the Phaeocystis/micro-heterotroph dietary index was systematically higher in April/May than in July/August ( $t$-test, $p<0.05)$. Conversely, both the diatom and flagellate dietary indices were systematically lower in April/May compared to July/ August ( $t$-test, $p<0.01$ ) (Fig. 24). Thus, between surveys, the fatty acid compositions of stages C5 and C6 complemented the direct estimates of naupliar diet composition, and reflected changes in the composition of the microplankton community. Within each survey, there was consistent spatial structure in the flagellate 

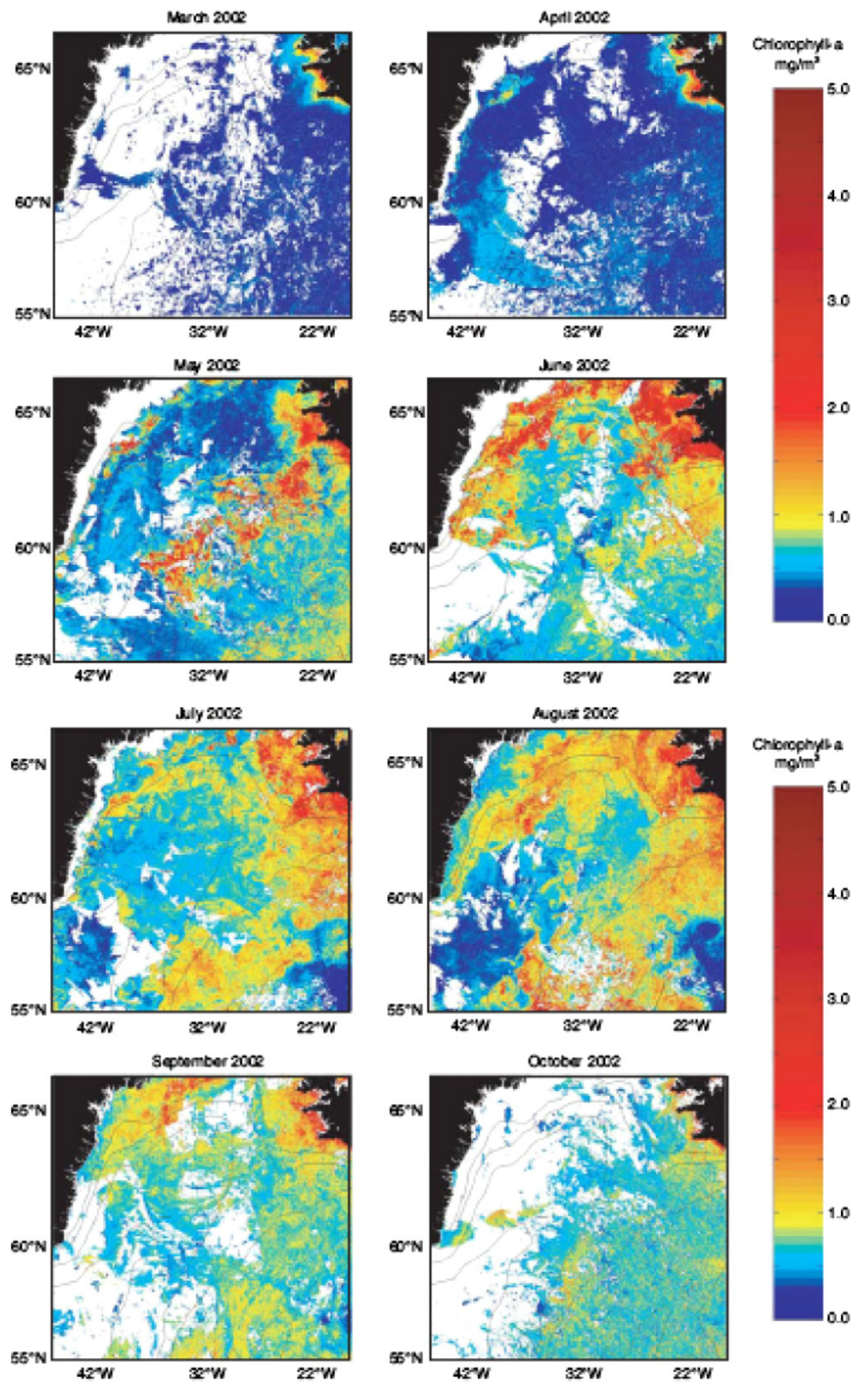

Fig. 22. Monthly averages for 2002 of surface chlorophyll $a\left(\mathrm{mg} \mathrm{m}^{3}\right)$ as measured by SeaWIFS. No interpolation has been used and white spaces indicate absence of data due to cloud cover. 

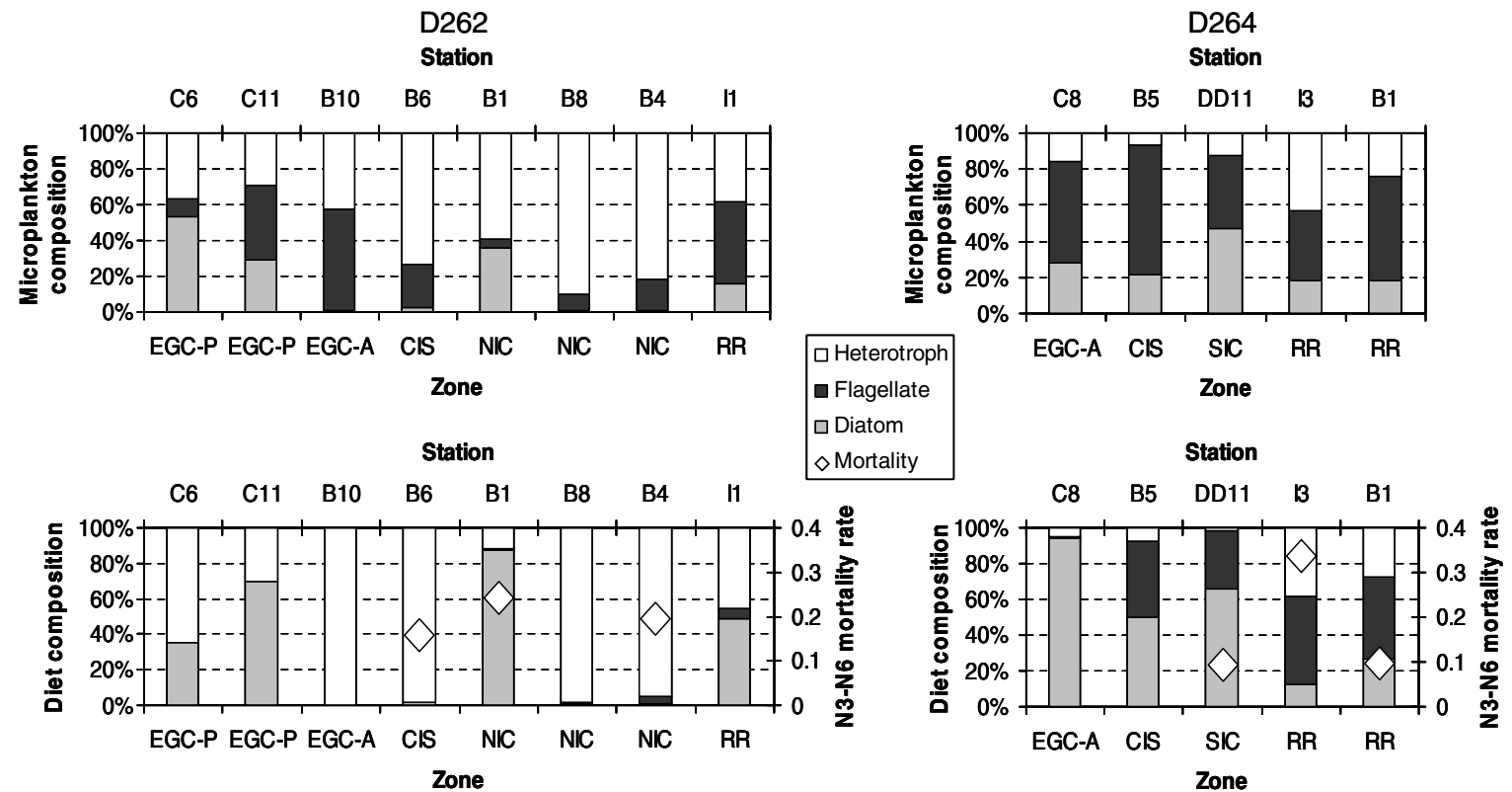

Fig. 23. Data from feeding experiments on N4 N6 C. finmarchicus nauplii at individual stations during surveys D262 (April/May) and D264 (July/August). Upper row, carbon biomass percentage composition of the microplankton community at the start of each incubation experiment. Lower row, diet composition of nauplii expressed as percentage of carbon biomass ingested at each station. Heterotrophs included ciliates and heterotrophic dinoflagellates. Flagellates included autotrophic dinoflagellates and microflagellates, but excluding Phaeocystis spp. Open diamond symbols on each diet composition panel indicate the mortality rate $\left(\mathrm{d}^{1}\right)$ of N3 N6 nauplii estimated from the demographic data collected at each station.
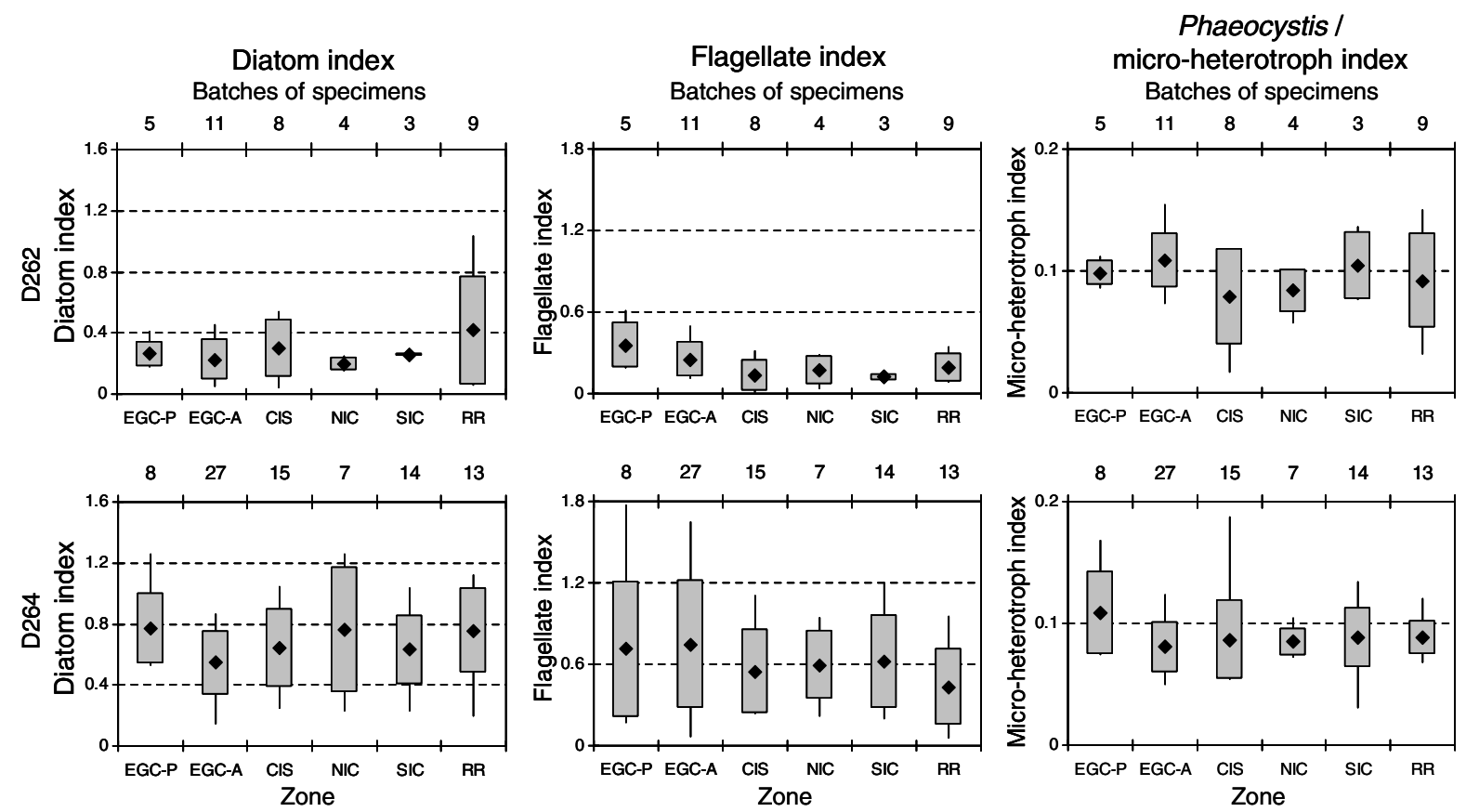

Fig. 24. Diatom, flagellate and micro heterotroph fatty acid biomarker indices of dietary composition in relation to zone, for $\mathrm{C} 5$ and female C6 C. finmarchicus collected in the upper $500 \mathrm{~m}$ of the water column. Upper row, survey D262 (April/May), lower row, survey D264 (July/August). Box and whisker plots for each zone show the maximum and minimum values, and the mean (diamond symbol) \pm 1 standard deviation. The number of batches of animals analysed from each zone are shown along the top of each panel. 
index, with higher values in the EGC zones than those elsewhere. In July/August the majority of flagellate index values $>1.0$ were from the EGC zones. The diatom bloom conditions in April/May were reflected in elevated values of the diatom index in copepodites in the RR zone, but not in the EGC zone, whilst in July/ August the majority of diatom index values $>1.0$ were from the NIC zone. Phaeocystis/micro-heterotroph indices showed little significant spatial structure, except for significantly $(t$-test, $p<0.05)$ greater values in the EGC-P zone in July/August than elsewhere, presumably reflecting the prior bloom of Phaeocystis spp. detected during April/May (Fig. 4). The copepodites in the EGC-A zone during July/August, where the greatest concentrations of entrants to the overwintering state were located, had the lowest mean values of the diatom and Phaeocystis/micro-heterotroph indices, and the highest values of the flagellate index.

\subsection{Comparison with NORWESTLANT and CPR data}

The NORWESTLANT data indicated that the distributions of females and recruitment that we observed in spring 2002 were structurally similar to those in 1963. Data from vertically hauled (100 m to surface) Hensen net samples collected during 4 periods (25 March 24 April. 25 April 24 May, 25 May 24 June and 25 June 24 July 1963) were extracted from the dataset and the abundances of females and C1 and C2 recruits mapped (Fig. 25). The distribution of sampling was optimal for addressing our question only in the April May period, and in that case the results were similar to those in 2002 (Fig. 6) in that maximum female abundance was centred over the deep basin, whilst the recruiting copepodite stages were distributed around the fringe. During the
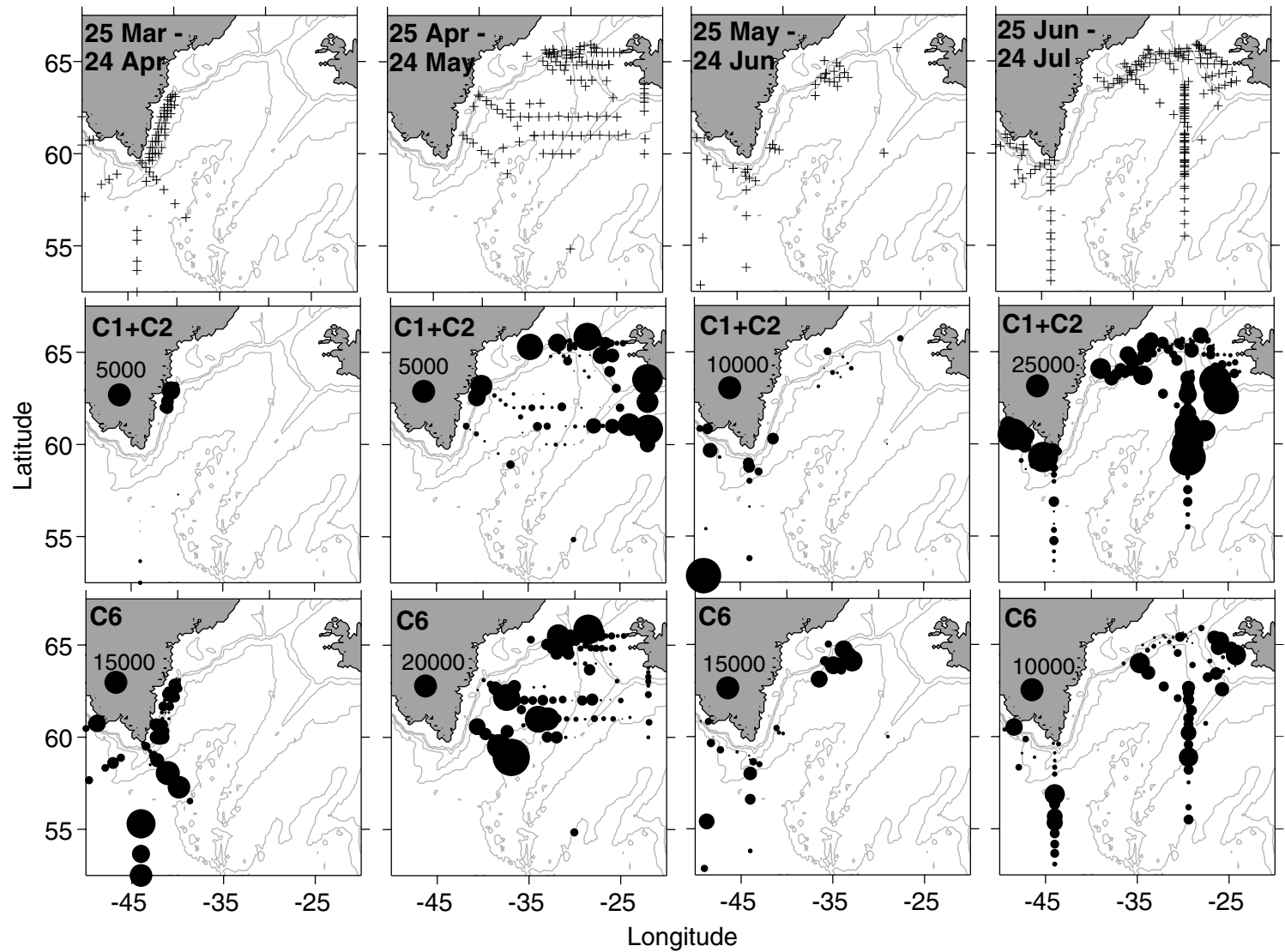

Fig. 25. NORWESTLANT sampling locations during successive periods in 1963 (upper row), and $0100 \mathrm{~m}$ Hensen net estimates of C. finmarchicus stage abundances $\left(\mathrm{m}^{2}\right.$ ). Middle row, stages $\mathrm{C} 1$ and $\mathrm{C} 2$, lower row, stage C6. No attempt was made to discriminate between different Calanus species in the sample analysis, and estimates of the volume sampled by the Hensen net are uncertain since there are no flowmeter data. 
other periods the distribution of samples did not allow a conclusive comparison, but the results were not contradictory with our findings.

CPR data from the transect polygon across the Irminger Sea from the Greenland shelf to the Reykjanes Ridge $\left(45^{\circ} \mathrm{W}, 59^{\circ} \mathrm{N}\right.$ to $25^{\circ} \mathrm{W}, 61^{\circ} \mathrm{N}$; Fig. 26) showed that within each of the time periods 19601968,1969 1975 and 1976 1986, stage C1 C4 Calanus spp. were most abundant at the east Greenland slope and over the Reykjanes Ridge, whilst the abundance of $C$. finmarchicus stages C5 C6 was highest over the basin rather than at the edges (Fig. 27). Also, in each time period the longitudinal minimum value of annual average colour index was located above water deeper than $2500 \mathrm{~m}$. Hence, although there is not necessarily a 1:1 relationship between the CPR colour index and chlorophyll- $a$ concentration, the data suggested that the central basin has consistently lower values of phytoplankton abundance than the fringes. We conclude that the patterns of demography and food environment that we observed in 2002 were probably typical for the region.

Examination of the interannual variability in $C$. finmarchicus abundance in the region from CPR data was problematic due to the intermittent and spatially-restricted nature of the survey routes. However, we extracted the data from the two most sampled $2^{\circ}$ longitude bins of the transect polygon (33 $29^{\circ} \mathrm{W}$, Fig. 26) and aggregated the log-transformed data for months April August as annual means (Fig. 28). Months outside the period April August were sampled sparsely and the samples that had been collected contained few specimens. Linear trend analysis found no significant trend $(p>0.05)$ in the abundance of C5 C6 and C1 C4 stages since 1958 , but there was a significant increasing trend $(p<0.025)$ in values of the colour index. The abundance of stages C5 C6 was significantly correlated at lag 0 with that of stages C1 C4 according to the modified Chelton method (Pyper and Peterman, 1998) (Table 3a). The correlation between stages C1 C4 and the phytoplankton colour index was marginally significant.

We compared the time-series of CPR abundance data with the NAO index (as a general measure of North Atlantic climate). There was no significant correlation between the NAO and Calanus stage abundances, whilst
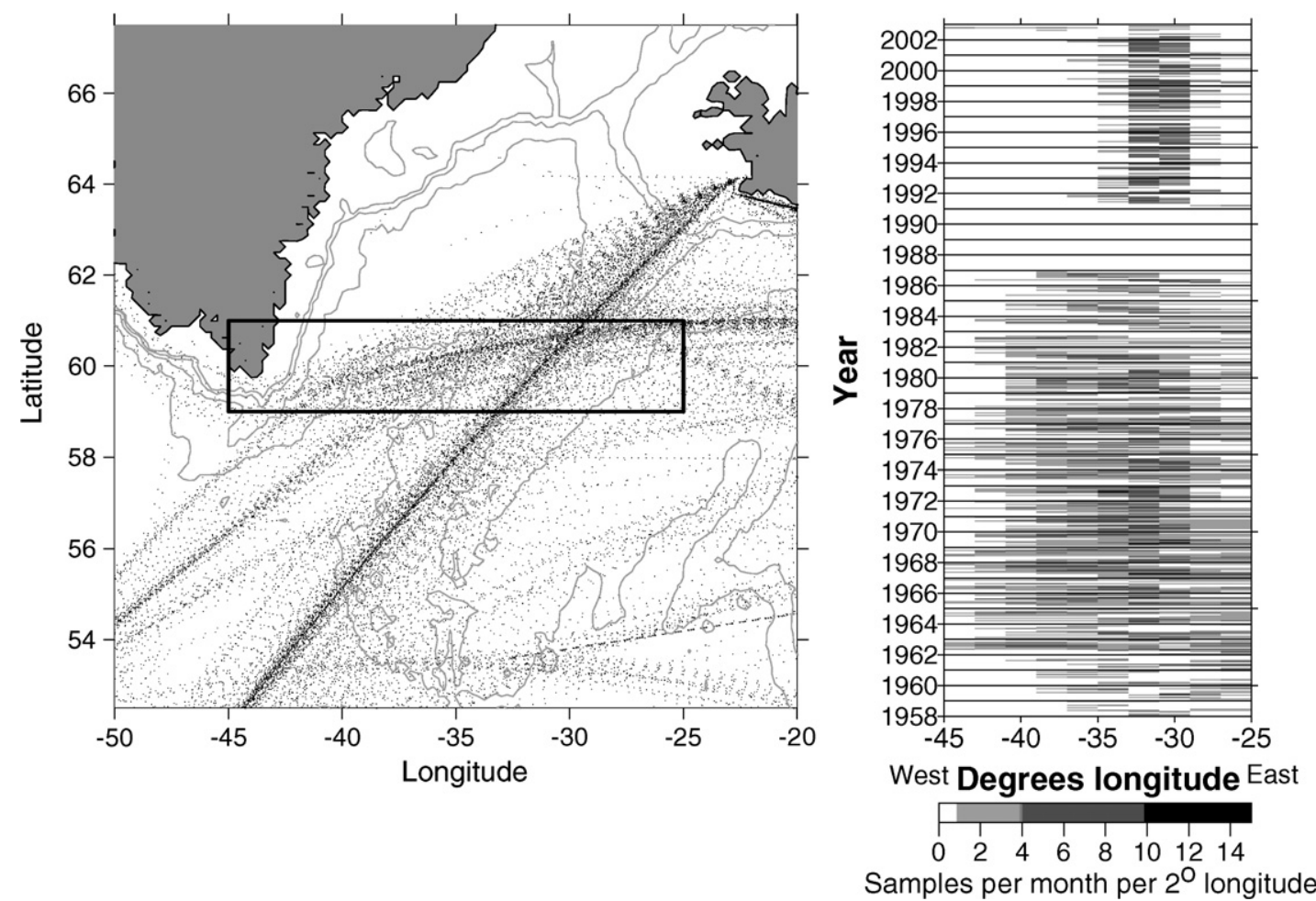

Fig. 26. CPR sample locations in the Irminger Sea region between 1958 and 2002. Left panel, distribution of samples in space. Right panel, distribution of samples in time. The greyscale in the right panel represents the number of samples per $2^{\circ}$ longitude interval and month in the transect polygon across the region shown in the left panel. 


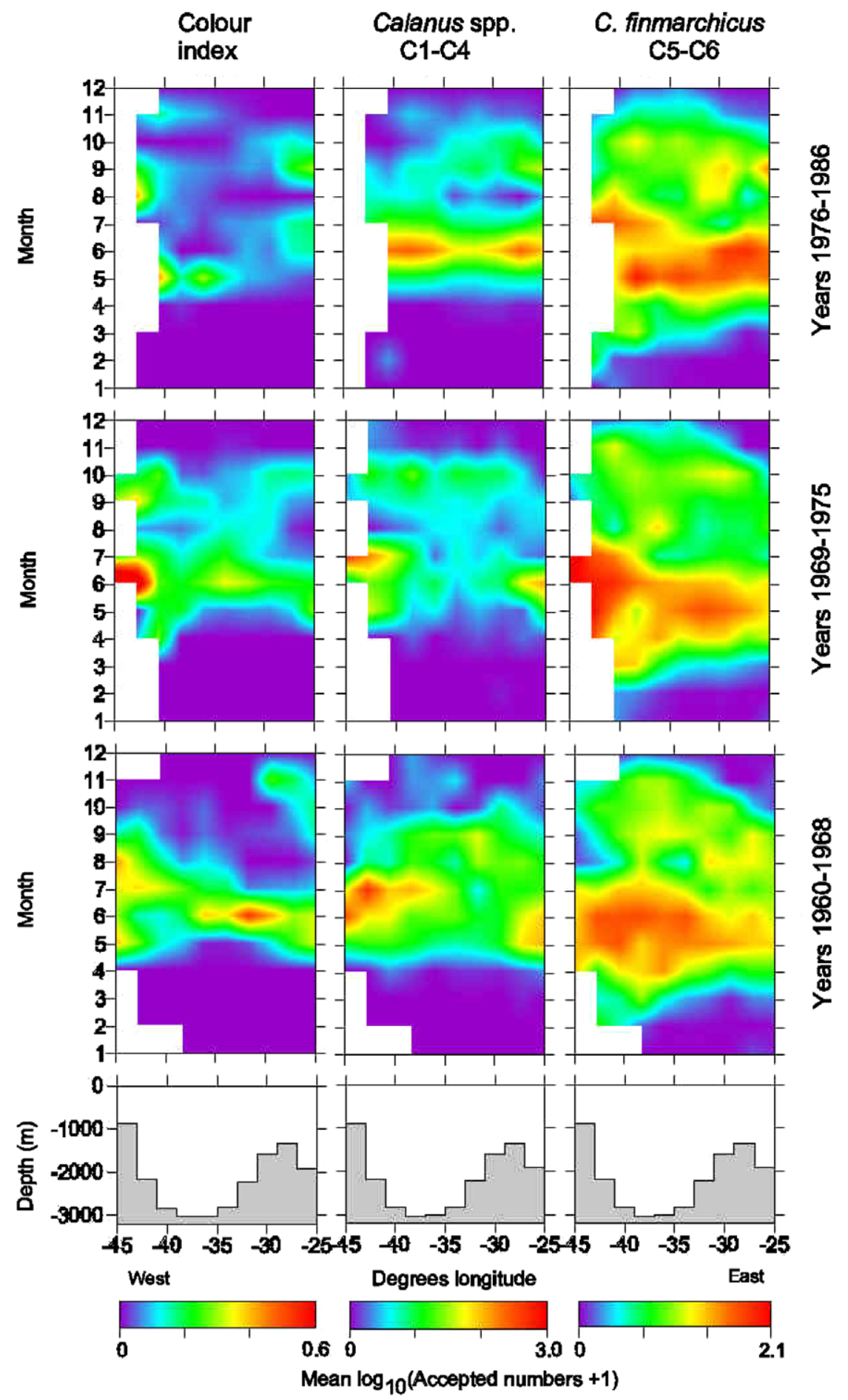

Fig. 27. Mean log accepted numbers of $C$. finmarchcius stages $\mathrm{C} 1 \mathrm{C} 4$ and $\mathrm{C} 5$ 6, and colour index, in CPR samples collected in the transect polygon shown in Fig. 26 during the years 1960 1968, 1969 1975, and 1976 1986. In each case, the data were bin averaged by month and $2^{\circ}$ longitude interval. The row of diagrams at the bottom of the figure shows the mean seabed depth in each $2^{\circ}$ longitude interval.

that with the colour index was found to be marginally significant $(p<0.05)$ according to the modified Chelton method (Table 3a). However, when the linear trends in the colour index and the NAO were removed, the corre- 


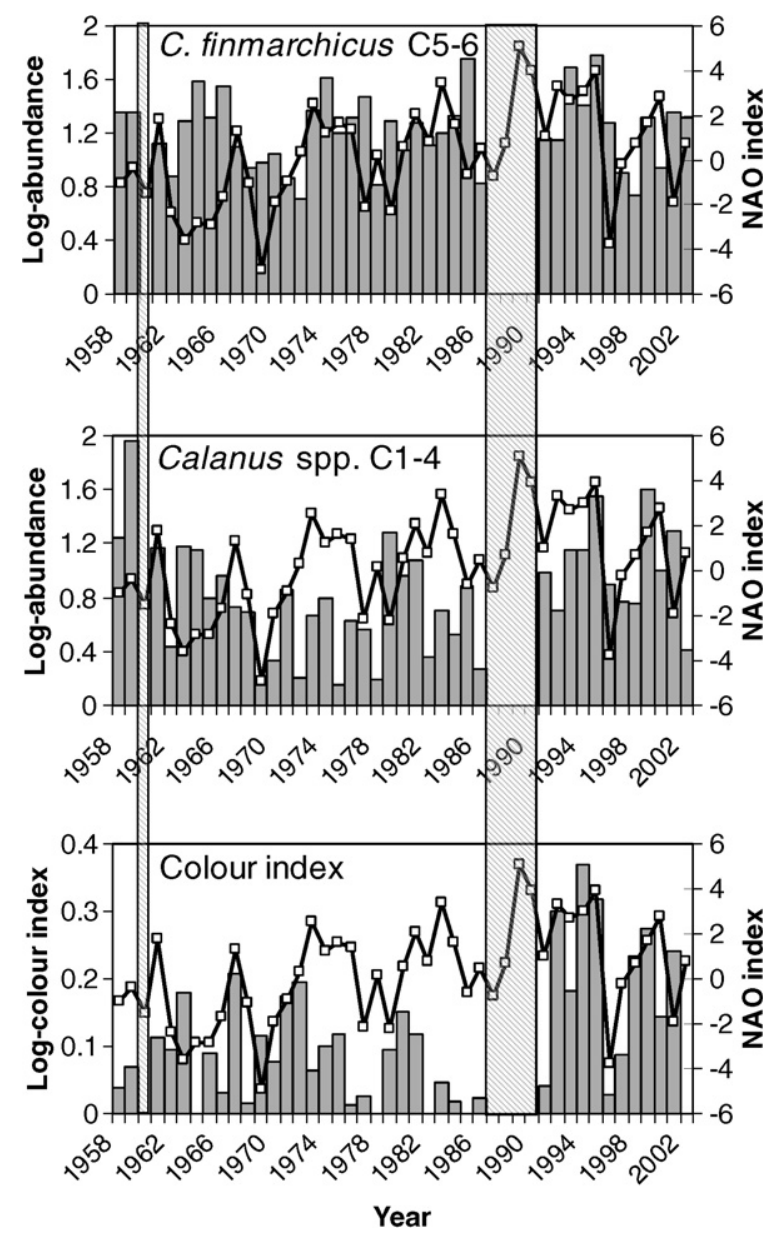

Fig. 28. Histogram bars indicate annual mean log abundance of $C$. finmarchicus stages C5 C6, C1 C4, and the colour index from CPR samples collected during April August in the 2 most heavily sampled $2^{\circ}$ longitude bins of the transect polygon shown in Fig. $26\left(3329^{\circ} \mathrm{W}\right)$. The North Atlantic Oscillation (NAO) index is superimposed as a line plot on each histogram set. Tick marks on the $x$ axis are annual from 1 January 1958 to 1 January 2003 in each case. Hatched boxes running through all three panels indicate periods of no CPR sampling.

Table 3a

Coefficients of correlation $r$ (values in bold) between time series of the NAO index, CPR colour index, CPR Calanus spp. stages C1 C4, and CPR C. finmarchicus stages C5 $\mathrm{C} 6$ from the polygon $33^{\circ} \mathrm{W}, 59^{\circ} \mathrm{N}$ to $29^{\circ} \mathrm{W}, 61^{\circ} \mathrm{N}$

\begin{tabular}{llrr}
\hline & Colour index & Calanus spp. C1-C4 & C. finmarchicus C5-C6 \\
\hline NAO & $\mathbf{0 . 3 5}(0.32,27)$ & $\mathbf{0 . 1 0}(0.31,29)$ & $\mathbf{0 . 1 0}(0.26,39)$ \\
Colour index & & $\mathbf{0 . 3 6}(0.32,25)$ & $<\mathbf{0 . 0 1}(0.24,49)$ \\
Calanus spp. C1-C4 & & $\mathbf{0 . 5 1}(0.22,54)$ \\
\hline
\end{tabular}

This tables shows analysis of data including trends. Figures in brackets are the critical value of $r$ at $p<0.05$, and the modified degrees of freedom $N^{*}$, calculated from Modified Chelton analyses taking into account serial autocorrelation within each time series. Shaded cells indicate $r<r_{\text {critical }}$ and hence no significant relationship.

lation became non-significant (Table 3b). Removal of linear trends in Calanus stage abundances did not affect the significance of the correlations between stages $\mathrm{C} 5 \mathrm{C} 6$ and $\mathrm{C} 1 \mathrm{C} 4$, and between $\mathrm{Cl} \mathrm{C} 4$ and the colour index. 
Table $3 b$

As Table $3 \mathrm{a}$ but with the linear trend in each variable removed prior to analysis

\begin{tabular}{llll}
\hline & Colour index & Calanus spp. C1-C4 & C. finmarchicus C5-C6 \\
\hline NAO & $\mathbf{0 . 2 5}(0.27,37)$ & $\mathbf{0 . 0 8}(0.25,42)$ & $\mathbf{0 . 0 9}(0.30,30)$ \\
Colour index & & $\mathbf{0 . 3 6}(0.30,29)$ & $\mathbf{0 . 0 1}(0.25,43)$ \\
Calanus spp. C1-C4 & & $\mathbf{0 . 5 1}(0.22,53)$ \\
\hline
\end{tabular}

\section{Discussion}

To summarise our field observations,

- The overwintering population of $C$. finmarchicus in November and December was composed predominantly $(7585 \%)$ of C5 copepodites, which were widely distributed across the Irminger Basin mainly at depths of $5002000 \mathrm{~m}$ in the Labrador Sea Intermediate Water mass (LSIW). In a separately published study, Bonnet et al. (2007) showed from the histological composition of digestive epithelium cells in C. finmarchicus collected during the surveys, that the overwintering stock was in a diapause state in all regions, except for some individuals distributed above $350 \mathrm{~m}$, in the EGC-A zone.

- We have no information on ascent timing, but by late April late May the majority of the surviving overwinter stock (G0) had developed to stage $\mathrm{C} 6$ females and males and migrated to the upper $50100 \mathrm{~m}$ of the water column.

- G0 females were widespread in the Atlantic-origin surface waters in the region in spring. Females in the Central Irminger Sea and Irminger Current zones had a lipid content only slightly less than that observed in the stock in the previous November/December (20 40\% dry weight) whilst those in the East Greenland Current were lipid-depleted ( $<10 \%$ dry weight).

- Per capita egg production in spring did not vary significantly across the region. However, population egg production (initiating G1) was highest in the Central Irminger Sea and Irminger Current.

- In spring, recruitment of G1 nauplii and copepodites was highest around the fringes of the Irminger Sea, in the EGC-A zone and over the Reykjanes Ridge. The predominant factors controlling this pattern appear to be have been egg mortality and starvation mortality of first feeding nauplii. Approximately one-third of egg mortality could be accounted for by hatching failure and the reminder by predation, in part due to cannibalism by the G0 adults.

- High mortality rates of naupliar stages 3 and 4 appeared to be linked to low chlorophyll- $a$ concentrations $\left(<0.6 \mathrm{mg} \mathrm{m}^{3}\right)$. These conditions persisted throughout the year in the Central Irminger Sea, making the central basin a poor environment for $C$. finmarchicus recruitment.

- A bloom of Phaeocystis spp. in the EGC-P zone was probably grazed by the G0 females in spring and G1 copepodites in summer. Flagellates were also an important component of the diet in the EGC zones, and diatoms dominated in the RR and NIC zones.

- By late July/early August the G1 individuals were accumulating in C4 and C5 with lipid contents of $6080 \%$ dry weight and were beginning to descend to overwintering depths. Descent timing was earlier in the east than in the west of the region, probably reflecting the warmer temperatures and consequently more rapid development. The greatest concentration of $\mathrm{C} 5$ in late summer was along and below the boundary between the EGC-A and CIS zones.

- Approximately 7\% of G1 developed to C6 rather than entering the overwintering stage, and they were spawning in July/August especially in the boundary between the EGC-A and CIS zones. The G2 offspring were present as early nauplii, but mortality rates of $\mathrm{N} 3 \mathrm{~N} 4$ were higher than in spring and were probably the limiting factor for population development. It is likely that G2 made little contribution to the overwintering stock.

- The spatial demography that we observed in 2001/2002 appears to be consistent with patterns for the region evident from the NORWESTLANT and CPR data.

The key spatial features of the demography are the basin-wide distribution of overwintering stages at depth and of G0 females at the surface in spring, contrasting with the peripheral distribution of recruitment. 
The apparent repeatability of this pattern of spatial demography implies that it arises as a consequence of some persistent oceanographic features of the region. Hence, the conundrum arising from the observations is how (if at all) is spatial closure of the C. finmarchicus life-cycle achieved in this region?

The mean circulation at $700 \mathrm{~m}$ depth in the region has been summarised from an analysis of data from an array of neutrally-buoyant, profiling, subsurface drifting floats (Lavender et al., 2005). Viewing our data in this framework shows clearly that the recruitment zone of $C$. finmarchicus coincides with the Irminger and East Greenland Current systems which transport at least the upper $1000 \mathrm{~m}$ of the water column water anticlockwise around the basin margin above the $2000 \mathrm{~m}$ isobath. To the east, there is input from the Iceland Basin, and to the west there is export around the southern tip of Greenland into the Labrador Sea. Along the east Greenland slope, the float analysis shows retroflection of this flow (at $700 \mathrm{~m}$ ) back into the central Irminger Sea and recirculation from the Labrador Sea. Pickart et al. (2003) estimated a 6-month duration for transport of Labrador Sea Intermediate Water into the Irminger Sea.

Velocities in the Irminger and East Greenland Current system $\left(1015 \mathrm{~cm} \mathrm{~s}{ }^{1}\right)$ are such that the patch of descending C4 and C5 along the east Greenland slope in summer 2002 (Fig. 7) would have been transported approximately $850 \mathrm{~km}$ since hatching, giving its approximate spawning source as being in the North Irminger Current zone (Fig. 2). Hence, a working hypothesis to emerge from our investigations is that:

- Survivors of recruitment along the western margins of the Irminger Basin will probably be exported to the Labrador Sea in the surface circulation by the time they have developed to the entry stage for overwintering. Evidence for descent in this region is provided by sampling in December 2002 by the research vessel 'Hudson' (E. Head pers. comm.; Heath et al., 2004), concurrent with Discovery survey D267. Calanus finmarchicus C4 and C5 copepodites were present at abundances of approximately $18,000 \mathrm{~m}^{2}$ above the $2000 \mathrm{~m}$ isobath southwest of Greenland, distributed between 400 and $1500 \mathrm{~m}$.

- Survivors of recruitment around the eastern and northern margins of the Irminger Basin will probably be distributed along the east Greenland slope by the time they have developed to the entry stage for overwintering. Evidence for descent in this region is provided by Discovery survey D264.

- Copepodites descending to overwintering depths along the eastern margin of the Irminger Sea (western face of the Reykjanes Ridge) are probably immigrants from spawning in the Iceland Basin.

- Direct descent is unlikely to be the main source of overwintering copepodites in the central Irminger Basin. Horizontal transport by sub-surface recirculation from the east Greenland slope, plus transport to the Irminger Sea in the LS Intermediate Water (Pickart et al., 2003) are the more likely sources.

If our hypothesis is correct, then the basis for a degree of spatial closure of the life-cycle of $C$. finmarchicus in the region would seem to exist. However, it is also clear that there must be extensive leakage to the Labrador Sea and input from the Iceland Basin. So, the Irminger Sea is unlikely to be a closed system with respect to population dynamics.

There must also be some exchange of $C$. finmarchicus between the Irminger Sea and the Iceland Shelf. There is no evidence of significant overwintering concentrations on the Iceland Shelf, and yet the production of C. finmarchicus in Icelandic shelf waters is considerable. The supposition is that the shelf waters are recolonised each spring from offshore. At the Westmann Islands south of Iceland, approximately fortnightly sampling (more intensive during May and June) in 1997 at two sites (water depth $100 \mathrm{~m}$ and $200 \mathrm{~m}$; Gislason et al., 2000) showed that small numbers $\left(<100 \mathrm{~m}^{2}\right)$ of $\mathrm{C} 5$ copepodites and immature female C6 were present at the end of the winter (mid-March). Thereafter, both C1 C2 copepodite and C6 female abundances increased approximately exponentially but the rate of increase in $\mathrm{C} 1 \mathrm{C} 2$ was more rapid and their abundance peaked earlier than that of the females (peak abundance of $\mathrm{C} 1 \mathrm{C} 241,500 \mathrm{~m}^{2}$ on 14 May; C6 females $11,300 \mathrm{~m}^{2}$ on 5 June). At the local water temperature $\left(7.58 .0^{\circ} \mathrm{C}\right)$, the peak of $\mathrm{C} 1 \mathrm{C} 2$ abundance should have corresponded to a spawning date of approximately 25 April, but at typical rates of mortality this cannot be explained by the local abundance of females at around that time (Heath et al., 2000a), even though the spring phytoplankton bloom begins in March close inshore around Iceland (Fig. 22), leading to potentially high percapita rates of egg production. Measurements of population egg production rates in the Icelandic shelf waters in early April 1997 (Gislason and Assthorsson, 2000), and later in April during 2002 (Discovery D262), were low on both occasions compared to offshore rates. Nevertheless, abundances of $\mathrm{C} 1$ and $\mathrm{C} 2$ on the shelf were 
higher than anywhere else in the region (Fig. 6). This anomaly is difficult to explain without invoking import of females and/or recruits onto the shelf from offshore (Gislason et al., 2000).

The accumulation of storage lipid (WE and TG) in C. finmarchicus is thought to be an important factor in triggering the onset of stage C5 descent to overwintering depths (Irigoien, 2004; Campbell, 2004). Our survey in late summer (July/August) sampled the C5 population at around the peak time of descent from the surface waters when lipid content was $6085 \%$ of dry weight, and spatial variability in lipid content reflected a northeast to south-west gradient in descent timing. The C5 lipid contents in late summer were high compared to measurements on overwintering populations elsewhere in the northern North Atlantic, eg. Faroe-Shetland Channel (Jónasdóttir, 1999) and Gulf of Maine (Miller et al., 1998, 2000). However, by the same comparison our measurements in November/December (20 40\% dry weight) were low. Assuming that the seasonal pattern of lipid accumulation in copepodites was stable from year-to-year and that, at the regional scale, the same population was sampled during each survey, our results imply approximately $50 \%$ loss of lipid content in the first 3 months of overwintering which would appear to be excessive compared to other studies (e.g. Comita et al., 1966; Tande, 1982). However, Heath et al. (2004) noted that temperatures at the overwinering depths of C. finmarchicus in the Irminger Sea $\left(35^{\circ} \mathrm{C}\right)$ were at the high end of the range for the species in the northern North Atlantic, so metabolic rates may have been higher than for populations in, for example, the Norwegian Sea, despite evidence from gut histology that by December the animals were in a diapause state (Bonnet et al., 2007). By April/May, the lipid content of C6 presumably represented the net effects of C5 utilisation during the remainder of the overwintering phase, moulting to C6, ascent to the surface, and any accumulation due to post-ascent feeding in the surface waters. However, it is difficult to directly compare our measurements in April/May with those in November/December, since advection, especially in the EGC zones, must mean that populations of animals with different histories were sampled on each occasion.

The GAM modelling of stage C5 vertical distributions indicated that descent of the G1 cohort to overwintering was not synchronous over the study area. The onset of descent was estimated to occur later towards the south-west (prior to 28 July (day 209) in the north-east, and around 17 August (day 229) in the south-west). For comparison, the onset of descent at Ocean Weatherstation M (OWS-M) in the Norwegian Sea $\left(66^{\circ} \mathrm{N} 2^{\circ} \mathrm{E}\right)$ in 1997 was estimated to be approximately day 165 (14 June; see Fig. 5 in Speirs et al., 2006). Hence, the northeast to south-west gradient in descent timing in our data was possibly part of a larger scale pattern extending over a much wider area and spanning at least 2 months in onset timing, at least in open ocean waters. Speirs et al. (2006) discussed the processes potentially influencing timing of entry to overwintering and how these might be represented in a model of population dynamics. Some function of lipid content in relation to development stage was concluded to be most likely biological trigger, allowing a proportion of individuals in a cohort to enter overwintering during C4 C5, but mainly in C5. In their model, Speirs et al. (2006) assumed that $70 \%$ of individuals attaining the end of stage $\mathrm{C} 5$ entered overwintering whilst the remainder progressed to $\mathrm{C6}$, and this simple caricature successfully reproduced annual time series data on copepodite abundances from several locations around the northern North Atlantic. An earlier version of the model (Speirs et al., 2005), in which entry to overwintering was triggered by food concentrations experienced during C5, was unable to reproduce observed dynamics over all of the observed time series. Hence, the conclusion is that the julian date of entry to overwintering is primarily a function of recruitment timing and subsequent development rates, as implied by the data from our study area.

In common with other investigations (Heath et al., 2004; Edvardsen et al., 2006), we found that a proportion (in our case approximately $10 \%$ ) of the overwintering population in November/December was in stage C4 rather than $\mathrm{C} 5$. The survival of overwintering $\mathrm{C} 4$, and hence their contribution to the $\mathrm{G} 0$ population in the following year, is not known. However, some of our data collected in May show appreciable abundances of $\mathrm{C} 4\left(12 \mathrm{~m}^{3}\right)$ at $200500 \mathrm{~m}$ depth concurrent with a separate surface group in the upper $100 \mathrm{~m}$ (Fig. 11). Perhaps the deeper C4's were survivors from the overwintering population ascending late to the surface, whilst the surface group were the leading edge of the G1 cohort progressing through the demographic structure. Also of interest, was the presence of small numbers $\left(<1 \mathrm{~m}^{3}\right)$ of $\mathrm{C} 1 \mathrm{C} 3$ copepodites deeper than $400 \mathrm{~m}$ in May and July/August (Fig. 10), which seems contrary to accepted views of demographic patterns in vertical distribution. As the abundances were low and the analyses were carried out on descent-leg samples, cross contamination from earlier (shallower) nets in the tow series might be an explanation. But, this cannot readily explain all of the instances, for example, the deep distribution of C3 on 14 August at station C10 
(Fig. 10), which was highly discrete and coincident with the vertical distribution of C4 and C5. This must reflect either mis-identification of development stages, which we consider unlikely given our quality control of the analyses, or a genuine behaviour by a small minority of the copepodite population. However, the absence of stage C3 from samples collected in November/December must indicate that if there was any descent of $\mathrm{C} 3$ to overwintering depths with the bulk of the $\mathrm{C} 4$ and $\mathrm{C} 5$ population, they either developed to $\mathrm{C} 4$ at depth or did not survive.

Turning to consideration of the productivity of surface living populations, we found no evidence that patterns of female per capita egg production rate could be responsible for the spatial demographic features of the study region. Per capita rates were consistent with those measured at OWS-M (Niehoff et al., 1999) and in the Faroe-Shetland Channel (Richardson et al., 1999) at equivalent chlorophyll concentrations, but there was no evidence that chlorophyll was a major determinant of egg production. Either chlorophyll was not representative of the food abundance for female copepods (Jónasdóttir et al., 2005), or concentrations as low as $0.3 \mathrm{mg} \mathrm{m}{ }^{3}$ were not limiting, or instantaneous food concentration was less important for egg production than internal body reserves, as suggested by Carlotti and Hirche (1997).

In contrast to egg production rates, we found that mortality rates were key to the case we have established for explaining the spatial patterns of recruitment. We identify three possible factors influencing spatial variability in mortality which lead to the observed patterns in recruitment: hatching failure of eggs, predation on eggs, and starvation of first-feeding nauplii. Our estimates of developmental changes in per capita mortality rate (Fig. 17) were close to those derived by Ohman et al. (2004) for Georges Bank. In both cases, mortality was initially high for eggs, low during $\mathrm{N} 2 / \mathrm{N} 3$, increased again through the later naupliar stages, and declined to low levels $\left(<0.1 \mathrm{~d}^{1}\right)$ for copepodite stages 34 . Ohman et al. (2004) estimated the mortality rate for eggs through to $\mathrm{N} 2$ to be approximately $0.5 \pm 0.1 \mathrm{~d}{ }^{1}$, whilst our data indicated mortality over the equivalent interval to be $0.7 \pm 0.1 \mathrm{~d}^{1}$ in spring and $0.4 \pm 0.5 \mathrm{~d}^{1}$ in summer. Ohman et al. also found high mortality rates for eggs, but no increase in mortality rate during the late naupliar stages at Ocean Weatherstation $\mathbf{M}$ in the Norwegian Sea or in the FLEX dataset from the northern North Sea. However, they found a somewhat different pattern in data from a Norwegian fjord (Lurefjord) (see also Eiane et al., 2002). Egg mortality rates were relatively low $\left(0.2 \mathrm{~d}^{1}\right)$, increased to $0.3 \mathrm{~d}^{1}$ during naupliar stages $\mathrm{N} 1$ and $\mathrm{N} 1$, and declined rapidly with further development.

Like Ohman et al. (2004) we assumed that development rate in our modified VLT model was a function solely of temperature. Whilst this is clearly reasonable for egg and early nauplii, food consumption rate must also affect development of stages beyond N3 and could have confounded our estimates of later stage mortality. Aksnes and Ohman (1996), Ohman et al. (2002) and Eiane and Ohman (2004) assessed the sensitivity of the VLT method, and concluded that errors in development rate of up to a factor of 2 lead to tolerable discrepancies in mortality estimates. The combined effects of temperature and food concentration on naupliar development rates are poorly defined from experimental studies, but Speirs et al. (2005) parameterised a relationship based on data reported by Campbell et al. (2001) which implies that for N3 N6, development rates are relatively insensitive to food concentration above approximately $35 \mathrm{mg} \mathrm{C} \mathrm{m}^{3}$. However, a reduction to $15 \mathrm{mg} \mathrm{C} \mathrm{m}^{3}$ results in a halving of development rate. Eighty five percent of our VLT estimates of mortality were at stations where food concentration (derived from chlorophyll measurements) was in the range 15 $35 \mathrm{mg} \mathrm{C} \mathrm{m}^{3}$ and hence should be within the factor of 2 tolerance range for errors in development rate. In support of this conclusion, Irigoien et al. (2003) reported that food consumption rates in the naupliar feeding experiments reported here varied by a factor of approximately 2 ( $75150 \mathrm{pg} \mathrm{C}$ ind ${ }^{1} \mathrm{~d}^{1}$ ) over the range of food concentrations studied during the spring and summer surveys. Two of our VLT stations were at food concentrations higher than $35 \mathrm{mg} \mathrm{C} \mathrm{m}^{3}\left(130\right.$ and $\left.289 \mathrm{mg} \mathrm{C} \mathrm{m}^{3}\right)$ and one at lower $\left(11 \mathrm{mg} \mathrm{C} \mathrm{m}^{3}\right)$. Hence, results from the extreme low food station should perhaps be treated with caution.

Ohman and Hirche (2001) and Irigoien et al. (2002) concluded that hatching success is not, in general, a major source of egg mortality in the field, and hence that predation is usually the principal cause. We found large variability in hatching success between point locations, with survey mean values that seem low compared to, for example, Calanus in the North Sea (Jónasdóttir et al., 2005). However, per capita egg production rates were higher in the North Sea than the Irminger Sea, and from laboratory experiments on various species it appears that there may be a relationship between hatching success and per capita egg production rate, such that success is high $(>80 \%)$ above some threshold of egg production (approximately 20 egg female ${ }^{1} \mathrm{~d}^{1}$ in 
Acartia tonsa), and much reduced and more variable (10 80\%) at lower per capita rates (e.g. Jónasdóttir and Kiørboe, 1996; Tang and Dam, 2001). Hence, there is no reason to suppose that our estimates of hatching success are unrealistically low.

Despite the low hatching success, our results suggested that this represented only approximately $30 \%$ of the total mortality of eggs in the sea, except perhaps in the EGC, and we presume that the bulk of the mortality was due to predation. A range of potential predators on $C$. finmarchcius eggs were present in the plankton (Gislason et al., 2007), including the parental population. Egg cannibalism, at least in the laboratory, is well known among copepod species and Calanus in particular (Daan et al., 1988 and see review by Bonnet et al., 2004). Ohman and Hirche (2001) and Ohman et al. (2004) have argued that cannibalistic predation by late stage copepodites on eggs and early naupliar stages is significant in the field, and an important density-dependent regulatory mechanism in the population dynamics of $C$. finmarchicus. Based on correlations between the daily mortality rate of egg-N2 stages (the prey) and adult female abundance (the predator), they concluded that early life stage mortality rates were conditionally dependent on adult population size, such that mortality was independent of adult abundance at low population size but became directly proportional at high abundance. In fact, such proportionality is not a particularly robust test for the existence of a predator-prey relationship. The diagnostic test is whether per capita rates of consumption by the predator scale with prey abundance according to a meaningful functional response (e.g. Holling, 1959; DeAngelis et al., 1975; Real, 1977). Ohman's proportionality test is only symptomatic of a functional response if prey and predator concentrations are correlated, and then implies that there is no satiation of the predator. If prey and predator concentrations are uncorrelated then proportionality between mortality rate and predator abundance can arise in the absence of an underlying functional response. In the case of $C$. finmarchicus females feeding on their own eggs, one might expect some correlation between depth integrated abundances of predator and prey, but this could be confounded by differences in vertical distribution which may develop after the eggs have been laid.

We tried to circumvent the interpretational problems associated with comparing prey mortality rates directly to predator abundance, by estimating the per-capita consumption rate of eggs by late stage copepodites, assuming that these were the sole predators and that all of the mortality was due to predation. The results gave evidence for an underlying functional response in which the per-capita consumption rate increased with egg (prey) abundance. The range of egg abundances encountered was apparently insufficient to observe satiation, and the non-linear shape of the response at low egg abundance was possibly suggestive of prey switching, whereby the predator tends to ignore the given prey when abundance is low and alternative items constitute a greater proportion of the available prey field (Holling type-III response; Holling, 1959). This type of behaviour has been described for Calanus pacificus, which has been shown to feed disproportionately on the prey of greatest relative abundance (Landry, 1981).

All of this interpretation must be tempered by the fact that late copepodites of $C$. finmarchicus are highly unlikely to be the only predators on the eggs. So, the per-capita consumption rates must be a maximum estimate of what could have been consumed. Working with $C$. helgolandicus in laboratory experiments, Bonnet et al. (2004) found egg ingestion rates of around 12 ind ${ }^{1} \mathrm{~d}{ }^{1}$ (near to the maximum estimated from our data, Fig. 20), at prey concentrations of around 60,000 eggs $\mathrm{m}^{3}$. We do not have direct observations of $C$. finmarchicus egg concentrations in the field, only the depth integrated abundances estimated from the production rate and the estimated mortality rate. However, using the ratio of peak N1 concentration $\left(\mathrm{m}^{3}\right)$ vs depth integrated N1 abundance $\left(\mathrm{m}^{2}\right.$ ) (effectively a measure of the degree of aggregation of newly hatched nauplii in the water column), we can estimate the likely peak egg concentrations $\left(\mathrm{m}^{3}\right)$. This indicates that the maximum in situ concentration must have been around $500 \mathrm{~m}^{3}$. Hence, our estimates imply a clearance rate of approximately $24,000 \mathrm{ml}$ ind ${ }^{1} \mathrm{~d}^{1}$, compared to a maximum laboratory-based estimate for females of $500 \mathrm{ml}$ ind ${ }^{1}$ d ${ }^{1}$. Clearly, we must have significantly overestimated the rate of cannibalism by assuming that all the losses were due to ingestion by the parental stock. Thus, whilst there is evidence that cannibalistic predation on $C$. finmarchicus eggs may have been occurring in the field, it seems unlikely that it was the major component of the overall predation mortality. More detailed investigation would require data on the full range of potential predators on eggs, and we are pursuing this as a separate exercise.

The final mortality factor identified as potentially responsible for the observed spatial patterns in recruitment was starvation of first-feeding nauplii at food concentrations less then approximately $0.6 \mathrm{mg}$ 
chlorophyll $\mathrm{m}^{3}$ (equivalent to $25 \mathrm{mg} \mathrm{C} \mathrm{m}^{3}$ ). Food availability for first feeding naupliar stages is known to be critical for development and survival to the transition to copepodite stage $\mathrm{C} 1$. For example, Calanus pacificus naupliar survival and development are impaired if first exposure to food is delayed for more than $610 \mathrm{~h}$ after the moult to N3 (Lopez, 1996). Studies at Ocean Weatherstation M in the Norwegian Sea during 1997, showed that a significantly smaller proportion of $C$. finmarchicus nauplii born before the onset of the spring phytoplankton bloom survived to the end of N6, compared to those born during the bloom (Hirche et al., 2001; Ohman and Hirche, 2001). The implication was that survival was critically dependent on food concentration during naupliar development.

Whilst food concentrations greater than approximately $25 \mathrm{mg} \mathrm{C} \mathrm{m}^{3}$ seem to be necessary for C. finmarchicus naupliar survival, Irigoien et al. (2003) showed that the composition of available prey is also important. Disaggregating the effects of prey type and size on feeding rate is difficult and, for example, Meyer et al. (2002) showed that when presented with cells of the same size, $C$. finmarchicus nauplii and adults showed no preference for algae from different taxonomic groups. However, from analysis of the same data as presented here, Irigoien et al. (2003) concluded that the feeding efficiency of nauplii on small flagellates was low, i.e. that the contribution of flagellates to the diet was less than would be expected from their relative biomass in the microplankton community. In addition, nauplii showed a preference for non-motile diatoms over motile ciliates, although clearance rates on Strombidium spp. increased as the contribution of diatoms to the microplankton carbon biomass decreased. However, since ciliate biomass in the open ocean is rarely comparable to that of diatoms during a phytoplankton bloom (Irigoien et al., 2005; Irigoien et al., 2003) concluded that ciliates alone were unlikely to support recruitment to copepodite stage $\mathrm{C} 1$ in the field.

The nutrient and phytoplankton dynamics of the Irminger Sea in 2002 were reported by Henson et al. (2006), Sanders et al. (2005) and Waniek et al. (2005). These studies clearly showed that the phytoplankton bloom in the Irminger Sea starts around the fringes and that pre-bloom nutrient conditions were present in the CIS zone during our April/May survey. In spring, the microplankton biomass in the Central Irminger Sea was $<30 \mathrm{mg} \mathrm{C} \mathrm{m}^{3}$ and composed predominantly of ciliates and small flagellates, representing very unsuitable feeding conditions for $C$. finmarchicus nauplii. In contrast, the biomass around the fringes of the basin (RR, NIC and EGC-A zones), was higher $\left(>40 \mathrm{mg} \mathrm{C} \mathrm{m}^{3}\right.$ ) and diatoms were a significant component of the biomass (see also Waniek et al., 2005). In the EGC-P zone, which Irigoien et al. (2003) referred to as the Greenland shelf, Phaeocystis spp. comprised the majority of the biomass, and the feeding incubations indicated that this inhibited naupliar feeding rates. During the summer survey D264, nitrate and phosphate depletion was present around the fringes of the basin but in the CIS zone, minimum surface nitrate levels were approximately $3 \mu \mathrm{M}$ and phosphate approximately $0.3 \mu \mathrm{M}$, neither of which should be limiting for phytoplankton. However, surface CIS silicate concentrations were $<2 \mu \mathrm{M}$ at which non-siliceous taxa should out-compete diatoms. As a result, summer microplankton biomass was lower around the fringes of the basin than in spring but similar in the central region. Flagellates were the dominant component of the biomass at most of the sampling stations, and our results indicated that N3 N4 mortality rates were in general higher. Irigoien et al. (2003) have suggested that the predominance of flagellates in the microplankton following the spring plankton bloom may be a reason for the characteristically poor recruitment to G2 copepodite cohorts in the North Atlantic despite there being apparently sufficient food as indicated by chlorophyll- $a$ concentrations (Heath et al., 2000a).

In conclusion, there seems to be no doubt from the evidence presented here that the Central Irminger Sea is an impoverished region with respect to the abundance and suitability of food for C. finmarchicus nauplii, and is hence unlikely to support significant recruitment to copepodite stages at any time of the year.

The data on dietary fatty acid biomarkers in late copepodites showed little relationship with mortality rates, but could tentatively be used as indicators of spatial origin given the observations of microplankton composition in the various zones, and assuming that fatty acid composition reflects integrated feeding history. The key conclusion from the data was that the G1 copepodites in the EGC-A zone, where the highest concentrations of entrants to the overwintering state were located in July/August, had the lowest mean dietary contributions from diatoms, micro-heterotrophs and/or Phaeocystis, and the highest from flagellates. From this observation, we conclude that a disproportionately high proportion of the G1 survivors originated from recruitment to areas exhibiting a higher than average biomass of dinoflagellates, and a lower than average biomass of micro-heterotrophs and/or Phaeocystis. These conditions were typically found around the fringes of 
the basin, but not in the EGC-P or CIS zones (Fig. 4). The dietary contribution of diatoms was probably less diagnostic of spatial origin, since blooms were apparently more localised in space and time.

According to the CPR surveys, the abundance and spatial demography of $C$. finmarchicus in the Irminger Sea since 1958 has been remarkably resilient to changes in climate, compared to some other regions of the North Atlantic. In areas where abundance has changed significantly over time (e.g. the northeastern Atlantic and North Sea), the underlying cause (where this can be discerned) invariably seems to involve climate related changes in the large-scale circulation that lead to disruption of the space time dynamics of the life cycle (Greene et al., 2003). In the case of the Irminger Sea, there are clear impacts of climate on the southward transport of sub-Arctic water masses in the region (increased convection in the Labrador Sea and Irminger Sea during years) with positive NAO index (Greene et al., 2003), increased transport in the Labrador Current and possibly the East Greenland Current during years with negative NAO index (Greene et al., 2003), and yet there is no evidence of a trend in $C$. finmarchicus abundance.

Barton et al. (2003) analysed data on the CPR colour index and winter NAO index, and concluded that although there were significant correlations between the two across much of the North Atlantic, this merely reflected an underlying increasing trend in both. De-trending the data, eliminated the correlations. Thus, although there is some linkage between the abundance of phytoplankton represented by the colour index and climate, the connection must be indirect and not immediately related to the oceanographic changes caused by the atmospheric processes reflected in the NAO index. Our findings support this conclusion for the Irminger Sea. Whatever the causes of variations in the colour index, they are apparently reflected in variations in the abundance of Calanus stages $\mathrm{C} 1 \mathrm{C} 4$, even after de-trending. Abundances of $\mathrm{C} 1 \mathrm{C} 4$ were also strongly correlated with those of C5 C6. Our findings imply that the long-term dynamics of $C$. finmarchicus in the Irminger Sea are more strongly dictated by food web and production processes, than by oceanographic impacts on lifecycle closure. Hence, our initial hypothesis that changes in the population dynamics and demography in the Irminger Sea might be explained in terms of the circulation and water mass distribution, was not supported. Perhaps this apparent resilience of the Irminger Sea population to variations in ocean circulation is an indication that the region is one of the core areas for $C$. finmarchicus in the North Atlantic.

\section{Acknowledgements}

This work was funded by the Natural Environment Research Council Marine Productivity Programme (grants: NER/T/S/2001/00164, NER/T/S/2001/01256, NE/C508393/1, and NER/T/S/2001/00142) and The Scottish Executive Environment and Rural Affairs Department project MF0754. A large number of staff at the participating institutes contributed in very many ways at sea and in a support capacity, and we thank them all. We especially thank the students (L. Bambini, M. Baptie, C. Booth, A. Chapman, G. Cleary, C. Cooke, D. Demain, A. Donald, H. Flint, Y. Garcia-Santiago, R. Harries, N. Jacob, A. Korycinska, A. Mair, J. McNeill, S. McRobert, R. Nevins, C. Ni Dhubhgaill, D. Nixon, E. O’Mahony, I. Roberts, H. Selley, R. Taylor, N. Thompson, H. Vatanen, G. Velema \& V. Vigiani) who participated in the plankton analysis summer schools where the majority of the plankton samples were processed. Thanks also to three reviewers of the manuscript who contributed a number of ideas and suggestions for improvement.

\section{References}

Aksnes, D.L., Ohman, M.D., 1996. A vertical life table approach to zooplankton mortality estimation. Limnology and Oceanography 41, 14611469.

Anderson, J.T., 1990. Seasonal development of invertebrate zooplankton on Flemish Cap. Marine Ecology Progress Series 67, 127 140.

Backhaus, J.O., Harms, I., Krause, M., Heath, M.R., 1994. An hypothesis concerning the space time succession of Calanus finmarchicus in the northern North Sea. ICES Journal of Marine Science 51, 169180.

Bacon, S., Reverdin, G., Rigor, I.G., Snaith, H.M., 2002. A freshwater jet on the east Greenland shelf. Journal of Geophysical Research 107 (C7). doi:10.1029/2001JC000935.

Bacon, S., Gould, W.J., Jia, Y., 2003. Open ocean convection in the Irminger Sea. Geophysical Research Letters 30 (5), 1246. doi:10.1029/ 2002 GL016271.

Bainbridge, V., Corlett, J., 1969. The zooplankton of the NORWESTLANT survey. Special Publications of the International Commission on Northwest Atlantic Fisheries 7, 101122. 
Barton, A.D., Greene, C.H., Monger, B.C., Pershing, A.J., 2003. The Continuous Plankton Recorder survey and the North Atlantic Oscillation: interannual to Multidecadal scale patterns of phytoplankton variability in the North Atlantic Ocean. Progress in Oceanography 58, 337358.

Batten, S.D., Walne, A.W., Edwards, M., Groom, S.B., 2003. Phytoplankton biomass from continuous plankton recorder data: an assessment of the phytoplankton colour index. Journal of Plankton Research 25, 697702.

Beare, D.J., Batten, S.D., Edwards, M., McKenzie, E., Reid, P.C., Reid, D.G., 2003. Summarising spatial and temporal information in CPR data. Progress in Oceanography 58, 217233.

Beaugrand, G., Edwards, M., John, A., Lindley, A. (Eds.), 2004. Continuous Plankton records: Plankton Atlas of the North Atlantic Ocean 1958 1999. Marine Ecology Progress Series Supplement 2004. Inter Research, Oldendorf/Luhe, p. 75.

Bonnet, D., Titelman, J., Harris, R., 2004. Calanus the cannibal. Journal of Plankton Research 26, 937948.

Bonnet, D., Harris, R.P., Hay, S., Invasgottir, A., Simon, O., 2007. Histological changes in the digestive epithelium in Calanus finmarchicus: a marker for diapause? Marine Biology 151, 313326.

Bruce, J.G., 1995. Eddies southwest of the Denmark Strait. Deep Sea Research Part I 42, 1329.

Burkill, P.H., Edwards, E.S., John, A.W.G., Sleigh, M.A., 1993. Microzooplankton and their herbivorous activity in the northeastern Atlantic Ocean. Deep Sea Research Part II 40, 479493.

Campbell, R.W., 2004. Reply to Horizons Article 'Some ideas about the role of lipids in the life cycle of Calanus finmarchicus' Irigoien (2004): I. Journal of Plankton Research 26, 979980.

Campbell, R.G., Wagner, M.L., Teegarden, G.J., Boudreau, C.A., Durbin, E.G., 2001. Growth and development rates of the copepod Calanus finmarchicus reared in the laboratory. Marine Ecology Progress Series 221, 161183.

Carlotti, F., Hirche, H. J., 1997. Growth and egg production of female Calanus finmarchicus: an individual based physiological model and experimental validation. Marine Ecology Progress Series 149, 91104.

Centurioni, L.R., Gould, J., 2004. Winter conditions in the Irminger Sea observed with profiling floats. Journal of Marine Research 62, 313336.

Chu, F. L.E., Lund, E.D., harvey, E., Adlof, R., 2003. Arachidonic acid synthetic pathways of the oyster protozoan parasite, Perkinsus marinus: evidence for usage of a delta 8 pathway. Molecular and Biochemical Parasitology 133, 4551.

Comita, G.W., Marshall, S.M., Orr, A.P., 1966. On the biology of Calanus finmarchicus. XIII. Seasonal change in weight, calorific value and organic matter. Journal of the Marine Biological Association of the UK 46, 117.

Daan, R., Gonzalez, S.R., Klein Breteler, W.C.M., 1988. Cannibalism in omnivorous calanoid copepods. Marine Ecology Progress Series $47,4554$.

Dalsgaard, J., St. John, M., Kattner, G., Muller Navarra, D., Hagen, W., 2003. Fatty acid trophic markers in the pelagic environment. Advances in Marine Biology 46, 225340.

DeAngelis, D.L., Goldstein, R.A., O’Neill, R.V., 1975. A model for trophic interactions. Ecology 56, 881892.

de Cuevas, B.A., Webb, D.J., Coward, A.C., Richmond, C.S., Rourke, E., 1999. The UK ocean circulation and advanced modelling project (OCCAM). In: Allan, R.J., Guest, M.F., Simpson, A.D., Henty, D.S., Nicole, D.A. (Eds.), High Performance Computing, Proceedings of HPCI Conference 1998, Manchester, 1214 January 1998, Plenum Press, pp. 325335.

Desvilettes, C.H., Bourdier, G., Amblard, C.H., Barth, B., 1997. Use of fatty acids for the assessment of zooplankton grazing on bacteria, protozoans and microalgae. Freshwater Biology 38, 629637.

Dickson, R.R., Brown, J., 1994. The production of North Atlantic Deep Water: sources, rates and pathways. Journal of Geophysical Research 99 (C6), 1231912341.

Dunn, J., Mitchell, R.B., Ritchie, B.J., 1985. A new multidepth high speed plankton sampler. ICES CM 1985/L:7, 10pp.

Dunn, J., Hall, C., Heath, M., Mitchell, R., Ritchie, B., 1993. ARIES, a system for concurrent physical, biological and chemical sampling at sea. Deep Sea Research 40, 867878 .

Durbin, E.G., Garrahan, P.R., Casas, M.C., 2000. Abundance and distribution of Calanus finmarchicus on the Georges Bank during 1995 and 1996. ICES Journal of Marine Science 57, 16641685.

Edvardsen, A., Pedersen, J.M., Slagstad, D., Semenova, T., Timonin, A., 2006. Distribution of overwintering Calanus in the North Norwegian Sea. Ocean Science Discussions 3, 2553.

Eiane, K., Ohman, M.D., 2004. Stage specific mortality of Calanus finmarchicus, Pseudocalanus elongatus and Oithona similis on Fladen Ground, North Sea, during a spring bloom. Marine Ecology Progress Series 268, 183193.

Eiane, K., Aksnes, D.L., Ohman, M.D., Sood, S., Martinussen, M.B., 2002. Stage specific mortality of Calanus spp. under different predation regimes. Limnology and Oceanography 47, 636645.

Falk Petersen, S., Hagen, W., Kattner, G., Clarke, A., Sargent, J., 2000. Lipids, trophic relationships and biodiversity in Arctic and Antarctic krill. Canadian Journal of Fisheries and Aquatic Sciences 57 (Suppl. 3), 178191.

Folch, J., Lees, M., Sloane Stanley, G.H., 1956. A simple method for the isolation and purification of total lipids from animal tissues. Journal of Biological Chemistry 226, 497509.

Frost, B.W., 1972. Effects of size and concentration of food particles on the feeding behavior of the marine planktonic copepod Calanus pacificus. Limnology and Oceanography 17, 805815.

Gislason, A., 2003. Life cycle strategies and seasonal migrations of oceanic copepods in the Irminger Sea. Hydrobiologia 503, 195 209.

Gislason, A., 2005. Seasonal and spatial variability in egg production and biomass of Calanus finmarchicus around Iceland. Marine Ecology Progress Series 286, 177192.

Gislason, A., Assthorsson, O.S., 2000. Winter distribution, ontogenetic migration, and rates of egg production of Calanus finmarchicus southwest of Iceland. ICES Journal of Marine Science 57, 17271739. 
Gislason, A., Assthorsson, O.S., Petursdottir, H., Gudfinnsson, H., Bodversdottir, A.R., 2000. Life cyle of Calanus finmarchicus south of Iceland in relation to hydrography and chlorophyll a. ICES Journal of Marine Science 57, 16191627.

Gislason, A., Eiane, K., Reynisson, P., 2007. Vertical distribution and mortality of Calanus finmarchicus during overwintering in oceanic waters southwest of Iceland. Marine Biology 150, 12531263.

Graeve, M., Hagen, W., Kattner, G., 1994. Herbivorous or omnivorous? On the significance of lipid compositions as trophic markers in Antarctic copepods. Deep Sea Research A 42, 915924.

Greene, C.H., Pershing, A.J., 2000. The response of Calanus finmarchicus populations to climate variability in the Northwest Atlantic: basin scale forcing associated with the North Atlantic Oscillation. ICES Journal of Marine Science 57, 15361544.

Greene, C.H., Pershing, A.J., Conversi, A., Planque, B., Hannah, C., Sameoto, D., Head, E., smith, P.C., Reid, P.C., Jossi, J., Mountain, D., Benfield, M.C., Wiebe, P.H., Durbin, E., 2003. Trans Atlantic responses of Calanus finmarchicus populations to basin scale forcing associated with the North Atlantic Oscillation. Progress in Oceanography 58, 301312.

Hamm, C., Reigstad, M., Riser, C.W., Muhlebach, A., Wassmann, P., 2001. On the trophic fate of Phaeocystis pouchetti. VII. Sterols and fatty acids reveal sedimentation of $P$. pouchetti derived organic matter via krill fecal strings. Marine Ecology Progress Series 209,55 69.

Hansen, B., Turrell, W.R., Osterhus, S., 2001. Decreasing overflow from the Nordic seas into the Atlantic Ocean through the Faroe Bank channel since 1950. Nature 411, 927930.

Hastie, T.J., Tibshirani, R.J., 1990. Generalized Additive Models. Chapman and Hall, p. 335.

Hays, G.C., Lindley, J.A., 1994. Estimating chlorophyll a abundance from 'phytoplankton colour' recorded by the Continuous Plankton Recorder survey: validation with simultaneous fluorometry. Journal of Plankton Research 16, 2334.

Head, E.J.H., Harris, L.R., Petrie, B., 1999. Distribution of Calanus spp. on and around the Nova Scotia Shelf in April: evidence for an offshore source of Calanus finmarchicus to the central and western regions. Canadian Journal of Fisheries and Aquatic Sciences 56, 24632476.

Head, E.J.H., Harris, L.R., Campbell, R.W., 2000. Investigations on the ecology of Calanus spp. In the Labrador Sea. I. Relationship between the phytoplankton bloom and reproduction and development of Calanus finmarchicus in spring. Marine Ecology Progress Series 193, 5373.

Head, E.H., Pepin, P., Runge, J., 2001. Proceedings of the workshop on 'The Northwest Atlantic ecosystem a basin scale approach'. Canadian Science Advisory Secretariat, Proceedings Series 2001/23. 112pp. URL http://www.dfo mpo.gc.ca/csas/Csas/proceedings/ 2001/PRO2001 023e.pdf.

Heath, M.R., Coombs, S.H. (Eds.), 1999. Investigation of Calanus finmarchicus migrations between oceanic and shelf seas off north west Europe (ICOS). Fisheries Oceanography, 8. Blackwell Science, p. 176, Suppl. 1.

Heath, M.R., Astthorsson, O.S., Dunn, J., Ellertsen, B., Gaard, E., Gislason, A., Gurney, W.S.C., Hind, A.T., Irigoien, X., Melle, W., Niehoff, B., Olsen, K., Skreslet, S., Tande, K.S., 2000a. Comparative analysis of Calanus finmarchicus demography at locations around the northeast Atlantic. ICES Journal of Marine Science 57, 15621580.

Heath, M.R., Fraser, J.G., Gislason, A., Hay, S.J., Jónasdóttir, S.H., Richardson, K., 2000b. Winter distribution of Calanus finmarchicus in the northeast Atlantic. ICES Journal of Marine Science 57, 16281635.

Heath, M., Carlotti, F., de Young, B., Fiksen, O., Werner, F., 2001. Secondary production in the oceans and the response to climate change. IGBP Global Change Newsletter 47, 912.

Heath, M.R., Boyle, P.R., Gislason, A., Gurney, W.S.C., Hay, S.J., Head, E.J.H., Holmes, S., Ingvarsdóttir, A., Jónasdóttir, S.H., Lindeque, P., Pollard, R.T., Rasmussen, J., Richards, K., Richardson, K., Smerdon, G., Speirs, D., 2004. Comparative ecology of overwintering Calanus finmarchicus in the northern North Atlantic, and implications for life cycle patterns. ICES Journal of Marine Science 61, 698708.

Henson, S., Sanders, R., Holeton, C., Allen, J., 2006. Timing of nutrient depletion, diatom dominance and a lower bound estimate of export production for the Irminger Basin. Marine Ecology Progress Series 313, 7384.

Hind, A., Gurney, W.S.C., Heath, M.R., Bryant, A.D., 2000. Overwintering strategies in Calanus finmarchicus. Marine Ecology Progress Series 193, 95107.

Hirche, H.J., Brey, T., Niehoff, B., 2001. A high frequency time series at ocean weather ship Station M Norwegian Sea: population dynamics of Calanus finmarchicus. Marine Ecology Progress Series 219, 205219.

Holliday, N.P., Waniek, J.J., Davidson, Wilson, D., Brown, R., Sanders, L., Pollard, R.T., Allen, J.T., 2006. Large scale physical controls on phytoplankton growth in the Irminger Sea. Part I: hydrographic zones, mixing and stratification. Journal of Marine Systems 59, 201218.

Holling, C.S., 1959. The components of predation as revealed by a study of small mammal predation of the European pine sawfly. Canadian Entomologist 91, 293320.

Hughes, S.L., Holliday, N.P. (Eds.), 2006. ICES Report on Ocean Climate 2005. ICES Cooperative Research Report 280. International Council for the Exploration of the Sea, Copenhagen, pp. 49.

Huntley, M., Strong, K.W., Dengler, A.T., 1983. Dynamics and community structure of zooplankton in the Davis Strait and Northern Labrador Sea. Arctic 365, 143161.

Hurrell, J.W., 2001. The North Atlantic Oscillation. In: Steele, J., Thorpe, S.A., Turekian, K.K. (Eds.). Encyclopedia of Ocean Sciences, vol. 4. Academic Press, London, United Kingdom, pp. 19041911.

ICNAF, 1968. Environmental Surveys. NORWESTLANT 1 3, 1963. International Commission for the Northwest Atlantic Fisheries (ICNAF)Special Publication, 7, part IV. Biological Data Record. Issued from the Headquarters of the Commission, Dartmouth, Nova Scotia.

Irigoien, X., 2004. Some ideas about the role of lipids in the life cycle of Calanus finmarchicus. Journal of Plankton Research $26,259263$. 
Irigoien, X., Harris, R.P., Verheye, H.M., Joly, P., Runge, J., Starr, M., Pond, D., Campbell, R., Shreeve, R., Ward, P., Smith, A.N., Dam, H.G., Peterson, W., Tirelli, V., Koski, M., Smith, T., Harbour, D., Davidson, R., 2002. Copepod hatching success in marine ecosystems with high diatom concentrations. Nature 419, 387389.

Irigoien, X., Titelman, J., Harris, R.P., Harbour, D., Castellani, C., 2003. Feeding of Calanus finmarchicus nauplii in the Irminger Sea. Marine Ecology Progress Series 262, 193200.

Irigoien, X., Flynn, K.J., Harris, R.P., 2005. Phytoplankton blooms: a 'loophole' in microzooplankton grazing impact? Journal of Plankton Research 27, 313321.

Jakobsen, P.K., Ribergaard, M.H., Quadfasel, D., Schmith, T., Hughes, C.W., 2003. Near surface circulation in the northern North Atlantic as inferred from Lagrangian drifters: variability from the mesoscale to interannual. Journal of Geophysical Research 108 (C8), 3251. doi:10.1029/2002JC001554.

Jónasdóttir, S.H., 1999. Lipid content of Calanus finmarchicus during overwintering in the Faroe Shetland Channel. Fisheries Oceanography 8 (Suppl. 1), 6172.

Jónasdóttir, S.H., Kiørboe, T., 1996. Copepod recruitment and food composition: do diatoms affect hatching success? Marine Biology 125,743750 .

Jónasdóttir, S.H., Kiørboe, T., Tang, K.W., St. John, M., Visser, A.W., Saiz, E., Dam, H.G., 1998. Role of diatoms in copepod production: good, harmless or toxic? Marine Ecology Progress Series 172, 305308.

Jónasdóttir, S., Gudfinnsson, H., Gislason, A., Astthorsson, O., 2002. Diet composition and quality for Calanus finmarchicus egg production and hatching success off south west Iceland. Marine Biology 140, 11951206.

Jónasdóttir, S.H., Trung, H.H., Hansen, F., Gartner, S., 2005. Egg production and hatching success in the calanoid copepods Calanus helgolandicus and Calanus finmarchicus in the North Sea from March to September 2001. Journal of Plankton Research 27, 12391259.

Kielhorn, W.V., 1952. The biology of the surface zone zooplankton of a boreo Arctic Atlantic Ocean area. Journal of the Fisheries Research Board of Canada 9, 223264.

Kovala, P.E., Larrance, J.D., 1966. Computation of phytoplankton cell numbers, cell volume, cell surface and plasma volume, per metre, from microscopic counts. University of Washington Department of Oceanography Special Reports No. 38, University of Washington, Seattle, WA.

Landry, M.R., 1981. Switching between herbivory and carnivory by the planktonic marine copepod Calanus pacificus. Marine Biology 65 , 7782.

Lavendar, K.L., 2001. The general circulation and open ocean deep convection in the Labrador Sea: a study using subsurface floats. PhD Thesis, University of California, Sandiego, Scripps Institution of Oceanography. pp. 131.

Lavender, K.L., Owens, W.B., Davis, R.E., 2005. The mid depth circulation of the subpolar North Atlantic Ocean as measured by subsurface floats. Deep Sea Research Part I 52, 767785.

Lessard, E.J., Swift, E., 1986. Dinoflagellates from the North Atlantic classified as phototrophic or heterotrophic by epifluorescence microscopy. Journal of Plankton Research 8, 12091215.

Lindeque, P.K., Hay, S.J., Heath, M.R., Ingvarsdottir, A., Rasmussen, J., Smerdon, G.R., Waniek, J., 2006. Merging conventional microscopy and molecular analysis to analyse the species composition of plankton samples. Journal of Plankton Research $28,221238$.

Lindeque, P.K., Harris, R.P., Jones, M.B., Smerdon, G.R., 1999. Simple molecular method to distinguish the identity of Calanus species (Copepoda: Calanoida) at any developmental stage. Marine Biology 133, 9196.

Longhurst, A., 1998. Ecological Geography of the Sea. Academic Press, pp. 398.

Lopez, M.D.G., 1996. Effect of starvation on development and survivorship of naupliar Calanus pacificus (Brodsky). Journal of Experimental Marine Biology and Ecology 203, 133146.

McClain, C.R., Feldman, G.C., Hooker, S.B., 2004. An overview of the SeaWIFS project and strategies for producing a climate research quality global ocean bio optical time series. Deep Sea Research II 51, 542.

Menden Deuer, S., Lessard, E.J., 2000. Carbon to volume relationships for dinoflagellates, diatoms, and other protist plankton. Limnology and Oceanography 45, 569579.

Meyer, B., Irigoien, X., Graeve, M., Head, R., Harris, R., 2002. Feeding rates and selectivity among nauplii, copepodites and adult females of Calanus finmarchicus and Calanus helgolandicus. Helgoland Marine Research 56, 169176.

Miller, C.B., Morgan, C.A., Prahl, F.G., Sparrow, M.A., 1998. Storage lipids of the copepod Calanus finmarchicus from Georges Bank and the Gulf of Maine. Limnology and Oceanography 43, 488497.

Miller, C.B., Crain, J.A., Morgan, C.A., 2000. Oil storage variability in Calanus finmarchicus. ICES Journal of Marine Science 57, 1786 1799.

Nelder, J.A., Mead, R., 1965. A simplex algorithm for function minimization. Computer Journal 7, 308313.

Niehoff, B., Klenke, U., Hirche, H. J., Irigoien, X., Head, R., Harris, R., 1999. A high frequency time series at Weathership M, Norwegian Sea, during the 1997 spring bloom: the reproductive biology of Calanus finmarchicus. Marine Ecology Progress Series 176, 81 92.

Ohman, M.D., Hirche, H.J., 2001. Density dependent mortality in an oceanic copepod population. Nature 412, 638641.

Ohman, M.D., Runge, J.A., Durbin, E.G., Field, D.B., Niehoff, B., 2002. On birth and death in the sea. Hydrobiologia $480,5568$.

Ohman, M.D., Eiane, K., Durbin, E.G., Runge, J.A., Hirche, H. J., 2004. A comparative study of Calanus finmarchicus mortality patterns at five locations in the North Atlantic. ICES Journal of Marine Science 61, 687697.

Orvik, K.A., Niiler, P.P., 2002. Major pathways of Atlantic water in the northern North Atlantic and Nordic seas toward Arctic. Geophysical Research Letters 29 (19), 2.1 2.4. doi:10.1029/2002GL015002.

Osterhus, S., Turrell, W.R., Hansen, B., Lundberg, P., Buch, E., 2001. Observed transport estimates between the North Atlantic and the Arctic Mediterranean in the Iceland Scotland region. Polar Research 20 (1), 169175. 
Pickart, R.S., Spall, M.A., Ribergaard, M.H., Moore, G.W.K., Milliff, R.F., 2002. Deep convection in the Irminger Sea forced by the Greenland tip jet. Nature 424, 152156.

Pickart, R.S., Straneo, F., Moore, G.W.K., 2003. Is Labrador Sea Water formed in the Irminger Basin? Deep Sea Research Part I 50, 23 52.

Planque, B., Batten, S., 2000. Calanus finmarchicus in the North Atlantic: the year of Calanus in the context of interdecadal change. ICES Journal of Marine Science 57, 15281535.

Pyper, B.J., Peterman, R.M., 1998. Comparison of methods to account for autocorrelation in correlation analyses of fish data. Canadian Journal of Fisheries and Aquatic Sciences 55, 21272140.

R Development Core Team, 2005. R: a language and environment for statistical computing. R Foundation for Statistical Computing, Vienna, Austria. ISBN 390005107 0. http://www.R project.org.

Read, J.F., 2001. CONVEX 91: water masses and circulation of the Northeast Atlantic subpolar gyre. Progress in Oceanography 48, 461 510.

Real, L., 1977. The kinetics of functional response. American Naturalist 111, 289300.

Reverdin, G., Niiler, P.P., Valdimarsson, H., 2003. North Atlantic surface ocean currents. Journal of Geophysical Research 108 (C1), 3002. doi:10.1029/2001JC001020.

Richardson, K., Jónasdóttir, S.H., Hay, S.J., Christoffersen, A., 1999. Calanus finmarchicus egg production and food availability in the Faroe Shetland Channel and northern North Sea: October March. Fisheries Oceanography 8, 153162.

Sameoto, D., Wiebe, P., Runge, J., Postel, L., Dunn, J., Miller, C., Coombs, S., 2000. Collecting zooplankton. In: Harris, R., Wiebe, P., Lenz, J., Skjoldal, H.R., Huntley, M. (Eds.), ICES Zooplankton Methodology Manual. Academic Press, pp. 5581.

Sanders, R., Brown, L., Henson, S.A., Lucas, M.I., 2005. New production in the Irminger Basin during 2002. Journal of Marine Systems 55, 291310.

Saunders, P.M., 2001. The dense northern overflows. In: Siedler, G., Church, J., Gould, W.J. (Eds.), Ocean Circulation and Climate; Observing and Modelling the Global Ocean. Academic Press, London, p. 712.

Serreze, M.C., Maslanik, J.A., Scambos, T.A., Fetterer, F., Stroeve, J., Knowles, K., Fowler, C., Drobot, S., Barry, R.G., Haran, T.M., 2003. A record minimum arctic sea ice extent and area in 2002. Geophysical Research Letters 30, 1110. doi:10.1029/2002GL106406.

Sigurdsson, T., Ratz, H. J., Pedchenko, A., Mamylov, V., Mortensen, J., Bethke, E., Stransky, C., Bjornsson, H., Melinkov, S., Bakay, Y., Drevetnyak, K., 1999. Report of the joint Icelandic/German/Russian trawl acoustic survey on pelagic redfish in the Irminger Sea and adjacent waters in June/July 1999. Annex to: Anon, 1999. Report of the North Western Working Group. ICES CM1999/ACFM:17, $37 \mathrm{pp}$.

Spall, M.A., Pickart, R.S., 2003. Wind driven recirculations and exchange in the Labrador and Irminger Seas. Journal of Physical Oceanography 33, 18291845.

Speirs, D.C., Gurney, W.S.C., Heath, M.R., Wood, S.N., 2005. Modelling the basin scale demography of Calanus finmarchicus in the northeastern Atlantic. Fisheries Oceanography 14, 333358.

Speirs, D.C., Gurney, W.S.C., Heath, M.R., Horbelt, W., Wood, S.N., de Cuevas, B.A., 2006. Ocean scale modelling of the distribution, abundance, and seasonal dynamics of the copepod Calanus finmarchicus. Marine Ecology Progress Series 313, 173192.

Strathmann, R.R., 1967. Estimating the organic carbon content of phytoplankton from cell volume or plasma volume. Limnology and Oceanography $12,411418$.

Talley, L.D., McCartney, M.S., 1982. Distribution and circulation of Labrador Sea Water. Journal of Physical Oceanography 12, 1189 1205.

Tande, K.S., 1982. Ecological investigations on the zooplankton community of Balsfjorden, northern Norway: generation cycles, and variations in body weight and body content of carbon and nitrogen related to overwintering and reproduction in the copepod Calanus finmarchicus (Gunnerus). Journal of Experimental Marine Biology and Ecology 62, 129142.

Tande, K.S., Miller, C.B. (Eds.), 2000. Population dynamics of Calanus in the North Atlantic. ICES Journal of Marine Science, 57 (6), and issued as ICES Marine Science Symposia, 212. Academic Press, pp. 351.

Tang, K.W., Dam, H.G., 2001. Phytoplankton inhibition of copepod egg hatching: test of an exudate hypothesis. Marine Ecology Progress Series 209, 197202.

Tittensor, D.P., DeYoung, B., Tang, C.L., 2003. Modelling the distribution, sustainability and diapause emergence timing of the copeopod Calanus finmarchicus in the Labrador Sea. Fisheries Oceanography 12, 299316.

van Aken, H., 2003. Decadal changes of the hydrography between Ireland and Cape Farewell. ICES Marine Science Symposia $219,8085$.

van Aken, H.M., de Boer, C.J., 1995. On the synoptic hydrography of intermediate and deep water masses in the Iceland Basin. Deep Sea Research Part I 42, 165189.

Veefkind, R.J. (1997). Carbon isotope ratios and composition of fatty acids: tags and trophic markers in pelagic organisms. PhD Thesis, University of Victoria, Canada. School of Earth and Ocean Sciences, p. 272.

Virtue, P., Mayzaud, P., Albessard, E., Nichols, P., 2000. Use of fatty acids as dietary indicators in northern krill, Meganyctiphanes norvegica, from northeastern Atlantic, Kattegat and Mediterranean waters. Canadian Journal of Fisheries and Aquatic Sciences 57 (Suppl. 3), 104114.

Walsh, J.E., Chapman, W.L., 2001. Twentieth century sea ice variations from observational data. Annals of Glaciology $33,444448$.

Waniek, J.J., Holliday, P.N., 2006. Large scale physical controls on phytoplankton growth in the Irminger Sea. Part II: model study of the physical and meteorological preconditioning. Journal of Marine Systems 59, 219237.

Waniek, J.J., Holliday, P.N., Davidson, R., Brown, L., Henson, S., Pollard, R., 2005. Freshwater control of the onset and species composition of the Greenland shelf spring bloom. Marine Ecology Progress Series 288, 4557.

Warner, A.J., Hays, G.C., 1994. Sampling by the Continuous Plankton Recorder survey. Progress in Oceanography $34,237256$. 
Webb, D.J., de Cuevas, B.A., Coward, A.C., 1998. The first main run of the OCCAM global ocean model. Internal Document 34, Southampton Oceanography Centre, Southampton (ftp://ftp.soc.soton.ac.uk/pub/occam/papers/occam tech1.pdf).

Webster, L., Walsham, P., Ahmed, Y., Richards, S., Hay, S., Heath, M., Moffat, C.F., 2006. Development and application of an analytical method for the determination of storage lipids, fatty acids and fatty alcohols in Calanus finmarchicus. Journal of Separation Science 29, 12051216.

Wood, S.N., 2004. Stable and efficient multiple smoothing parameter estimation for generalized additive models. Journal of the American Statistical Association 99, 637686. 